\section{Synthesis and catalysis of chemically reduced metal-metalloid amorphous alloys $\dagger$}

\author{
Yan Pei, ${ }^{a}$ Gongbing Zhou, ${ }^{a}$ Nguyen Luan, ${ }^{b}$ Baoning Zong, ${ }^{* c}$ Minghua Qiao*a and \\ Franklin (Feng) Tao*a
}

Received 21st May 2012

DOI: $10.1039 / \mathrm{c} 2 \operatorname{cs} 35182 \mathrm{j}$

Amorphous alloys structurally deviate from crystalline materials in that they possess unique short-range ordered and long-range disordered atomic arrangement. They are important catalytic materials due to their unique chemical and structural properties including broadly adjustable composition, structural homogeneity, and high concentration of coordinatively unsaturated sites. As chemically reduced metal-metalloid amorphous alloys exhibit excellent catalytic performance in applications such as efficient chemical production, energy conversion, and environmental remediation, there is an intense surge in interest in using them as catalytic materials. This critical review summarizes the progress in the study of the metal-metalloid amorphous alloy catalysts, mainly in recent decades, with special focus on their synthetic strategies and catalytic applications in petrochemical, fine chemical, energy, and environmental relevant reactions. The review is intended to be a valuable resource to researchers interested in these exciting catalytic materials. We concluded the review with some perspectives on the challenges and opportunities about the future developments of metal-metalloid amorphous alloy catalysts.

\section{Introduction}

Amorphous alloys are also referred to as non-crystalline alloys or metallic glasses. Noting that only in very few cases a single

${ }^{a}$ Department of Chemistry and the Shanghai Key Laboratory of Molecular Catalysis and Innovative Materials, Fudan University, Shanghai 200433,P.R. China.E-mail:mhqiao@fudan.edu.cn

${ }^{b}$ Department of Chemistry and Biochemistry, University of Notre Dame, Notre Dame, Indiana, USA 46556.E-mail: ftao@nd.edu

${ }^{c}$ State Key Laboratory of Catalytic Materials and Reaction

Engineering, Research Institute of Petroleum Processing,

Beijing 100083, P. R. China.E-mail: zongbn.ripp@sinopec.com

$\dagger$ Part of the bimetallic nanocatalysts themed issue. metal can be made into the amorphous form, ${ }^{1}$ it is adequate to use the term "alloy" here. Amorphous alloys are intrinsically different from their crystalline counterparts in the arrangement of the constituting atoms. The atoms only have shortrange ordering in amorphous alloys, while these short-range ordered structures (analogous to atomic clusters) ${ }^{2}$ are linked randomly with each other, thus lacking the long-range ordered topological structure. ${ }^{3}$ Short-range ordering means that the nearest interatomic distances and coordination numbers are constant. The extremely disordered atomic arrangement in long range renders amorphous alloys isotropic and homogeneous structure devoid of structural characteristics of crystalline

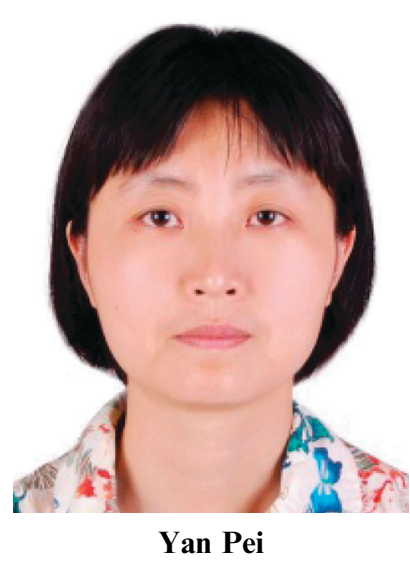

Yan Pei completed her BSc in applied chemistry in 1998 at Nanjing University of Chemical Technology. In 2007 she obtained her PhD in Physical Chemistry in Prof. Kangnian Fan and Prof. Minghua Qiao's group at Fudan University. She is currently an assistant research fellow in the Department of Chemistry, Fudan University. Her research interest focuses on the synthesis and characterization of novel metal catalysts for selective hydrogenation.

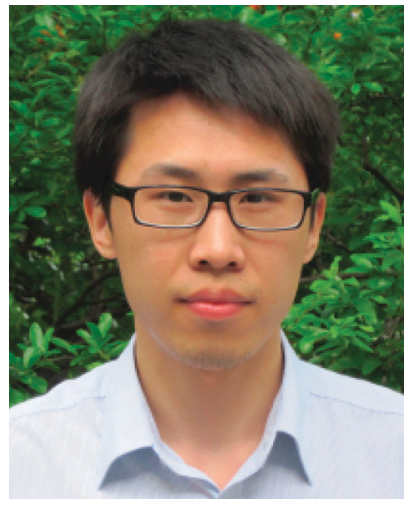

Gongbing Zhou
Gongbing Zhou received his $B S c$ in applied chemistry from South China University of Technology in 2009. He is currently a PhD candidate at Fudan University, working under the supervision of Prof. Minghua Qiao. His current research effort concentrates mainly on the development of aromatics hydrogenation catalysts for cycloolefins production. 
materials such as grain boundaries, dislocations, and stacking faults. ${ }^{4}$ These structural peculiarities of amorphous alloys lead to unique mechanical and physical properties such as soft magnetism, high tensile strength and elasticity, and high corrosion resistance promising for a wide range of applications. ${ }^{5}$

In 1933, Zahn and Kramer pioneeringly discovered amorphous alloys via the evaporation-deposition technique. ${ }^{6}$ However, it was not until 1980 that Smith et al. published their leading work on the catalytic application of amorphous alloys. ${ }^{7}$ The successful preparation of $\mathrm{Fe}-\mathrm{Co}-\mathrm{B}$ amorphous alloy particles by reduction of metal ions with $\mathrm{KBH}_{4}$ in aqueous solution by van Wonterghem et al. in 1986 greatly stimulated the blossom of amorphous alloys in catalysis, since the chemical reduction method is very convenient and much less demanding on the synthetic apparatus as compared to other techniques for the preparation of amorphous alloys, e.g., the rapid quenching technique. ${ }^{8}$ In fact, catalytic studies on amorphous alloys may be traced back to an earlier work of Brown and coworkers in 1953, who observed that $\mathrm{Ni}-\mathrm{B}$ particles catalyzed $\mathrm{H}_{2}$ production from aqueous $\mathrm{NaBH}_{4},{ }^{9}$ although the amorphous structure was not recognized at that time.

According to Molnár et al. ${ }^{10}$ and Baiker, ${ }^{11}$ in principle, amorphous alloys have the following merits that justify them as high-performance catalytic materials:

(1) Unlike crystalline alloys, the composition of the amorphous alloys can be adjusted in a wide range. The continuous control of the composition and the accompanying electronic property permit the fine tuning of the catalytic performance to meet the activity and/or selectivity demands.

(2) The isotropic and homogeneous characters of the amorphous alloys afford a uniform dispersion of active sites in a chemically identical environment, which is beneficial for the development of catalysts with high or exclusive selectivity.

(3) The high density of coordinatively unsaturated sites (CUSs) on amorphous alloys is important for heterogeneous catalysis, as the CUSs, similar to the low-coordination number step sites and kink sites on crystalline catalysts, are essential for the bonding and activation of the reactants, which ensures a high catalytic activity.

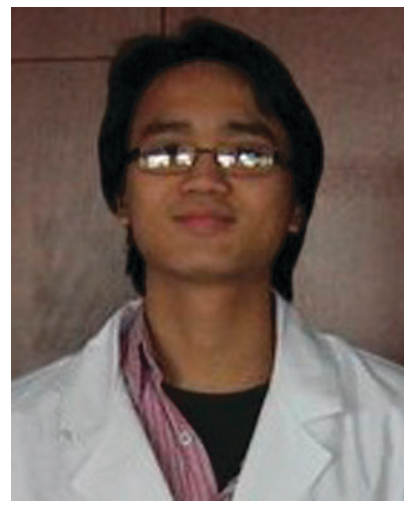

Nguyen Luan
Nguyen Luan is a graduate student at Department of Chemistry and Biochemistry at University of Notre Dame. He works on preparation of bimetallic nanocatalysts and in situ and operando studies of surface chemistry and structure of nanocatalysts.

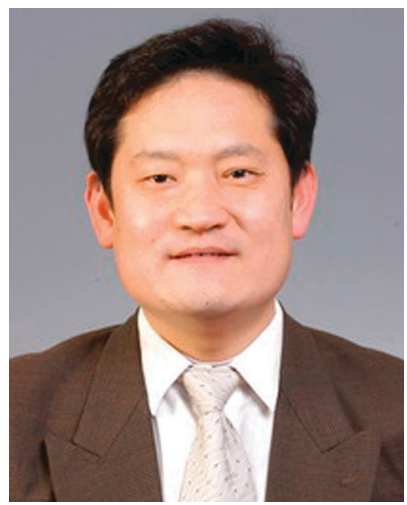

Baoning Zong
Baoning Zong received his BSc of Chemistry in 1985 from Peking University and his PhD of Chemical Engineering from the Research Institute of Petroleum Processing (RIPP) of Sinopec in 1991 under the supervision of Prof. Enze Min. He then joined RIPP, Sinopec. From 1995 to 1996, he worked as a postdoctoral fellow with Prof. G. Ertl at Fritz-Haber-Institute der Max-Plank-Gesellschaft. Since 1997, he has been a senior engineer of RIPP, Sinopec. He concentrated on catalytic applications and industrialization of amorphous metal alloys and magnetic stabilized bed reactor.

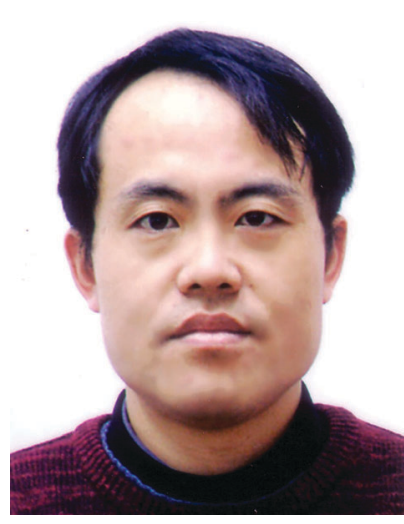

Minghua Qiao
Minghua Qiao received his BSc in Chemistry in 1994 and his PhD in 2000 from Fudan University, where he worked under the direction of Prof. Jingfa Deng. From 1997 to 1999, he temporarily studied in the Laboratory of Surface Chemistry led by Prof. Guoqin $\mathrm{Xu}$ at the National University of Singapore. In 2006, he became full professor for Physical Chemistry at Fudan University. His research concerns the design and characterization of amorphous alloys, skeletal alloys, metal-molecular sieve composite materials, and their applications in hydrogenation and energy-related catalysis.

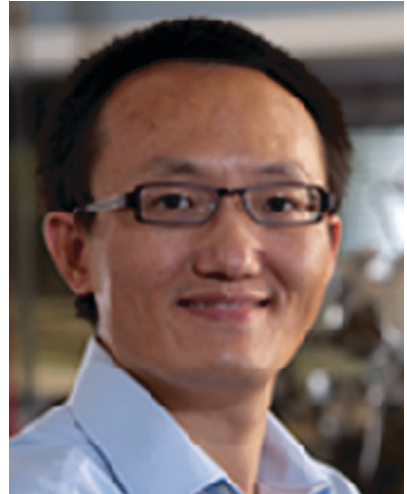

Franklin (Feng) Tao
Franklin (Feng) Tao joined Department of Chemistry and Biochemistry at University of Notre Dame as a tenure-track assistant professor in 2010 after obtaining a PhD in chemistry from Princeton University followed by a postdoctoral fellowship at Lawrence Berkeley National Lab and University of California at Berkeley. He is currently leading a research group interested in catalysis, energy science, and nanoscience. He published about 70 research peer-reviewed articles in international journals and two books by Wiley. He serves on advisory board of Catalysis Science and Technology. 
It is worthy of note that there are two other forms of metal catalysts that also hold the merits of amorphous alloy catalysts mentioned above. One is the so-called single-site metallic catalysts, i.e., a single atom (or ion) functions as the active site of chemical turnover. Site-isolation is an essential characteristic of single-site catalysts. The other is nanocluster catalysts characterized by molecular aggregates between 2 and 30 atoms, as defined by Gates and coworkers ${ }^{12}$ and Thomas. ${ }^{13}$ As compared to amorphous alloys, the term "long-range" is virtually inapplicable to these metal catalysts bearing especially small dimension. More details about these novel catalysts and their promising applications can be found in reviews by Thomas and coworkers. ${ }^{14-18}$

In terms of the preparation of amorphous alloy catalysts, the rapid quenching method and the chemical reduction method mentioned above are two most frequently adopted means. ${ }^{10,11,19-22}$ Since the rapid quenching method should ensure a cooling rate of at least $10^{5}-10^{6} \mathrm{~K} \mathrm{~s}^{-1}$ in an inert atmosphere or in vacuo, it is technologically more challenging and costly for bench-scale preparation. The compositions of some amorphous alloys prepared by this method are limited by their high melting points. Thus sometimes only amorphous alloys with the ratio of different elements near the eutectic composition can be obtained. In this respect, the chemical reduction method is more versatile and economical.

The chemical reduction method involves the reduction of metal salt with reductants such as borohydride $\left(\mathrm{BH}_{4}{ }^{-}\right)$or hypophosphite $\left(\mathrm{H}_{2} \mathrm{PO}_{2}{ }^{-}\right)$usually in an aqueous solution, producing metal-boride $(\mathrm{M}-\mathrm{B})$ or metal-phosphide $(\mathrm{M}-\mathrm{P})$ amorphous alloy particles. ${ }^{8,23}$ The chemical reduction method can conveniently integrate with traditional catalyst preparation methods or new materials synthetic strategies. Preparation parameters such as temperature, $\mathrm{pH}$, solvent, metal source, metal/reductant ratio, adding sequence, and adding speed strongly affect the composition and structure of the amorphous alloys, ${ }^{24-31}$ thus providing abundant possibilities for the manipulation of the catalytic performance. Aside from binary $\mathrm{M}-\mathrm{B}(\mathrm{P})$ amorphous alloys, amorphous alloys with one or more metals or metalloids can be readily prepared by using a mixed solution of metal salts or reductants. ${ }^{23,32-36}$ Chemical reduction of metal ions adsorbed on supports leads to supported amorphous alloy catalysts. ${ }^{22,37}$ The large surface area of the support can accommodate amorphous alloy nanoparticles in high dispersion, which greatly improves the utility of the active sites. Owing to the stabilization effect of the support as a heat sink, the supported amorphous alloy nanoparticles can retain their amorphous structure at temperatures higher than the unsupported counterparts, thus remarkably extending the applications and lifetime of the amorphous alloys in catalysis. ${ }^{22}$ In addition, characters of supports such as porosity, acidity, and hydrophilicity offer additional means for the tailoring of the reaction pathway. All these features make amorphous alloys attractive materials in heterogeneous catalysis.

Several excellent reviews have been published on the advances in the catalysis on rapidly quenched ${ }^{10,11,38}$ and chemically reduced amorphous alloy catalysts ${ }^{21,22}$ in the last century. To distinguish from these reviews, our review will focus on research efforts mainly in the new century on chemically reduced metal-metalloid amorphous alloy catalysts. The fundamental aspects of the amorphous alloy catalysts, i.e., structural and electronic properties, as well as promotion effects, will be addressed after introduction. Next, progress in the preparation strategies of amorphous alloy catalysts will be reviewed, with special emphasis on the designed synthesis of size-specific amorphous alloy nanoparticles, tailored assembly of amorphous alloys with novel morphologies, and new protocols for the supporting of amorphous alloys. Then, applications of the amorphous alloy catalysts in petrochemical, fine chemical, energy, and environment relevant reactions will be presented. Lastly, we will concisely discuss on some of the scientific challenges and opportunities in this field.

\section{Basic physical aspects}

\subsection{Structural property}

There are only few in-depth studies on the structural information of the metal-metalloid amorphous alloy catalysts. ${ }^{39-42}$ In most cases, the amorphous structure is qualitatively determined by conventional characterization techniques such as X-ray diffraction (XRD), a combination of transmission electron microscopy (TEM) and selected area electron diffraction (SAED), and differential scanning calorimetry (DSC). For amorphous alloys, their XRD patterns are only characterized by a featureless broad peak. Under TEM observation, the chemically reduced amorphous alloy particles usually display spherical contour or irregularly shaped aggregates of spherical particles. In the SAED pattern, there is a diffractive halo, rather than distinct rings or dots characteristic of microcrystallites or single crystals, respectively. DSC reveals exothermic peak(s) due to the occurrence of structure transition and/or crystallization. These characterizations are unable to provide quantitative structural information of the amorphous alloys. Thus an accurate structure-performance relationship cannot be established. Although high-resolution TEM (HRTEM) is powerful in elucidating the microstructure of crystals, the high-energy electron beam of several hundreds of keVs is detrimental even to crystalline materials, not to mention the thermodynamically metastable amorphous alloys. So, we should be very careful when using this technique to investigate and interpret the microstructure of amorphous alloys.

As far as the short-range ordered and long-range disordered structure of the amorphous alloy is concerned, an extended X-ray absorption fine structure (EXAFS) technique is very suitable for its structural determination. Although neutron beam-based techniques are also powerful in structural analysis of amorphous alloys, these techniques are far less accessible. EXAFS measures the photo-absorption coefficient in the vicinity of the ionization edge of the element of choice, which is a unique probe for the revelation of the local atomic and electronic structure of absorbing centers. ${ }^{43,44}$ EXAFS provides direct information on the local environment of a specific atom without the requirement of long-range ordered structure as required for XRD. Analysis of the EXAFS spectra allows for the extraction of bonding distances, number and type of 


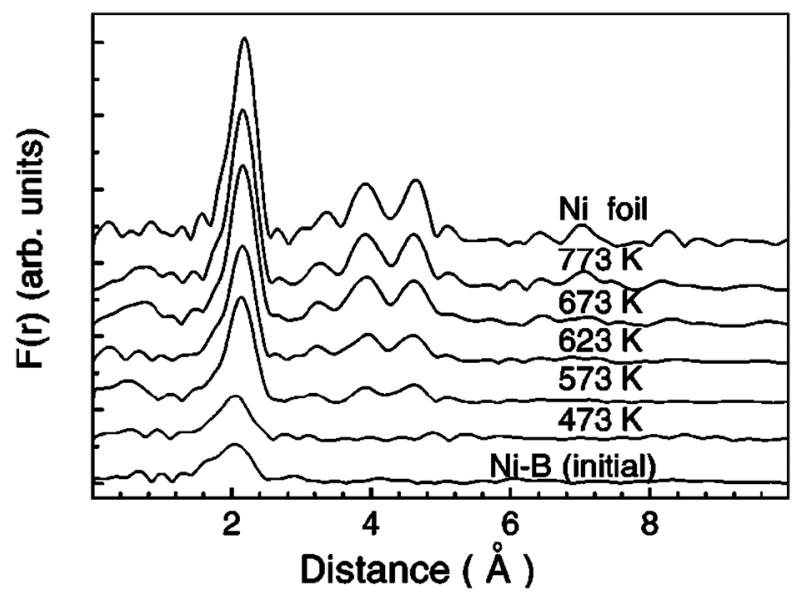

Fig. 1 Radial distribution functions of an ultrafine $\mathrm{Ni}-\mathrm{B}$ amorphous alloy annealed at different temperatures. Reproduced from ref. 39 with kind permission from the American Physical Society.

neighboring atoms within the first few shells around the center atom, which are especially valuable for the interpretation of the microstructure of amorphous alloys. The major limitation of EXAFS is that it only provides structure-averaged information of the same absorber atoms. If absorber atoms adopt several configurations, individual local structural information cannot be obtained.

Fig. 1 shows the radial distribution functions (RDFs) of the as-prepared and thermally treated $\mathrm{Ni}_{70} \mathrm{~B}_{30}$ samples, obtained from their $k^{3} \chi(k)$ by Fourier transform of the EXAFS spectra. ${ }^{39}$ Only one prominent peak due to the first nearest neighbor of $\mathrm{Ni}$ atoms is observed for the as-prepared and 473 K-annealed samples, which unambiguously confirms their amorphous structure. In contrast, for crystalline Ni foil, aside from the intense first peak, there are distinct second and third nearest-neighbor peaks. By fitting the EXAFS spectra, the $\mathrm{Ni}-\mathrm{Ni}$ and $\mathrm{Ni}-\mathrm{B}$ distances and coordination numbers were determined. The Ni-Ni distance in the amorphous sample is much longer than that in the completely crystallized one. Considerable $\mathrm{Ni}-\mathrm{B}$ coordination exists in the amorphous sample, while it is negligible in the completely crystallized sample.

By means of EXAFS, subtle structural difference between different amorphous alloys can be distinguished, which is unachievable by conventional techniques. For $\mathrm{Ni}_{70} \mathrm{~B}_{30}$ prepared at various temperatures, Wei and coworkers revealed that the coordination geometry surrounding $\mathrm{Ni}$ atoms is a structure of amorphous Ni-like for the sample prepared at $273 \mathrm{~K}$, suggesting that $\mathrm{Ni}$ and $\mathrm{B}$ atoms aggregated into Ni- and B-enriched clusters, respectively. ${ }^{42}$ It is possible that only small fractions of $\mathrm{B}$ enter into the $\mathrm{Ni}$ cluster, and/or $\mathrm{Ni}$ and $\mathrm{B}$ atoms only interact at the interface between their respective clusters. $\mathrm{Ni}_{70} \mathrm{~B}_{30}$ prepared at $313 \mathrm{~K}$ has amorphous $\mathrm{Ni}_{3} \mathrm{~B}$-like structure with shorter first $\mathrm{Ni}-\mathrm{B}$ coordination distance. These results indicate that the preparation temperature strongly affects the local structure of the $\mathrm{Ni}_{70} \mathrm{~B}_{30}$ amorphous alloy.

The above finding on the microstructure of $\mathrm{Ni}_{70} \mathrm{~B}_{30}$ prepared at $273 \mathrm{~K}$ is partly in line with the report of Geng et al., which evidenced by HRTEM that their Ni-B nanoparticles prepared by chemical reduction are made up of tiny $\mathrm{Ni}$ nanoparticles (1-3 nm) embedded in a matrix of B-containing species. ${ }^{45}$ It is noticed that the Ni nanoparticles in their Ni-B sample are crystalline, which may be caused by differences in the preparation conditions. It should be stressed that chemical reduction does not always lead to amorphous structure. For example, when copper salt was reduced by $\mathrm{KBH}_{4}, \mathrm{Cu}$ crystallites were obtained. ${ }^{46-48}$ When the $\mathrm{pH}$ of the solution for the preparation of the Ni-P alloy was 8.1 or lower, reflections assignable to $f c c$ Ni emerged. ${ }^{31}$

With the aid of EXAFS, the structure-performance relationship can be described at a more microscopic level. Wei and coworkers studied the effect of annealing temperature on the structure of nano-amorphous $\mathrm{Ni}-\mathrm{B}$ and the benzene hydrogenation activity. ${ }^{40}$ It was found that below $573 \mathrm{~K}$, Ni-B samples retained their original amorphous structure. At $573 \mathrm{~K}$ and $623 \mathrm{~K}$, the nano-amorphous $\mathrm{Ni}-\mathrm{B}$ was crystallized into nano-crystalline $\mathrm{Ni}$ and crystalline $\mathrm{Ni}_{3} \mathrm{~B}$. At $773 \mathrm{~K}$, crystalline $\mathrm{Ni}_{3} \mathrm{~B}$ was decomposed to crystalline $\mathrm{Ni}$, and nano-crystalline $\mathrm{Ni}$ aggregated into large $\mathrm{Ni}$ grains. Combined with the temperature-dependent intrinsic activity, the catalytic activity of various $\mathrm{Ni}$ phases in benzene hydrogenation is ranked as nanocrystalline $\mathrm{Ni}>$ nano-amorphous $\mathrm{Ni}-\mathrm{B}$ alloy $>$ crystalline $\mathrm{Ni} \approx$ crystalline $\mathrm{Ni}_{3} \mathrm{~B}$.

$\mathrm{X}$-ray absorption near-edge structure (XANES) is also powerful in providing electronic and geometric information. Qiao and coworkers observed that with the increment of the amount of $\mathrm{Fe}$ in the $\mathrm{Co}-\mathrm{B}$ amorphous alloy, the $\mathrm{Co} K$-edge XANES spectra remained identical, but in sharp difference from that of the Co foil (Fig. 2). ${ }^{41}$ The close resemblance of the Co $K$-edge XANES spectra, along with the virtually unchanged structural parameters derived from EXAFS, strongly indicates that the metal atoms in $\mathrm{Co}-\mathrm{B}$ and $\mathrm{Co}-\mathrm{Fe}-\mathrm{B}$ amorphous alloys have identical local symmetry. Thus, the intensity of the pre-edge peak in Fig. 2 can be taken as a measure of the occupation degree of the $3 \mathrm{~d}$ holes. According to the figure,

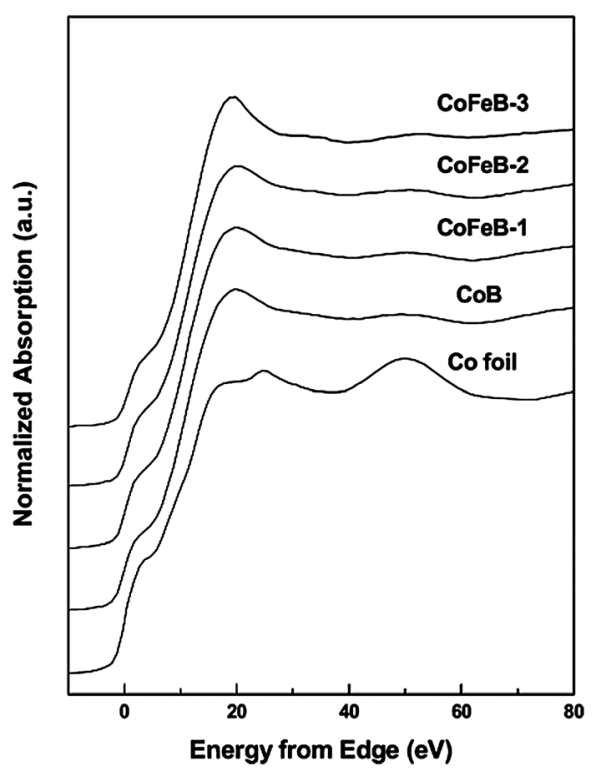

Fig. 2 Normalized Co $K$-edge XANES spectra for the Co foil and the $\mathrm{Co}-\mathrm{B}$ and $\mathrm{Co}-\mathrm{Fe}-\mathrm{B}$ catalysts. Reproduced from ref. 41 with kind permission from Elsevier. 
Co in these amorphous alloys has similar $3 \mathrm{~d}$ population irrespective of the $\mathrm{Fe}$ content. Thus, the influence of $\mathrm{Fe}$ on the $\mathrm{Co}-\mathrm{B}$ amorphous alloy was attributed to the geometrical effect, rather than the electronic effect.

\subsection{Electronic property}

Metal-metalloid amorphous alloys exhibit high catalytic activity and/or selectivity in a large collection of reactions. Reaction rates faster than typical rates on RANEY ${ }^{\circledR} \mathrm{Ni}$ or comparable to those on noble metal catalysts have been reported. ${ }^{49-55} \mathrm{~A}$ rational interpretation of the mechanism responsible for the enhanced catalytic performance of the amorphous alloys requires not only a clarification of the microstructure, but also an understanding of the electronic property.

It is interesting that photoelectron spectroscopic investigations suggest that the electronic effects of $\mathrm{B}$ or $\mathrm{P}$ alloying with $\mathrm{Ni}$ are at variance, though both metalloids are more electronegative than Ni. For a Ni-B amorphous alloy, there is a consensus that $\mathrm{B}$ displays a positive binding energy (BE) shift, ${ }^{56-60}$ which is interpreted as electron donation from B to $\mathrm{Ni}^{56-59}$ or to oxygen species left in the alloy. ${ }^{21,60}$ For a Ni-P amorphous alloy, the situation is more complicated. Negative $\mathrm{BE}$ shift, ${ }^{21,56,57,60}$ no significant BE shift, ${ }^{61}$ and compositiondependent BE shift of $\mathrm{P}^{58,59}$ have been documented. Imanaka and Tamaki found that $\mathrm{P}$ displayed positive $\mathrm{BE}$ shift for $\mathrm{Ni}-\mathrm{P}$ alloys containing $\geq 75 \%$ of $\mathrm{Ni}$, while negative $\mathrm{BE}$ shift for alloys with lower $\mathrm{Ni}$ content. ${ }^{58,59}$ To eliminate the possible interferences of the charging effect and spectrometer workfunction on the BE shifts, under strictly defined characterization conditions, Deng and coworkers verified that B showed positive $\mathrm{BE}$ shift relative to elemental $\mathrm{B}$ in the $\mathrm{Ni}-\mathrm{B}$ amorphous alloy, $\mathrm{P}$ displayed no detectable $\mathrm{BE}$ change relative to elemental $\mathrm{P}$ for the Ni-P amorphous alloy with surface composition of $\mathrm{Ni}_{76} \mathrm{P}_{24}$, and $\mathrm{Ni}$ in both alloys showed no $\mathrm{BE}$ shift relative to Ni foil. ${ }^{62}$ Based on the positive BE shift of $\mathrm{B}$ for the Ni-B amorphous alloy, Okamoto et al. claimed that $\mathrm{B}$ donated electrons to the alloying $\mathrm{Ni}^{56,57}$ The charge transfer may be evidence of the bonding between $\mathrm{Ni}$ and $\mathrm{B}$ in the amorphous alloy, which leads to a smaller $\mathrm{Ni}-\mathrm{B}$ atomic distance than the summation of Goldschmidt radii of individual atoms as determined by EXAFS, ${ }^{63}$ as also observed on the $\mathrm{Co}-\mathrm{B}$ amorphous alloy. ${ }^{41}$

The invariant $\mathrm{Ni} 2 \mathrm{p}$ BE of $\mathrm{Ni}$ after alloying with $\mathrm{B}$ may be justified by the following argument. ${ }^{64}$ From $\mathrm{Ni}^{0}$ to $\mathrm{Ni}^{2+}$, the Ni $2 p$ BE shift is $c a$. $+1 \mathrm{eV}$, while from $\mathrm{B}^{0}$ to $\mathrm{B}^{3+}$, the $\mathrm{B} 1 \mathrm{~s} \mathrm{BE}$ shift is $c a$. $+6 \mathrm{eV}$. By considering the $\mathrm{B} 1 \mathrm{~s} \mathrm{BE}$ shift of $+1.1 \mathrm{eV}$ in the Ni-B amorphous alloy, along with the surface composition of $\sim \mathrm{Ni}_{75} \mathrm{~B}_{25}$, an estimation gave a Ni $2 \mathrm{p}$ BE shift of $-0.06 \mathrm{eV}(\Delta \mathrm{BE}=-(1.1 \times 0.25) /(6 \times 0.75))$, which is well within the detection error of $\pm 0.2 \mathrm{eV}$ on a conventional XPS spectrometer. This argument can analogously explain the apparently unchanged BEs of Co $2 \mathrm{p}, \mathrm{Fe} 2 \mathrm{p},{ }^{41}$ and $\mathrm{Ru} 3 \mathrm{~d}$ levels ${ }^{65}$ in $\mathrm{M}-\mathrm{B}$ amorphous alloys. Actually, Diplas et al. observed the slight negative $\mathrm{BE}$ shifts of the Ni $2 p$ and $3 p$ levels of $\mathrm{Ni}-\mathrm{B}$ amorphous alloys containing 30 at $\%$ and 50 at $\%$ of B at improved energy resolution. ${ }^{66}$ Based on Auger parameter measurements and primary and secondary features of the XPS spectra, they proved that the positive BE shift of B is not caused by the final state effect, but rather by electron donation from B to Ni. The seemingly contradiction between the direction of electron transfer and the electronegativity sequence of $\mathrm{Ni}$ and $\mathrm{B}$ is rationalized by considering the increase in the electron density at the $\mathrm{Ni}$ sites in the $\mathrm{Ni}-\mathrm{B}$ amorphous alloys to be a result of shortening of the interatomic distances via the formation of hybridized bonds between $\mathrm{Ni}$ and $\mathrm{B}$ atoms. ${ }^{66}$ In a successive work, the authors extended this conclusion to $\mathrm{Ni}-\mathrm{P}$ and $\mathrm{Ni}-\mathrm{S}$ systems, and suggested that the $\mathrm{Ni}$ sites experiencing a higher electron density in the $\mathrm{Ni}-\mathrm{X}(\mathrm{X}=\mathrm{B}, \mathrm{S}, \mathrm{P})$ amorphous alloys than in pure $\mathrm{Ni}$ could be the reason for the increased catalytic activity. ${ }^{67}$ Moreover, using density function theory (DFT) calculations, Diplas and Løvvik found that the Ni 3d density of state (DOS) of the Ni-B, Ni-P, and Ni-S alloys shows strong similarity to that of $\mathrm{Pt}$, which may account for their high activity in $\mathrm{H}_{2}$ evolution reaction. ${ }^{68}$ However, it should be cautious that their periodic models may not be adequate to represent the geometric structure of amorphous alloys.

Since amorphous alloys lack long-range ordered structure and can be looked as a stacking of metal-metalloid atomic clusters with short-range ordering, ${ }^{3}$ a cluster model seems to be a proper choice to represent the local structure of amorphous alloys. As experiments have indicated the presence of direct $\mathrm{B}-\mathrm{B}$ contact in $\mathrm{M}-\mathrm{B}$ amorphous alloys ${ }^{69}$ and the absence of direct $\mathrm{P}-\mathrm{P}$ contact in $\mathrm{M}-\mathrm{P}$ amorphous alloys, ${ }^{70}$ Fan and coworkers constructed $\mathrm{M}_{m} \mathrm{~B}_{2}$ and $\mathrm{M}_{n} \mathrm{P}(\mathrm{M}=\mathrm{Ni}, \mathrm{Co})$ cluster models and calculated their geometric and electronic properties using DFT. ${ }^{71-74}$ Electron donation from $\mathrm{B}$ to Ni or $\mathrm{Co}$ and electron donation from $\mathrm{Ni}$ or $\mathrm{Co}$ to $\mathrm{P}$ were demonstrated by their theoretical simulations. For $\mathrm{TiO}_{2}(110)$ surfacesupported $\mathrm{Co}_{2} \mathrm{~B}_{2}$ or $\mathrm{NiFeB}_{2}$ clusters, DFT calculations similarly gave the direction of electron donation from $\mathrm{B}$ to metals. ${ }^{75,76}$ Using $\mathrm{Ni}_{n} \mathrm{P}(n=1-6)$ cluster models, the experimentally observed inverse of the direction of electron donation between $\mathrm{Ni}$ and $\mathrm{P}^{58,59}$ was nicely reproduced at $n=6 .^{72}$

\subsection{Promotion effect}

Inclusion of metal promoter(s) in metal-metalloid amorphous alloy catalysts can optimize the catalytic performance by affecting the structural and/or electronic characteristics. Promoters are generally present in the oxidized state and/or metallic state, depending on their reducibility and alloying ability. ${ }^{77}$ When the promoter is in the oxidized state, e.g., early transition metal, it generally promotes the dispersion of the amorphous alloy by inhibiting the agglomeration of the nanoparticles and improves the active surface area. The acidic property of oxidized metal species is favorable for the adsorption and activation of polar groups, such as carbonyl groups and nitro groups. When the promoter is in the metallic state, e.g., late transition metal, it not only stabilizes the amorphous structure, but also forms chemical bonds with the constituting atoms of the amorphous alloy, which tune the electron population at the Fermi level. ${ }^{78}$ Furthermore, the promoter may change the composition of the M-B amorphous alloy, ${ }^{51,79}$ which affects the local structure and electronic property of $\mathrm{M}$ alloying with $\mathrm{B}$.

For instance, Mo and Ce have been used as promoters for $\mathrm{Co}-\mathrm{B}^{80}$ and Ni-B catalysts. ${ }^{81,82}$ These promoters, in the form 
of $\mathrm{MoO}_{3}$ and $\mathrm{CeO}_{2}$, not only accelerated the reaction rate, but also elevated the crystallization temperature $\left(T_{\mathrm{c}}\right)$. The $\mathrm{Cr}$ promoter in the $\mathrm{Ni}-\mathrm{B}$ catalyst, most likely in the form of $\mathrm{Cr}_{2} \mathrm{O}_{3}$, functioned as participants between $\mathrm{Ni}-\mathrm{B}$ nanoparticles, thus enhancing the dispersion of the active sites, and as Lewis acid sites that can lower the $\pi^{*} \mathrm{CO}$ orbital of the reactant, thus directing a carbonyl group-bonded configuration. ${ }^{83}$ Addition of $\mathrm{Sn}$ to the $\mathrm{Ru}-\mathrm{B} / \gamma-\mathrm{Al}_{2} \mathrm{O}_{3}$ catalyst not only improves the dispersion and thermal stability significantly, but also increases the $\mathrm{B} / \mathrm{Ru}$ ratio, the electron density of $\mathrm{Ru}$, and the adsorption strength of $\mathrm{H}_{2}{ }^{84}$ Promotion of the Ni-B nanocatalyst with $\mathrm{W}$ or Mo caused an increment of the B content associated with $\mathrm{Ni}$, which thus altered the hydrogenation activity. ${ }^{79}$

The promotion effect of metallic $\mathrm{Co}$ on the Ni-B amorphous alloy was interpreted both electronically and structurally. Co donates electron to $\mathrm{Ni}$, leading to electron-enriched $\mathrm{Ni}$ and electron-deficient Co. ${ }^{34,85}$ The structural disorder of the $\mathrm{Ni}-\mathrm{Co}-\mathrm{B}$ catalyst increases with the content of metallic $\mathrm{Co}^{78}$ The promotion effect of metallic $\mathrm{Fe}$ has been studied on $\mathrm{Ni}-\mathrm{B}^{86}$ and Ni-P catalysts. ${ }^{87}$ The promotion effect of $\mathrm{Fe}$ was attributed to electron donation from metallic $\mathrm{Fe}$ to $\mathrm{Ni}$, which is favorable for the activation and hydrogenation of polar groups. Incorporation of $\mathrm{Fe}$ into the $\mathrm{Co}-\mathrm{B}$ catalyst favored the hydrogenation of carbonyl groups via the ensemble size effect. ${ }^{41}$ Although the oxidation state of La was not specified, the effect of $\mathrm{La}$ on the $\mathrm{Ni}-\mathrm{B}$ catalyst was interpreted as electronic modification of $\mathrm{Ni}$ by La. ${ }^{51}$ It is acknowledged that the change in the electron density at the Fermi level can affect the dissociative chemisorption of $\mathrm{H}_{2}$, which will influence the hydrogenation activity in reactions where $\mathrm{H}_{2}$ dissociation is the rate-determining step $(\mathrm{rds}) .{ }^{78,88,89}$

\section{Synthesis of metal-metalloid amorphous alloy catalysts with well defined morphologies}

\subsection{Monodispersed nanoparticles}

The chemical reduction method has been most frequently adopted to synthesize nanosized amorphous alloy catalysts. Conventionally, the reduction is performed by adding a solution containing the chemical reductant to a solution containing the metal salt or vice versa, at a certain temperature under stirring. The vigorous and exothermic reduction reaction may induce severe agglomeration or aggregation of the nanoparticles, thereby lowering the catalytic efficiency. To remove the disadvantage of conventional chemical reduction methods, various preparative strategies to uniform amorphous alloy nanoparticles have been developed, including the microemulsion method, ${ }^{53,90,91}$ polymer stabilization, ${ }^{92-94}$ and sonochemical technique. ${ }^{95-99}$

3.1.1 Microemulsion method. Microemulsion solutions are transparent, isotropic liquid media with nanosized water (oil) droplets dispersed in a continuous oil (water) phase and stabilized by surfactant molecules at the water/oil interface. The microemulsion method is suitable for the preparation of uniform particles with controllable sizes and morphologies. Surfactant-covered liquid droplets can function as micro- or nano-reactors providing a homogeneous microenvironment

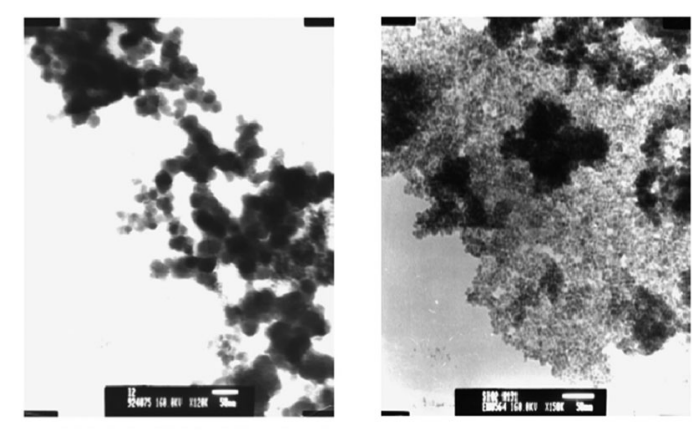

Fig. 3 TEM micrographs of NiB (left) and ME-NiB (0.15 M) (right) catalysts. Reproduced from ref. 53 with kind permission from Elsevier.

for the formation of nanoparticles. The surfactant may adsorb on the nanoparticle surface when the particle size approaches that of the liquid droplet, acting as a protective agent to stabilize and restrict the size of the nanoparticles. Liaw and coworkers prepared surfactant-stabilized Ni-B catalysts $(\mathrm{ME}-\mathrm{NiB})$ in a ternary microemulsion system of watercetyl-trimethyl-ammonium bromide (CTAB)- $n$-hexanol. ${ }^{53}$ It was found that the particle sizes of the ME-NiB were not fully dominated by the size of the water-in-oil (W/O) reverse microemulsion droplets. They were also influenced by the composition of the microemulsion, the concentration of the $\mathrm{Ni}$ salt, the amount and the addition speed of $\mathrm{NaBH}_{4}$, and the temperature. The particle size and size distribution of the ME-NiB were substantially reduced and narrowed to $3-8 \mathrm{~nm}$, as compared to the size $(20-50 \mathrm{~nm})$ of conventional Ni-B nanoparticles (Fig. 3). In a similar approach, Wu and coworkers synthesized spherical and rod-like $\mathrm{Fe}-\mathrm{B}$ alloys in pseudo-ternary $\mathrm{W} / \mathrm{O}$ microemulsions. ${ }^{91}$ The particle size was mainly determined by the size of the microemulsion droplets, and the key factor affecting the morphology (spherical or rodlike) of the $\mathrm{Fe}-\mathrm{B}$ nanoparticles was the interfacial property relevant to the $n$-butanol/CTAB ratio.

Synthesis in $\mathrm{W} / \mathrm{O}$ microemulsions has limitations of low concentration of the product and environmental pollution. $\mathrm{Li}$ and coworkers designed an oil-in-water $(\mathrm{O} / \mathrm{W})$ microemulsion system comprising cyclohexane, polyethylene glycol (PEG), and water for the fabrication of uniform $\mathrm{Co}-\mathrm{B}$ nanoparticles in large quantities. ${ }^{90}$ Uniform $\mathrm{Co}-\mathrm{B}$ nanoparticles with controllable particle sizes from 6 to $20 \mathrm{~nm}$ were synthesized by adjusting the cyclohexane content.

3.1.2 Polymer stabilization. The polymer stabilization method, which takes advantage of surface modification by the polymer molecules, is effective in improving the dispersion and stability of the nanoparticles. The reactive surfaces of the nanoparticles can be saturated with functionalized polymer molecules immediately after nucleation at multiple sites through the functional groups of the polymer, thus sterically preventing the agglomeration of the nanoparticles. ${ }^{100,101}$

Liaw and coworkers used water-soluble polyvinylpyrrolidone (PVP) as a capping agent to prepare the PVP-stabilized $\mathrm{Ni}-\mathrm{B}$ and $\mathrm{Co}-\mathrm{Ni}-\mathrm{B}$ catalysts. ${ }^{92,94}$ The molecular weight of $\mathrm{PVP}$ and the $\mathrm{PVP} /$ metal ratio in the salt solution affected the particle size and distribution of the nanoparticles. The particle size and distribution of $\mathrm{PVP}-\mathrm{Ni}-\mathrm{B}$ were decreased and 

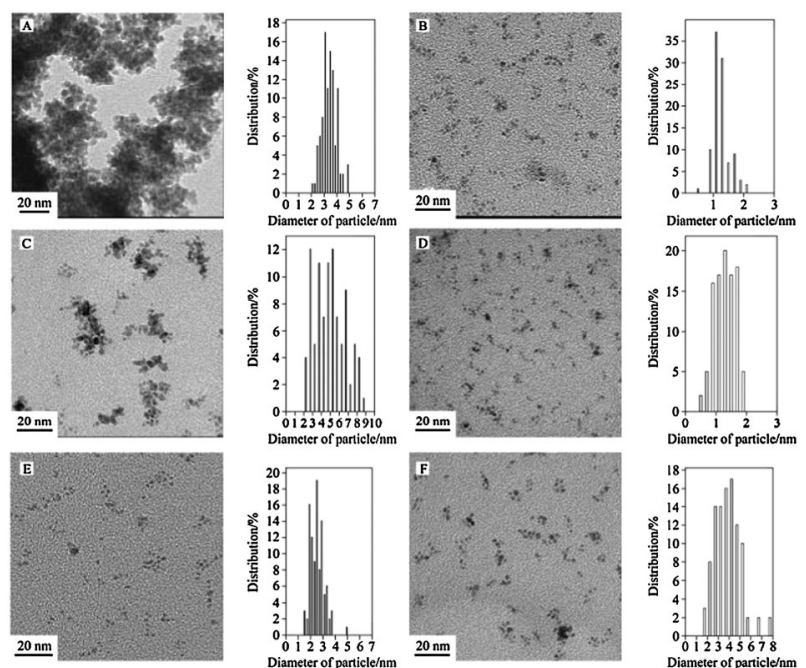

Fig. 4 TEM images (left) and the corresponding particle size distribution histograms (right) of the PVP-stabilized $\mathrm{Ru}-\mathrm{B}$ colloids. Reproduced from ref. 93.

narrowed to 3-5 $\mathrm{nm}$ under optimal preparation conditions, which was about one-tenth of that of $\mathrm{Ni}-\mathrm{B}$ without PVP protection. $^{94}$ Moreover, PVP-Ni-B was more stable than conventional $\mathrm{Ni}-\mathrm{B}$ at temperatures above $573 \mathrm{~K}$, despite the much smaller particle size of the former. Similar results were observed on the PVP-Co-Ni-B catalyst. ${ }^{92}$ Bu et al. prepared a series of PVP-stabilized $\mathrm{Ru}-\mathrm{B}$ colloidal catalysts in the range of 1.3-3.9 nm with sharp size distribution (Fig. 4). ${ }^{93}$ The stirring time for mixing PVP and $\mathrm{RuCl}_{3}$ and after $\mathrm{KBH}_{4}$ addition, the $\mathrm{Ru} / \mathrm{PVP}$ ratio, and the $\mathrm{RuCl}_{3}$ concentration influenced the size of the $\mathrm{Ru}-\mathrm{B}$ colloidal particles.

3.1.3 Ultrasound-assisted reduction. The ultrasoundassisted chemical reduction method has been proven to be effective in preparing amorphous alloys with homogeneous particle size. Ultrasonication can induce chemical reaction and inhibit particle aggregation due to acoustic cavitation, which produces unusual chemical environments. ${ }^{102-107}$ Generally, the particle size can be controlled by adjusting the ultrasonication power ${ }^{96-98}$ or time. $^{95,96}$ The effect of ultrasonication on the particle size is very pronounced for the $\mathrm{Ru}-\mathrm{B}$ nanoparticles. ${ }^{98}$ The conventional $\mathrm{Ru}-\mathrm{B}$ nanoparticles displayed irregular, broadly distributed particles from 15-50 nm. In sharp contrast, the ultrasound-assisted reduction gave rise to monodispersed and spherical $\mathrm{Ru}-\mathrm{B}$ nanoparticles with a much smaller size of 2.4-4.9 nm.

Besides the advantageous effect on reducing the particle size, the ultrasound-assisted method can induce a higher surface elemental $\mathrm{B} / \mathrm{M}$ ratio. The improvement of the surface $\mathrm{B} / \mathrm{M}$ ratio was identified on $\mathrm{Co}-\mathrm{B},{ }^{96} \mathrm{Ni}-\mathrm{B},{ }^{97}$ and $\mathrm{Ru}-\mathrm{B}$ nanoparticles ${ }^{98}$ reduced under ultrasonication. The increased surface $\mathrm{B}$ content can invoke a stronger electronic interaction with $\mathbf{M}$ and higher thermal stability by impeding the migration of the metal atoms.

\subsection{Special morphology}

Nearly all metal-metalloid amorphous alloys prepared by conventional chemical reduction methods are present in the form of nonporous spherical nanoparticles due to their isotropic nature. In order to achieve high utility of the active species, a usual practice is to reduce the particle size to as small as possible. However, this may evoke separation problems as well as severe agglomeration. Inspired by natural materials with fascinating functions and enhanced properties associated with their unique shape and/or morphology, synthesis of materials with controlled texture and morphology is drawing more and more attention. ${ }^{108,109}$ When used as catalysts, materials with special morphology may offer some advantages over their solid counterparts in terms of improved surface accessibility, easy recovery, and reduced cost. ${ }^{110}$ Thus, a combination of the amorphous structure and new morphology is expected to lead to amorphous alloys with enhanced catalytic properties.

3.2.1 Hollow morphology. The hard-templating method has been most frequently used to fabricate amorphous alloys with special nanostructures, because of its advantage in transcriptive imprinting of the template morphology. By electroless plating of the desired amorphous alloy on the shape-decisive hard template, various amorphous alloys with hollow structures have been synthesized, including $\mathrm{Ni}-\mathrm{B}^{111}$ and Ni-P hollow microspheres, ${ }^{112,113}$ and $\mathrm{Co}-\mathrm{Ni}-\mathrm{P}$ hollow rods. ${ }^{114}$ This synthetic strategy usually involves three steps as shown in Scheme 1. ${ }^{11}$ Firstly, the surface of the hard template is activated to facilitate the deposition of the amorphous alloy. Secondly, the amorphous alloy is deposited on hard templates, such as polystyrene (PS) microspheres, ${ }^{111,113}$ hollow glass microspheres, ${ }^{112}$ or Bacillus, a kind of rod-shaped bacteria, ${ }^{114}$ to form core-shell structure through electroless plating. Finally, the core is removed by dissolution ${ }^{11,113}$ or thermal annealing $^{114}$ to obtain the hollow structures (Fig. 5). We should be cautious that thermal annealing might be harmful to the amorphous structure. ${ }^{114}$ It is easy to control the morphology and diameter of the amorphous alloy hollow materials by using templates of different morphologies and dimensions. The thickness of the amorphous alloy shell is adjustable by varying the plating time ${ }^{111,112}$ or the concentration of the reductant. ${ }^{111}$ The plating time and the $\mathrm{pH}$ of the plating solution also influence the quality of the amorphous alloy shell. ${ }^{113}$

Fabrication of hollow amorphous alloy materials through the soft-templating strategy led to $\mathrm{Ni}-\mathrm{B}$ hollow spheres, ${ }^{115}$ $\mathrm{Fe}-\mathrm{B}, \mathrm{Co}-\mathrm{B}, \mathrm{Ni}-\mathrm{B},{ }^{116} \mathrm{Ni}-\mathrm{P}-\mathrm{B}, \mathrm{Ni}-\mathrm{Cu}-\mathrm{B}$, and $\mathrm{Ni}-\mathrm{Co}-\mathrm{B}$ hollow nanotubes. ${ }^{117}$ The formation of $\mathrm{Ni}-\mathrm{B}$ hollow spheres

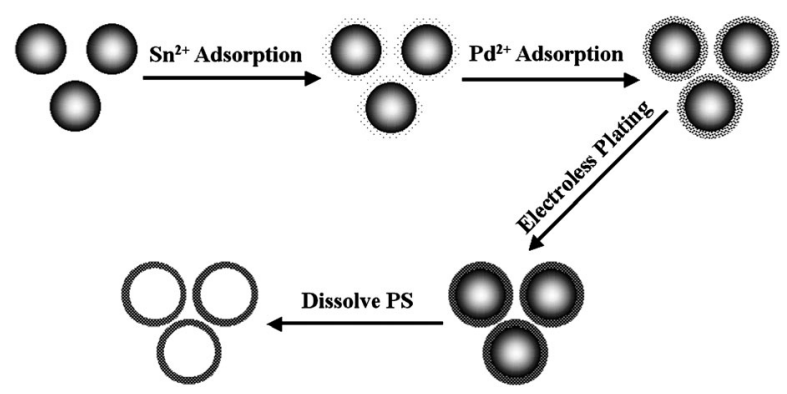

Scheme 1 Schematic outline of the steps involved in the fabrication of amorphous Ni-B hollow spheres. Reproduced from ref. 111. 

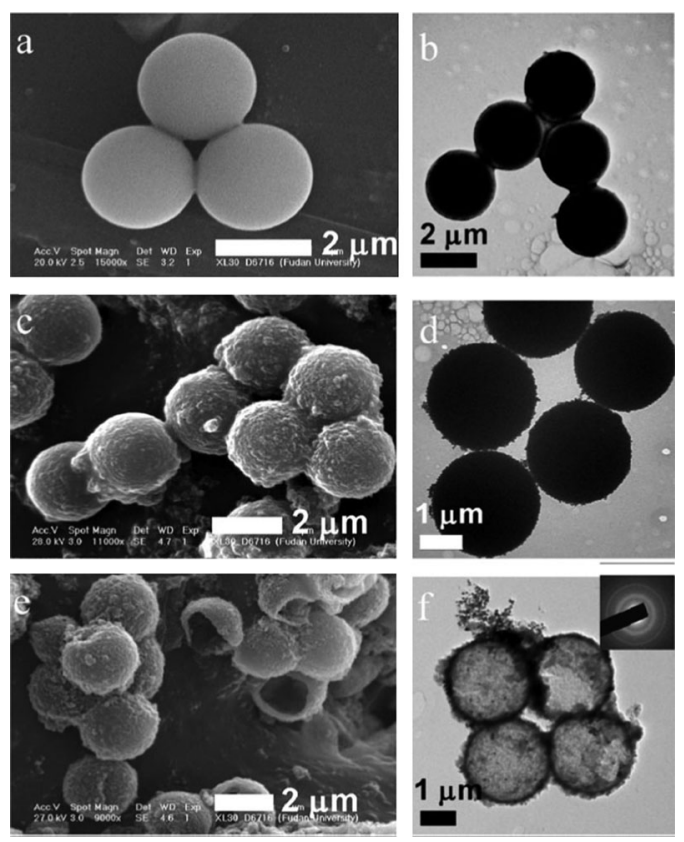

Fig. 5 SEM (a, c and e) and TEM (b, d and f) micrographs of the PS microspheres before and after Ni-B deposition: (a and b) pristine PS microspheres; (c and d) core-shell Ni-B-PS composites; (e, f) Ni-B hollow spheres. Inset shows the SAED pattern of the Ni-B hollow spheres. Reproduced from ref. 111.

is based on the emulsion droplets formed by the water-PEGcyclohexylamine system, which provides an in situ template for the deposition of the Ni-B amorphous alloy. ${ }^{115}$ The average cavity size of the product is almost the same as the diameter of the microemulsion droplet template.

Ding and coworkers synthesized $\mathrm{Fe}-\mathrm{B}, \mathrm{Co}-\mathrm{B}$, and $\mathrm{Ni}-\mathrm{B}$ nanotubes with uniform size by using lyotropic non-ionicanionic mixed surfactants as a template. ${ }^{116}$ For example, the $\mathrm{Fe}-\mathrm{B}$ nanotubes they synthesized are several micrometers long and have inner and outer diameters of $c a$. 50-55 and 60-65 nm, respectively (Fig. 6). By introducing $\mathrm{P}-, \mathrm{Co}-$, and $\mathrm{Cu}-$ containing compounds during the preparation, ternary $\mathrm{Ni}-\mathrm{P}-\mathrm{B}, \mathrm{Ni}-\mathrm{Co}-\mathrm{B}$, and $\mathrm{Ni}-\mathrm{Cu}-\mathrm{B}$ nanotubes were obtained. ${ }^{117}$ These authors proposed that the presence of the lyotropic liquid crystals (LCs) was the key for the formation of the amorphous alloy nanotubes. During the reduction of metal ions located in the layer structure of the LCs, the released $\mathrm{H}_{2}$ results in the

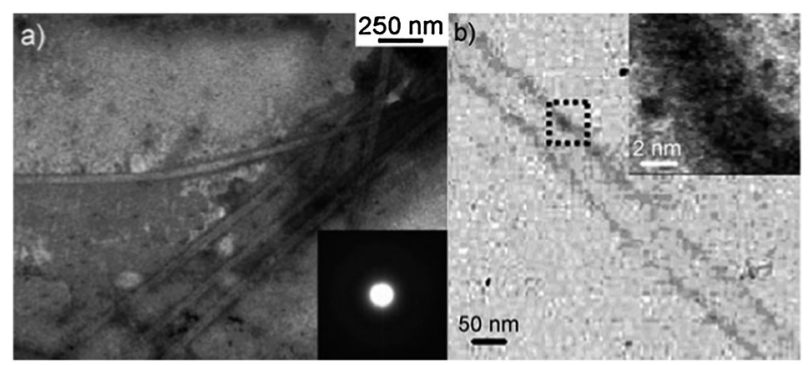

Fig. 6 (a) TEM image $(80 \mathrm{kV})$ of Fe-B nanotubes; inset: the corresponding SAED pattern; (b) HRTEM image $(200 \mathrm{kV})$ of one isolated $\mathrm{Fe}-\mathrm{B}$ nanotube inset: expansion of marked section. Reproduced from ref. 116 with kind permission from Wiley-VCH. cleavage and curling of the layered structure, leading to the formation of nanotubes.

3.2.2 Mesoporous texture. Mesoporous amorphous alloys represent a new trend towards the design of amorphous alloys with high surface area and large and uniform pore channels, which are attractive in catalytic applications. The mesopores facilitate a facile access of the guest molecules to the active sites, showing promise for an improved catalytic performance. ${ }^{18,119}$ It has long been remained a great challenge to synthesize mesoporous amorphous alloys through surfactant selfassembly, since the surfactant-templated mesoporous structure is fragile to the vigorous and strongly exothermic reaction between the metal ions and the reductant.

Some strategies have been proposed to withhold the regular LC mesophases during chemical reduction. Successful endeavors include adding antifoaming agents, using metal salts in which anions have strong affinity to the cations, and selecting surfactants that can adsorb metal cations or $\mathrm{BH}_{4}{ }^{-}$to smooth the reduction process. ${ }^{120,121}$ Worm-like mesoporous $\mathrm{Ni}-\mathrm{B},{ }^{122}$ $\mathrm{Co}-\mathrm{B},{ }^{120,123,124}$ and $\mathrm{Ru}-\mathrm{B}^{121}$ have been synthesized (Scheme 2). Furthermore, Li and coworkers synthesized mesoporous $\mathrm{Fe}-\mathrm{B}$, $\mathrm{Co}-\mathrm{B}, \mathrm{Ni}-\mathrm{B}$, and $\mathrm{Ni}-\mathrm{Co}-\mathrm{B}$ microspheres with tunable chamber size via co-templating from syringe-squeezing and surfactant self-assembly. ${ }^{125}$ In this approach, yolk-shell structured Ni-B microspheres with an average diameter of $c a .200 \mathrm{~nm}$ were successfully synthesized. The formation mechanism was proposed as the establishment of the integrated outer shell and the ectoentad stepwise reduction of the $\mathrm{Ni}^{2+}$ ions inside the droplet. The mesoporous amorphous alloys prepared by the soft-templating strategy were of poor ordering degree. Only worm-like rather than regular mesopores have been constructed, since the measures mentioned above are still insufficient to completely suppress the damage of the LC mesophase by the drastic reduction process.

Nanocasting using mesoporous silica as a hard template is one of the most common strategies to fabricate crystalline materials with regular mesostructures. ${ }^{126,127}$ Using the ultrasoundassisted reductant infiltration strategy, Chen et al. synthesized $\mathrm{Ni}-\mathrm{B}$ nanoarray replicated from mesoporous siliceous SBA-15. ${ }^{128}$ The silica-free Ni-B nanoarray is constructed by hexagonally packed nanowires with a uniform diameter of ca. $5 \mathrm{~nm}$. These nanowires are interconnected by thinner $\mathrm{Ni}-\mathrm{B}$ wires originating from the micropores within the wall of SBA-15, ${ }^{119}$ thus ensuring the integrated structure of the $\mathrm{Ni}-\mathrm{B}$ nanoarray after hard template removal.

3.2.3 Other morphologies. Amorphous alloys with chainlike, ${ }^{129}$ rod-like, ${ }^{129,130}$ and thin film ${ }^{131,132}$ morphologies have

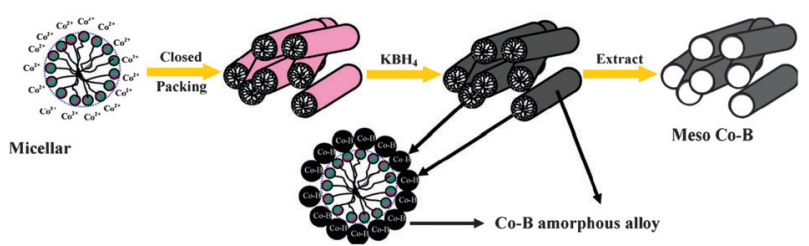

Scheme 2 Schematic illustration of the formation of mesoporous structure in $\mathrm{Co}-\mathrm{B}$ amorphous alloy particles. Reproduced from ref. 120 with kind permission from Elsevier. 
been reported in the literature. Chain- and rod-like $\mathrm{Co}-\mathrm{B}$ nanomaterials were prepared by chemical reduction in CTAB and PVP aqueous solutions, respectively. ${ }^{129}$ The chain-like Co-B was constructed by spherical particles connected oneby-one with nanoflakes on the particle surface. The rod-like Co-B was ca. $5 \mu \mathrm{m}$ in length and $1 \mu \mathrm{m}$ in diameter, with a porous structure formed by interlaced nanowires. $\mathrm{Li}$ and coworkers prepared chain-like $\mathrm{Co}-\mathrm{B}$ by chemical reduction of $\mathrm{Co}^{2+}$ ions in a dodecanethiol-water biphasic system based on spontaneous self-assembly. ${ }^{133}$ Dodecanethiol is essential for the formation of $\mathrm{Co}-\mathrm{B}$ nanochains, which generates a biphasic system with aqueous solution and induces dipoles on Co-B nanoparticles. Rod-like $\mathrm{Fe}-\mathrm{B}$ was prepared using anodic aluminum oxide (AAO) as the template. ${ }^{130}$ The Fe-B nanoparticles were self-assembled within the uniform channels of AAO. By varying the duration of preparation, sphere- or rod-shaped $\mathrm{Fe}-\mathrm{B}$ nanomaterials were obtained.

Patel and coworkers synthesized $\mathrm{Co}-\mathrm{B}$ nanoparticleassembled thin films with an average roughness of $\sim 264 \mathrm{~nm}$ using pulsed laser deposition (PLD). ${ }^{131,132}$ The peculiarities of the $\mathrm{Co}-\mathrm{B}$ nanoparticles produced by PLD were related to their well-defined spherical shape and to their high particle density distribution free from coalescence, a deleterious process inhibiting the favorable surface/volume ratio that is critical to the catalysis process. ${ }^{132}$ The Co-B film catalyst is easy to recover, and hence can be used to control the on-off of $\mathrm{H}_{2}$ generation by catalytic decomposition of $\mathrm{NaBH}_{4}$ and $\mathrm{NH}_{3} \mathrm{BH}_{3}$, which is a difficult task for $\mathrm{Co}-\mathrm{B}$ nanoparticles.

\section{Synthesis of supported metal-metalloid amorphous alloy catalysts}

\subsection{Synthetic strategy}

In comparison with unsupported nanosized amorphous alloy catalysts, supported amorphous alloy catalysts not only permit easy product separation and catalyst recycle, but also generally possess improved catalytic efficiency and thermal stability owing to the attractive characters of the support. ${ }^{37,82}$ Many endeavors have been devoted to the preparation of supported amorphous alloy catalysts. The conventional method involves impregnation of the support by metal salt solution for a certain period, followed by drying at above $373 \mathrm{~K}$, and then subjected to chemical reduction. This method has limitations of loss of the active species during chemical reduction and reaction, severe agglomeration of the amorphous alloy nanoparticles, and weak metal-support interaction.

4.1.1 Modified drying process. Since the drying process is essential to the distribution of the metal cations on the support and hence the dispersion of the active species after reduction, modified drying methods, including two-step drying approach ${ }^{64}$ and microwave heating, ${ }^{134,135}$ have been proposed. Deng and coworkers developed the two-step drying approach for the preparation of $\mathrm{Ni}-\mathrm{B} / \gamma-\mathrm{Al}_{2} \mathrm{O}_{3} \cdot{ }^{64}$ As compared to the one-step drying approach, the two-step drying approach led to higher $\mathrm{Ni}-\mathrm{B}$ dispersion and higher thermal stability, attributable to the better distribution of the metal ions on $\gamma-\mathrm{Al}_{2} \mathrm{O}_{3}$ during the modified drying process.
Microwave heating has attracted much attention in catalyst preparation due to its rapid and even heating ability leading to uniform distribution of the active species on the support. ${ }^{136} \mathrm{It}$ is found that microwave heating did not alter the composition, electronic property, and intrinsic catalytic activity of $\mathrm{Ni}-\mathrm{B} /$ $\mathrm{SiO}_{2}$, but led to smaller particle size, higher dispersion, and better thermal stability. ${ }^{134}$

4.1.2 Reductant impregnation. Different from catalysts reduced by $\mathrm{H}_{2}$, the chemical reduction method opens the avenue to load the reductant on the support first, i.e., the reductant-impregnation method. As compared to the conventional metal salt-impregnation approach, the reductantimpregnation method can lead to amorphous alloy catalysts with different composition and structure. ${ }^{137-139}$ The Ni-B/AC catalyst prepared in this reversed impregnation sequence has larger surface area and porosity than that prepared in the conventional sequence, ${ }^{139}$ which was also observed when using $\mathrm{SiO}_{2}$ and $\mathrm{Al}_{2} \mathrm{O}_{3}$ as supports, ${ }^{137,138}$ suggesting that it is a common phenomenon only related to the impregnation sequence. The reductant-impregnation method is also crucial for the successful preparation of silica sol-dispersed $\mathrm{Ni}-\mathrm{B}$ nanoclusters, since gelation readily took place when $\mathrm{Ni}(\mathrm{OAc})_{2}$ was mixed with the silica sol first. ${ }^{140}$ Using the reductant-impregnation method, the Ni-B nanoclusters are homogenously dispersed with a particle size of only $1-2 \mathrm{~nm}$ on the silica surface.

4.1.3 Wetness reduction/deposition. Wang et al. employed the chemical deposition method and the impregnationwetness-reduction method for the preparation of $\mathrm{Ni}-\mathrm{B} / \mathrm{TiO}_{2}$ catalysts. ${ }^{141}$ The former involves the reduction of a mixture of metal salt solution and support by the reductant. The latter cancels the drying step as compared to the conventional method. Most of the $\mathrm{Ni}^{2+}$ ions in the solution were carried over to $\mathrm{TiO}_{2}$ by the former, while the Ni loading was only about one half of the nominal value by the latter, implying that only the strongly adsorbed $\mathrm{Ni}^{2+}$ ions can survive in this approach. On both catalysts, the half-spherical particle shape implies that the Ni-B nanoparticles bound tightly with $\mathrm{TiO}_{2}$. The strong interaction between the highly dispersed Ni-B nanoparticles and $\mathrm{TiO}_{2}$ accounts for the improved thermal stability of these catalysts.

4.1.4 Electroless plating. Electroless plating is a wellestablished technique for the fabrication of amorphous alloy coatings. ${ }^{142}$ Electroless plating is characterized by a surface activation step and a plating solution containing stabilizer(s) to avoid its autogeneous decomposition. Zhang and coworkers investigated the preparation parameters of the $\mathrm{Ni}-\mathrm{B} / \mathrm{MgO}$ catalysts by Ag-activated electroless plating. ${ }^{135,143,144}$ The size, composition, and loading of the $\mathrm{Ni}-\mathrm{B}$ nanoparticles depended on the starting ethylenediamine $(\mathrm{EN}) / \mathrm{Ni}^{2+}$ ratio and $\mathrm{pH}$. The $\mathrm{Ni}-\mathrm{B}$ particle size increased monotonically from $\sim 16$ to $35 \mathrm{~nm}$ when the $\mathrm{pH}$ increased from 12.4 to 13.6. Higher $\mathrm{EN} / \mathrm{Ni}^{2+}$ ratio and $\mathrm{pH}$ led to higher $\mathrm{Ni}$ content in $\mathrm{Ni}-\mathrm{B}$. Addition of stabilizers to the plating solution changed the texture of the $\mathrm{Ni}-\mathrm{B}$ particles from porous to solid. ${ }^{143}$ Electroless plating under microwave irradiation increased the particle size, $\mathrm{Ni}$ loading, and $\mathrm{B}$ content of the $\mathrm{Ni}-\mathrm{B} / \mathrm{MgO}$ catalysts. ${ }^{135}$ 


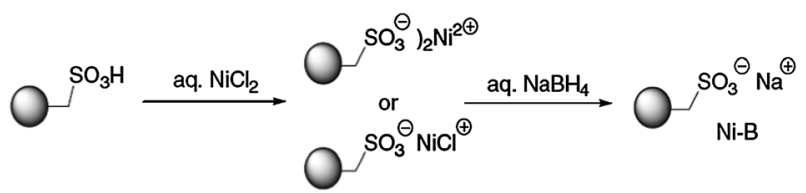

and

$$
\begin{aligned}
\mathrm{BH}_{4}^{-}+2 \mathrm{H}_{2} \mathrm{O} & \longrightarrow \mathrm{BO}_{2}^{-}+4 \mathrm{H}_{2} \uparrow \\
2 \mathrm{BH}_{4}^{-}+2 \mathrm{H}_{2} \mathrm{O} & \longrightarrow 2 \mathrm{~B} \uparrow+2 \mathrm{OH}^{-}+5 \mathrm{H}_{2} \uparrow
\end{aligned}
$$

Scheme 3 Preparation of polymer-supported nanoamorphous Ni-B particles. Reproduced from ref. 145 with kind permission from Springer Science.

4.1.5 Ion exchange. Ion exchange followed by chemical reduction is effective in the preparation of cationic exchange resin-supported amorphous alloy catalysts (Scheme 3). Using this strategy, Wen and coworkers obtained polymer-supported $\mathrm{Ni}-\mathrm{B}$ nanoparticles with adjustable $\mathrm{Ni}$ loadings and low degree of agglomeration. ${ }^{145}$ After one ion exchange-reduction cycle, the Ni loading was $53.5 \mathrm{wt} \%$. The loading was increased to $74.5 \mathrm{wt} \%$ after the second cycle. After several exchanges until the solution being almost neutral, the Ni loading reached as high as $93.2 \mathrm{wt} \%$. The $\mathrm{Ni}-\mathrm{B}$ particles were $60-70 \mathrm{~nm}$ in size and distributed evenly on the polymer surface. Such a high $\mathrm{Ni}$ loading has not been observed on $\mathrm{SiO}_{2}, \mathrm{Al}_{2} \mathrm{O}_{3}, \mathrm{AC}$, and $\mathrm{TiO}_{2}{ }^{146}$

4.1.6 In situ reduction. Reduction of unsaturated groups by borohydride in the presence a transition metal salt has long been documented. ${ }^{147}$ During the reaction, the M-B particles are formed in situ as the catalyst. Caddick et al. used in situ generated $\mathrm{Ni}-\mathrm{B}$ particles to promote the reduction of nitriles. ${ }^{148}$ Rahman and Jonnalagadda modified this reaction protocol by adding $\mathrm{SiO}_{2}$-supported $\mathrm{Ni}\left(\mathrm{NO}_{3}\right)_{2}$ instead of individual nickel salt to the reaction system containing $\mathrm{NaBH}_{4} \cdot{ }^{149,150}$ The $\mathrm{Ni}-\mathrm{B} / \mathrm{SiO}_{2}$ catalyst was formed in situ by $\mathrm{NaBH}_{4}$ reduction of $\mathrm{Ni}\left(\mathrm{NO}_{3}\right)_{2} / \mathrm{SiO}_{2}$. The $\mathrm{Ni}-\mathrm{B}$ particles are tightly bound to the $\mathrm{SiO}_{2}$ surface, as there was no leaching of the metal in the filtrate.

\subsection{Mesoporous support}

Regular mesoporous materials have shown great potential in catalysis, which is closely related to their specific features such as extremely high surface area and narrow pore size distribution. Their large channels allow diffusion of bulky compounds and present different types of shape selectivity such as reactant, product, and transition state. ${ }^{151}$ These merits offer possibilities for obtaining highly dispersed amorphous alloy catalysts with better utilization of the active sites. The additional advantage of the improved dispersion is the reduced probability of agglomeration and thus, enhanced stability. ${ }^{152-155}$

It is expected that the size of the supported $\mathrm{M}-\mathrm{B}$ amorphous alloy particles is closely related to their location on the mesoporous support. The uniform mesopore channels can confine the growth of the particles, leading to smaller particle size and more homogeneous particle size distribution, while the external surface does not have such a confinement effect. However, it was found that only SBA-15 can effectively accommodate amorphous alloy nanoparticles. ${ }^{153-155}$
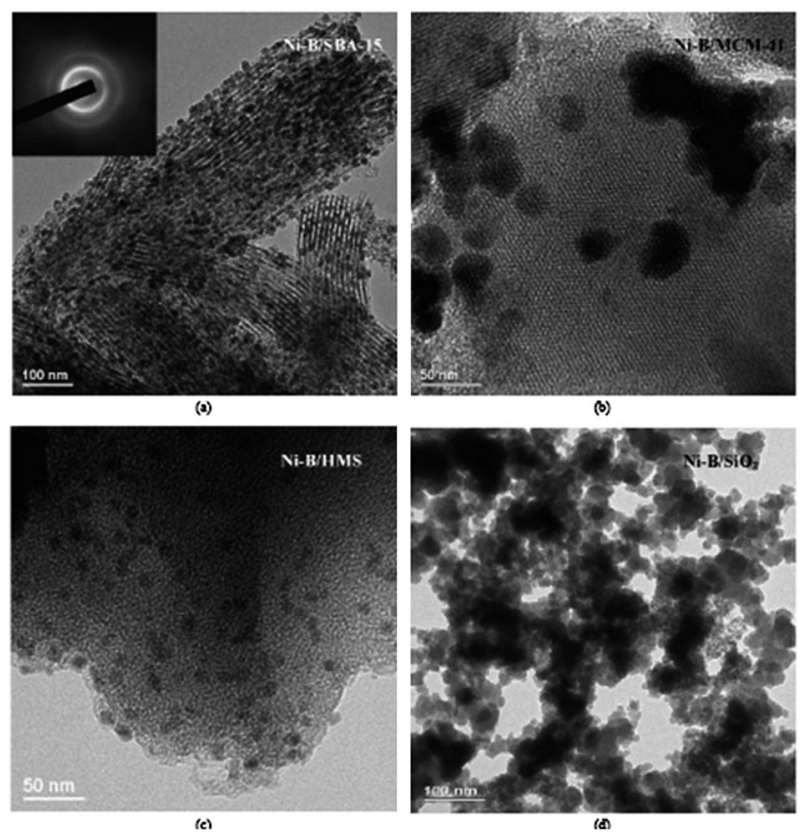

Fig. 7 TEM images of (a) Ni-B/SBA-15, (b) Ni-B/MCM-41, (c) $\mathrm{Ni}-\mathrm{B} / \mathrm{HMS}$, and (d) $\mathrm{Ni}-\mathrm{B} / \mathrm{SiO}_{2}$ catalysts. Inset in (a) is the SAED pattern of the Ni-B particles. Reproduced from ref. 154 with kind permission from Elsevier.

Using the reductant-impregnation strategy, Chen et al. prepared SBA-15-, MCM-41-, and HMS-supported Ni-B catalysts. ${ }^{153,154}$ The Ni-B nanoparticles were uniformly dispersed in the SBA-15 channels, with the average particle size of $c a .6 \mathrm{~nm}$. While on MCM-41 or HMS with a channel size of $c a .3 \mathrm{~nm}$, the Ni-B nanoparticles were mainly located on the external surface bearing much larger particle size (Fig. 7). Similarly, nearly all $\mathrm{Co}-\mathrm{B}$ nanoparticles were confined in the channels of SBA-15, while most Co-B nanoparticles agglomerated on the exterior of MCM-41. ${ }^{155}$ Moreover, for commercial $\mathrm{SiO}_{2}-$ supported $\mathrm{Ni}-\mathrm{B}$ and $\mathrm{Co}-\mathrm{B}$ catalysts, the $\mathrm{Ni}-\mathrm{B}^{154}$ and $\mathrm{Co}-\mathrm{B}$ particles $^{155}$ were predominantly situated on the exterior, although the average pore diameter of commercial $\mathrm{SiO}_{2}$ was much larger than those of MCM-41 and HMS and slightly larger than that of SBA-15. It seems that the regular and large mesopores and the micropores connecting the mesopores are essential for the retainment of amorphous alloy nanoparticles in the channels of SBA-15, since its pseudo-3D pore structure can facilitate the rapid dissipation of the released $\mathrm{H}_{2}$, which otherwise expels the nanoparticles out of the channels.

Grafting of functional groups on the channel walls of regular mesoporous silicas induced the deposition of the $\mathrm{Ni}-\mathrm{B}$ nanoparticles on the interior surface. ${ }^{156}$ For conventional $\mathrm{Ni}-\mathrm{B} / \mathrm{SBA}-15$ prepared by $\mathrm{NiCl}_{2}$ impregnation followed by $\mathrm{KBH}_{4}$ reduction, most of the $\mathrm{Ni}-\mathrm{B}$ nanoparticles were located on the external surface. When SBA-15 was grafted with the aminopropyl $\left(\mathrm{NH}_{2}\right)$ groups, the same preparation method led to homogeneous distribution of $\mathrm{Ni}-\mathrm{B}$ nanoparticles in the mesoporous channels, attributable to the coordination of the $\mathrm{Ni}^{2+}$ ions with the grafted $\mathrm{NH}_{2}$ groups. The smooth reduction of the $\mathrm{NH}_{2}$-coordinated $\mathrm{Ni}^{2+}$ ions can effectively suppress the drastic release of $\mathrm{H}_{2}$. The grafting of $\mathrm{CH}_{3}$ groups on the channel walls of SBA-15 also improved the 
distribution of the Ni-B nanoparticles, ${ }^{156}$ which is explained by the enhanced surface hydrophobicity that slowed down the reaction between $\mathrm{Ni}^{2+}$ ions and $\mathrm{BH}_{4}{ }^{-157}$ Surface grafting also increased the surface $\mathrm{B}$ content for $\mathrm{Ni}-\mathrm{B}$ supported on $\mathrm{NH}_{2}$-SBA-15 and $\mathrm{CH}_{3}-\mathrm{SBA}-15$, with a more prominent increment observed on the former.

Besides regular mesoporous silicas, carbon nanotubes (CNTs) with uniform mesopores are suitable as a support for encapsulating amorphous alloy nanoparticles. Wang et al. synthesized the $\mathrm{Ni}-\mathrm{B} / \mathrm{CNTs}$ catalyst by $\mathrm{NiCl}_{2}$ impregnation followed by $\mathrm{KBH}_{4}$ reduction. ${ }^{158}$ As compared to $\mathrm{Ni}-\mathrm{B} /$ $\gamma-\mathrm{Al}_{2} \mathrm{O}_{3}$, the Ni-B nanoparticles on CNTs are more dispersed. The thermal stability of $\mathrm{Ni}-\mathrm{B} / \mathrm{CNTs}$ is better than $\mathrm{Ni}-\mathrm{B} /$ $\gamma-\mathrm{Al}_{2} \mathrm{O}_{3}$, since the unique pore structure of the CNTs protects $\mathrm{Ni}-\mathrm{B}$ nanoparticles from aggregation. Furthermore, CNTs may donate electron to $\mathrm{Ni}$, leading to active sites enriched with more electrons.

\section{Catalytic applications}

Because of their attractive structural and electronic characters, the chemically reduced metal-metalloid amorphous alloys have been employed to catalyze a wide range of reactions. The reactions involved are extended from model reactions to industrially more relevant reactions, from non-selective reactions to more challenging selective hydrogenation, hydrogenolysis, dehydroheteroatom, energy/fuel production, pollutant removal, and bond forming reactions, as will be described in the following context.

\subsection{Hydrogenation of olefinic bonds}

5.1.1 Hydrogenation of acrylonitrile. Hydrogenation of acrylonitrile to propionitrile is an important process for industrial synthesis of dichloropropionate used in herbicides. For this reaction, the $\mathrm{Ni}-\mathrm{B} / \mathrm{SiO}_{2}$ amorphous alloy catalyst showed higher intrinsic activity than the $\mathrm{Ni} / \mathrm{SiO}_{2}$ catalyst. ${ }^{159}$ The calcination temperature before and after chemical reduction of the catalyst affected the activity. ${ }^{160}$ For the catalyst precursor, the optimal calcination temperature is $473 \mathrm{~K}$. Calcination of the as-reduced catalyst up to $573 \mathrm{~K}$ did not deteriorate the activity. Microwave heating of the catalyst precursor led to $\mathrm{Ni}-\mathrm{B} / \mathrm{SiO}_{2}$ with a hydrogen uptake rate of $0.117 \mathrm{mmol} \mathrm{s}^{-1} \mathrm{~g}_{\mathrm{Ni}}{ }^{-1}$, as compared to $0.068 \mathrm{mmol} \mathrm{s}^{-1} \mathrm{~g}_{\mathrm{Ni}}{ }^{-1}$ on the catalyst without microwave heating. ${ }^{134}$ However, microwave heating did not change the intrinsic activity.

5.1.2 Hydrogenation of tricyclopentadiene (TCPD). The hydrogenation of TCPD through dihydrotricyclopentadiene (DHTCPD) to tetrahydrotricyclopentadiene (THTCPD) is of great importance (Scheme 4), ${ }^{161}$ as THTCPD provides more propulsive energy than traditional fuels from refinery. ${ }^{162} \mathrm{In}$ general, the second hydrogenation step is kinetically more difficult than the first one. ${ }^{163}$ Zhang and coworkers reported that the $\mathrm{Pd}-\mathrm{B} / \gamma-\mathrm{Al}_{2} \mathrm{O}_{3}$ catalyst exhibited higher activity for the successive hydrogenation of DHTCPD than $\mathrm{Pd} / \gamma-\mathrm{Al}_{2} \mathrm{O}_{3}$ reduced by $\mathrm{H}_{2}$, with the selectivity of $76 \%$ to the production of THTCPD on the former and $68 \%$ on the latter at similar conversion levels of TCPD. ${ }^{161}$ The better catalytic performance of the amorphous alloy catalyst was attributed to its

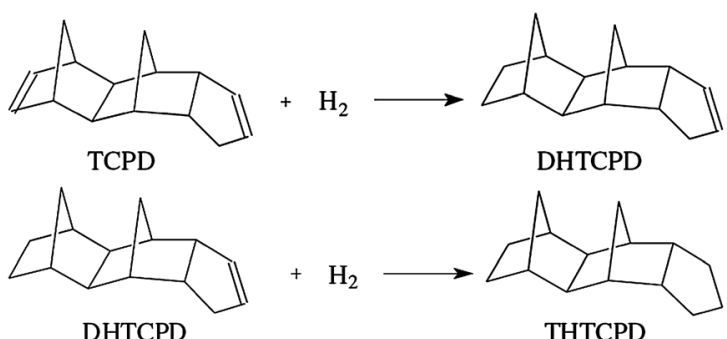

Scheme 4 Hydrogenation of TCPD to THTCPD. Reproduced from ref. 161 with kind permission from Elsevier.

higher $\mathrm{H}_{2}$ adsorption capacity, since the hydrogenation activity depended linearly on the amount of $\mathrm{H}_{2}$ adsorbed. ${ }^{164}$

5.1.3 Hydrogenation of sulfolene. Hydrogenation of sulfolene to sulfolane is an important industrial process due to the wide application of sulfolane as a solvent for both extraction and reaction. ${ }^{165}$ Mostly, the hydrogenation is carried out in the liquid phase at elevated hydrogen pressure over RANEY ${ }^{\circledR}$ Ni. However, the serious disadvantage of RANEY ${ }^{\circledR} \mathrm{Ni}$ such as short lifetime due to sulfur poisoning makes it necessary to develop catalysts with excellent activities.

Tao and coworkers investigated the catalytic performance of Ni-based amorphous alloy catalysts in sulfolene hydrogenation. The Ni-Co-B amorphous alloy catalyst with a $\mathrm{Ni} / \mathrm{Co}$ molar ratio of 2.3 exhibited a sulfolane yield of $98 \%$, higher than the yield of $86 \%$ on RANEY ${ }^{\circledR} \mathrm{Ni}$ under the same reaction conditions. ${ }^{166}$ The Ni-P amorphous alloy catalysts prepared at $283-303 \mathrm{~K}$ had high specific surface area (200-300 $\left.\mathrm{m}^{2} \mathrm{~g}^{-1}\right)$, thus high catalytic activity. ${ }^{167}$ The supports for the Ni-B amorphous alloy catalysts played an important role in the activity. With the same catalyst weight, the $\mathrm{TiO}_{2}-$ supported $\mathrm{Ni}-\mathrm{B}$ catalyst with a $\mathrm{Ni}$ loading of $7.20 \mathrm{wt} \%$ exhibited comparable sulfolane yield to that of the unsupported Ni-B. ${ }^{168}$ The MgO-supported Ni-B catalyst exhibited remarkably higher activity than $\mathrm{Ni}-\mathrm{B} / \mathrm{TiO}_{2} \cdot{ }^{143,144}$ The superior activity of $\mathrm{Ni}-\mathrm{B} / \mathrm{MgO}$ was attributed to the promotion effects of $\mathrm{MgO}$ on the characteristics of the Ni-B particles, the distribution of $\mathrm{Ni}-\mathrm{B}$ particles, as well as the active surface area of Ni. Moreover, the initial catalytic activity of $\mathrm{Ni}-\mathrm{B} /$ expanded graphite was about twice of that $\mathrm{Ni}-\mathrm{B} / \mathrm{MgO} .{ }^{169}$ Using chitosanmediated expanded graphite as a support could further improve the catalytic activity. ${ }^{170}$

\subsection{Hydrogenation of the phenyl ring}

5.2.1 Complete hydrogenation of benzene. Hydrogenation of benzene to cyclohexane is a basic reaction in the petrochemical industry and environment protection. Cyclohexane is the precursor for the manufacture of nylon- 6 and nylon-66. Since benzene hydrogenation was realized for the first time using finely divided Ni as a catalyst by Sabatier in $1926,{ }^{171}$ this reaction has been extensively studied. ${ }^{172} \mathrm{Up}$ to now, the hydrogenation of benzene to cyclohexane is still an active area of research. ${ }^{173,174}$

Deng and coworkers found that under the same reaction conditions, the $\mathrm{Ni}-\mathrm{B} / \gamma-\mathrm{Al}_{2} \mathrm{O}_{3}$ catalyst prepared by the two-step drying approach gave a benzene conversion of $95 \%$, as compared to $69 \%$ on the catalyst prepared by the conventional method. ${ }^{64,175}$ 
While both catalysts displayed identical turnover frequencies (TOFs), the higher benzene conversion on the former was due to the improved dispersion of the active sites by the modified drying approach. Zhang et al. employed bentonite and CNTs as supports for Ni-B for gas phase hydrogenation of benzene. ${ }^{176}$ They identified that the $\mathrm{Ni}-\mathrm{B} /$ bentonite catalyst was more active and more resistant to sulfur poisoning than $\mathrm{Ni}$ /bentonite. Ni-B/bentonite also showed better catalytic performance than $\mathrm{Ni}-\mathrm{B} / \mathrm{Al}_{2} \mathrm{O}_{3}$, owing to the better dispersion of $\mathrm{Ni}-\mathrm{B}$ and the stronger acidity of bentonite. On Ni-B/CNTs, the benzene conversion was $58 \%$ at $363 \mathrm{~K}$, while a similar conversion was obtained at $20 \mathrm{~K}$-higher on $\mathrm{Ni}-\mathrm{B} / \gamma-\mathrm{Al}_{2} \mathrm{O}_{3}$, which was attributed to the unique electronic property and pore structure of the CNTs. ${ }^{158,177}$ High benzene conversion was reported on the $\mathrm{Ru}-\mathrm{B} / \mathrm{CNT}$ s catalyst with a low $\mathrm{Ru}$ loading of less than $0.5 \mathrm{wt} \%{ }^{178}$

The Ni-P catalysts exhibited higher TOFs than RANEY ${ }^{\circledR}$ $\mathrm{Ni}$ in benzene hydrogenation. ${ }^{179}$ However, they are far less active than $\mathrm{Ni}-\mathrm{B} .{ }^{180}$ In addition, no significant $\mathrm{S}$ resistance was observed on $\mathrm{Ni}-\mathrm{P} .{ }^{22}$ On the other hand, the superior thermal stability of $\mathrm{Ni}-\mathrm{P}^{180}$ implies that it may be more suitable for high-temperature reactions. The thermal stability of Ni-P was further improved by supporting on CNTs. ${ }^{181}$ And the weight specific activity of Ni-P/CNTs was $c a$. four times of the unsupported $\mathrm{Ni}-\mathrm{P}$ nanoparticles.

$\mathrm{Co},{ }^{22,34,78} \mathrm{~W},{ }^{77,179}$ rare earth metals ( $\left.\mathrm{La}, \mathrm{Sm}, \mathrm{Yb}, \mathrm{Nd}\right),{ }^{176,182}$ and $\mathrm{Pt}^{183}$ are effective promoters for amorphous alloy catalysts in benzene hydrogenation. The promotion effect of Co on $\mathrm{Ni}-\mathrm{B}$ was the most prominent at the $\mathrm{Co} / \mathrm{Ni}$ molar ratio of unity. The areal specific activity of the optimal $\mathrm{Ni}-\mathrm{Co}-\mathrm{B}$ catalyst is $c a$. five times of that of $\mathrm{Ni}-\mathrm{B} .{ }^{34} \mathrm{By}$ further incorporating $\mathrm{W}$ into $\mathrm{Ni}-\mathrm{Co}-\mathrm{B}$, the TOF was doubled, and after as much as 30 times of reuse the catalytic activity was dropped to one half of the original value, likely due to the presence of residual oxygen in the reaction system. ${ }^{77}$ Similarly, Li and $\mathrm{Xu}$ found that promotion of $\mathrm{Ni}-\mathrm{P} / \mathrm{SiO}_{2}$ by $\mathrm{W}$ increased the intrinsic activity. ${ }^{179} \mathrm{La}, \mathrm{Sm}, \mathrm{Yb}$, and $\mathrm{Nd}$ not only enhanced the catalytic activity, but also improved $\mathrm{S}$ resistance. ${ }^{176,182}$ Addition of a small quantity of $\mathrm{Pt}(0.07 \mathrm{wt} \%)$ to $\mathrm{Ni}-\mathrm{B} /$ pseudoboehmite-modified mordenite drastically improved the catalytic activity and $\mathrm{S}$ resistance. ${ }^{183}$ The reaction temperature required for complete conversion of benzene was reduced by $50 \mathrm{~K}$ in the presence of $\mathrm{Pt}$.

5.2.2 Partial hydrogenation of benzene. Hydrogenation of benzene to cyclohexene is of great industrial interest, since cyclohexene can be easily converted to value-added cyclohexanol, caprolactam, and adipic acid by typical olefin reactions. However, to obtain cyclohexene from benzene is thermodynamically less favorable (Scheme 5). In 1999, Xie et al. reported that the $\mathrm{Ru}-\mathrm{B} / \mathrm{SiO}_{2}$ catalyst exhibited excellent selectivity to cyclohexene, ${ }^{184}$ which aroused extensive research interest in partial hydrogenation of benzene over amorphous alloy catalysts.

The effect of the content elemental $\mathrm{B}$ in $\mathrm{Ru}-\mathrm{B}$ on the selectivity to cyclohexene was investigated in the literature. ${ }^{28}$ The cyclohexene selectivity increased remarkably from $25 \%$ to $51 \%$ when the B content increased from 1.9 to $10.1 \mathrm{~mol} \%$, which are higher than the value of $19 \%$ on $\mathrm{Ru}$ powder reduced by $\mathrm{H}_{2}$.

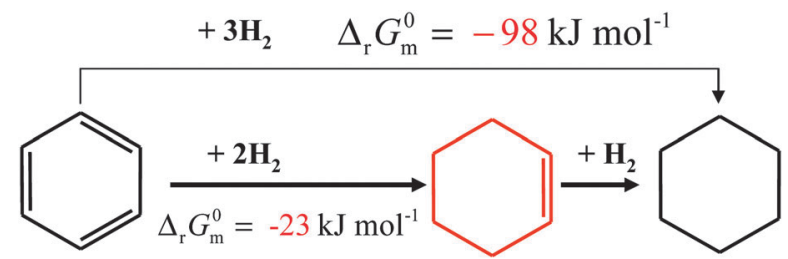

Scheme 5 Hydrogenation pathway of benzene to cyclohexene and cyclohexane.

The size of the $\mathrm{Ru}-\mathrm{B}$ nanoparticles is another important factor influencing the selectivity to cyclohexene. On PVP-stabilized $\mathrm{Ru}-\mathrm{B}$ colloids in the size range of 1.3 to $3.9 \mathrm{~nm}, \mathrm{Bu}$ et al. identified that smaller particle size led to higher activity and higher cyclohexene selectivity. ${ }^{93}$ The cyclohexene yield of ca. $17 \%$ was obtained on the $1.3 \mathrm{~nm}-\mathrm{PVP}-\mathrm{Ru}-\mathrm{B}$ colloids in the absence of any additional reaction modifier.

On the $\mathrm{Ru}-\mathrm{B} / \mathrm{SiO}_{2}$ catalyst the cyclohexene selectivity was $50 \%$, which was much higher than $22 \%$ on $\mathrm{Ru} / \mathrm{SiO}_{2}$ reduced by $\mathrm{H}_{2}{ }^{184}$ To achieve a high cyclohexene selectivity, the hydrophilicity of the support plays an important role. ${ }^{185-187}$ Wang et al. reported that the $\mathrm{Ru}-\mathrm{B} / \mathrm{Al}_{2} \mathrm{O}_{3} \cdot x \mathrm{H}_{2} \mathrm{O}$ colloidal catalyst is more active and selective than $\mathrm{Ru}-\mathrm{B} / \gamma-\mathrm{Al}_{2} \mathrm{O}_{3} .{ }^{188}$ Activity and selectivity enhancement was also observed on a $\mathrm{Ru}-\mathrm{B}$ colloidal catalyst stabilized by in situ formed silica as compared to commercial $\mathrm{SiO}_{2}$-supported catalysts. ${ }^{189}$

Liu et al. investigated the effect of the preparation method and the types of zirconia on the catalytic performance of $\mathrm{Ru}-\mathrm{B} .{ }^{190}$ The $\mathrm{Ru}-\mathrm{B} / \mathrm{ZrO}_{2} \cdot x \mathrm{H}_{2} \mathrm{O}$ catalyst prepared by the chemical mixing method, similar to the sol-gel method, exhibited an impressive cyclohexene selectivity of $50 \%$ in the absence of reaction modifiers, as compared to $20 \%$ and $15 \%$ on $\mathrm{Ru}-\mathrm{B} / \mathrm{ZrO}_{2} \cdot x \mathrm{H}_{2} \mathrm{O}$ and $\mathrm{Ru}-\mathrm{B} / \mathrm{ZrO}_{2}$ prepared by the conventional method, respectively, and $28 \%$ on the unsupported $\mathrm{Ru}-\mathrm{B}$. On the $\mathrm{Ru} / \mathrm{ZnO}-\mathrm{ZrO}_{x}(\mathrm{OH})_{y}$ catalyst prepared by the chemical mixing method and reduced by $\mathrm{NaBH}_{4}$, a cyclohexene selectivity of $72 \%$ was reported at a benzene conversion of $78 \%$ without the aid of reaction modifiers. ${ }^{191}$

The promoters can enhance the cyclohexene selectivity on $\mathrm{Ru}-\mathrm{B}$ by stabilizing the hydrogenation intermediate, ${ }^{190}$ by improving the dispersion of the active sites, ${ }^{192}$ or by promoting the formation of electron-deficient active species. ${ }^{193}$ It is found that the addition of $2.5 \mathrm{wt} \%$ of $\mathrm{Zn}$ to $\mathrm{Ru}-\mathrm{B} / \mathrm{ZrO}_{2} \cdot x \mathrm{H}_{2} \mathrm{O}$ increased the cyclohexene yield from $33 \%$ to $46 \%$ without the aid of reaction modifiers. ${ }^{190}$ The same promotion effect of $\mathrm{Zn}$ was observed on $\mathrm{Ru} / \mathrm{ZnO}-\mathrm{ZrO}_{x}(\mathrm{OH})_{y}$, on which the cyclohexene yield amounted to $56 \%$ at the $\mathrm{Zn} / \mathrm{Zr}$ molar ratio of 10 , while it was only $6.8 \%$ on $\mathrm{Ru} / \mathrm{ZrO}_{x}(\mathrm{OH})_{y}{ }^{191} \mathrm{La},{ }^{192} \mathrm{Co},{ }^{193}$ and $\mathrm{Fe}^{194,195}$ also showed a positive effect in partial hydrogenation of benzene. Addition of $\mathrm{La}$ to $\mathrm{Ru}-\mathrm{B} / \mathrm{ZrO}_{2}$ increased the activity and selectivity. ${ }^{192}$ $\mathrm{On} \mathrm{Ru}-\mathrm{Co}-\mathrm{B} / \gamma-\mathrm{Al}_{2} \mathrm{O}_{3}$, the maximum yield of cyclohexene was $29 \%$ with a cyclohexene selectivity of $46 \%$ in the absence of reaction modifiers. ${ }^{193} \mathrm{On} \mathrm{Ru}-\mathrm{Fe}-\mathrm{B} / \mathrm{ZrO}_{2}$, a cyclohexene yield of $57 \%$ at a benzene conversion of $81 \%$ was reported. ${ }^{195}$

\subsection{Hydrogenation of carbonyl groups}

5.3.1 Hydrogenation of glucose. Sorbitol is widely used as a starting feedstock for Vitamin $\mathrm{C}$ synthesis, an emulsifier for fatty acid ester production, an intermediate for drug design, 
and an additive in food, cosmetic and paper products. Although there is natural sorbitol, its large-scale production always depends on the catalytic hydrogenation of glucose most frequently on RANEY ${ }^{\circledR} \mathrm{Ni} .{ }^{196} \mathrm{Ni}-\mathrm{B}$ nanoparticles were found to be about one order of magnitude more active than RANEY ${ }^{\circledR} \mathrm{Ni}$ in glucose hydrogenation. ${ }^{197}$ Promotion of $\mathrm{Ni}-\mathrm{B}$ by $\mathrm{W}$ further enhanced the catalytic activity. The apparent activation energy on the nanosized $\mathrm{Ni}-\mathrm{W}-\mathrm{B}$ was $54.7 \mathrm{~kJ} \mathrm{~mol}^{-1}$, lower than $81.5 \mathrm{~kJ} \mathrm{~mol}^{-1}$ determined on RANEY ${ }^{\circledR}$ Ni. Chemical reduction of nickel ions complexed with ethylenediamine or hydrazine under ultrasonication led to $\mathrm{Ni}-\mathrm{B}$ catalysts more active than conventional $\mathrm{Ni}-\mathrm{B}$ and RANEY ${ }^{\circledR} \mathrm{Ni}^{198,199}$

$\mathrm{Ru}-\mathrm{B}$ was highly active in glucose hydrogenation, showing intrinsic activity about $11-20$ times of that of $\mathrm{Ni}-\mathrm{B}$ or $\mathrm{Co}-\mathrm{B}{ }^{58}$ The superior activity of $\mathrm{Ru}-\mathrm{B}$ can be related to its especially low apparent activation energy of $14.5 \mathrm{~kJ} \mathrm{~mol}^{-1}$. Ru-B can be used repetitively for more than 13 times without significant deactivation, showing its excellent durability. Promotion of $\mathrm{Ru}-\mathrm{B}$ with $\mathrm{Cr}$ decreased the intrinsic activity, but the catalyst showed higher weight specific activity due to the improved surface area. ${ }^{200}$ Supporting $\mathrm{Ru}-\mathrm{B}$ on $\mathrm{SiO}_{2}$ further increased the intrinsic activity. ${ }^{201}$

5.3.2 Hydrogenation of fructose. Mannitol is extensively used in food and pharmaceutical industries as a non-toxic, non-hygroscopic, and low caloric sweetener. In industry, mannitol is produced by catalytic hydrogenation of fructose or syrups (mixtures of glucose and fructose), with sorbitol as the main byproduct (Scheme 6). Hydrogenation of pure fructose over conventional Ni-based catalysts gave mannitol selectivity and yield of $c a .45-50 \% .{ }^{202}$ The industrial hydrogenation of invert sugar (glucose/fructose $=1 / 1$, obtained by the hydrolysis of sucrose) over RANEY ${ }^{\mathbb{R}} \mathrm{Ni}$ produced a mixture of mannitol and sorbitol in a weight ratio of about $25 / 75 .{ }^{203}$ Liaw and coworkers found that $\mathrm{Co}-\mathrm{Ni}-\mathrm{B}$ and PVPstabilized $\mathrm{Co}-\mathrm{Ni}-\mathrm{B}$ are much more active than $\mathrm{Ni}-\mathrm{B}, \mathrm{Co}-\mathrm{B}$, and RANEY ${ }^{\circledR} \mathrm{Ni}$ in the hydrogenation of fructose and invert sugar. ${ }^{85}$ Moreover, PVP-Co-Ni-B is about twice as active as $\mathrm{Co}-\mathrm{Ni}-\mathrm{B}$ in fructose hydrogenation. Although the selectivity to mannitol was improved only slightly to above $30 \%$ in the hydrogenation of invert sugar, the highly active $\mathrm{Co}-\mathrm{Ni}-\mathrm{B}$ and $\mathrm{PVP}-\mathrm{Co}-\mathrm{Ni}-\mathrm{B}$ are promising to replace $\mathrm{RANEY}{ }^{\mathbb{R}} \mathrm{Ni}$ for this reaction.

5.3.3 Hydrogenation of maltose. Hydrogenation of maltose to maltitol is important owing to the applications of maltitol<smiles>O=C(CO)C(O)C(O)C(O)CO</smiles>

Scheme 6 Hydrogenation of fructose.

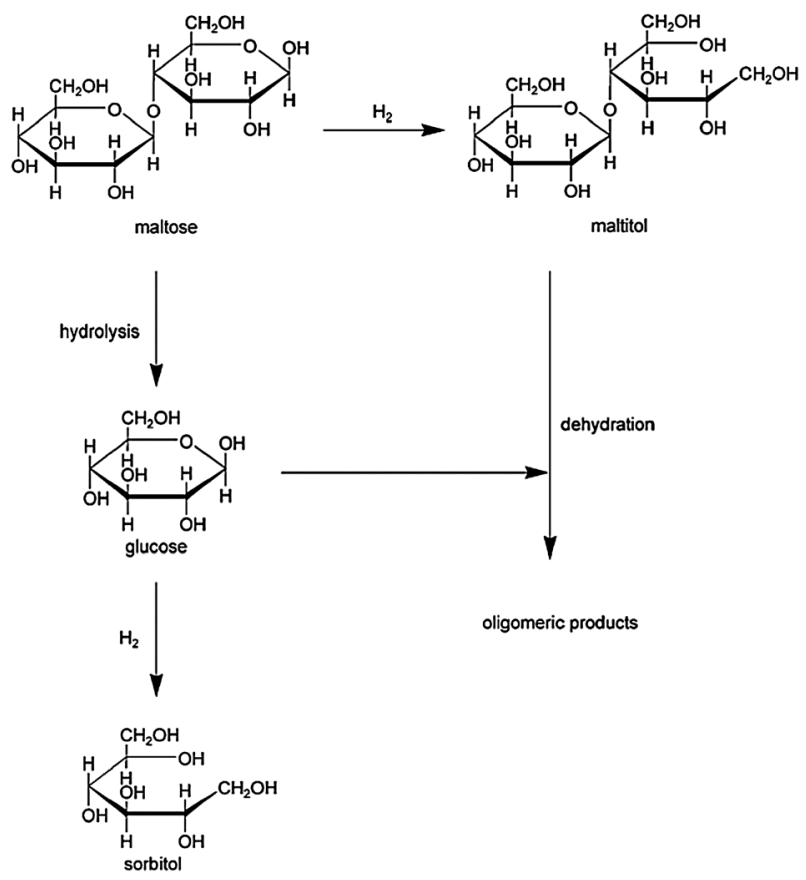

Scheme 7 Reaction network for maltose hydrogenation. Reproduced from ref. 206 with kind permission from Wiley-VCH.

as a sugar substitute in modern nutrition and in diabetic food, and as an intermediate for pharmaceutical production. ${ }^{204}$ Although RANEY ${ }^{\circledR} \mathrm{Ni}$ is widely used in this industrial process, the leaching of $\mathrm{Ni}$ during hydrogenation and the poor selectivity to maltitol make this catalyst less profitable. ${ }^{205}$ Amorphous alloy catalysts are excellent for this reaction. $\mathrm{Ni}-\mathrm{P}, \quad \mathrm{Ru}-\mathrm{P},{ }^{206} \mathrm{Ru}-\mathrm{B},{ }^{98,121,206} \mathrm{Co}-\mathrm{P},{ }^{206,207} \mathrm{Co}-\mathrm{B}$, and $\mathrm{Co}-\mathrm{P}-\mathrm{B}^{207}$ displayed maltitol selectivity up to $100 \%$. For comparison, only $75 \%$ selectivity was obtained on RANEY ${ }^{\circledR}$ $\mathrm{Ni}$ due to the formation of sorbitol and trace amounts of undefined byproduct (Scheme 7) ${ }^{206}$ Moreover, the amorphous alloy catalysts exhibited higher intrinsic activity than RANEY ${ }^{\circledR}$ $\mathrm{Ni}^{206}$ These merits signify that amorphous alloy catalysts are attractive alternatives to RANEY ${ }^{\mathbb{R}} \mathrm{Ni}$ in the hydrogenation of maltose to maltitol.

As compared to Co- and Ni-based amorphous alloy catalysts, Ru-based amorphous alloy catalysts showed much higher activity in the hydrogenation of maltose. ${ }^{206}$ The intrinsic activity was ranked as $\mathrm{Ru}-\mathrm{P}>\mathrm{Ru}-\mathrm{B} \gg \mathrm{Co}-\mathrm{P}>\mathrm{Ni}-\mathrm{P} \gg \mathrm{RANEY}^{\mathbb{R}}$ $\mathrm{Ni}$. Ru-P also exhibited a weight specific activity nearly one order of magnitude of that of $\mathrm{Ru}-\mathrm{B}$, despite the higher dispersion degree of $\mathrm{Ru}-\mathrm{B}$. The apparent activation energy of maltose hydrogenation is $27 \mathrm{~kJ} \mathrm{~mol}^{-1}$ and $32 \mathrm{~kJ} \mathrm{~mol}^{-1}$ on $\mathrm{Ru}-\mathrm{P}$ and $\mathrm{Ru}-\mathrm{B}$, respectively. In addition, $\mathrm{Ru}-\mathrm{P}$ and $\mathrm{Ru}-\mathrm{B}$ are more durable than RANEY ${ }^{\mathbb{R}} \mathrm{Ni}$ in the recycling test, since they are more vulnerable to leaching.

Because $\mathrm{Ru}$ is expensive, ${ }^{208}$ it is desirable to enhance its utility by synthesizing catalysts with large active surface area. On worm-like mesoporous $\mathrm{Ru}-\mathrm{B}$ with an active surface area of $33.8 \mathrm{~m}^{2} \mathrm{~g}^{-1}$, the weight specific activity was drastically increased to $662 \mathrm{mmol} \mathrm{h}^{-1} \mathrm{~g}^{-1}$, as compared to $176 \mathrm{mmol} \mathrm{h}^{-1} \mathrm{~g}^{-1}$ on conventional $\mathrm{Ru}-\mathrm{B} .{ }^{121}$ The monodispersed $\mathrm{Ru}-\mathrm{B}$ nanoparticles with an average size of $2.4 \mathrm{~nm}$ are nearly two times more active than conventional Ru-B. ${ }^{98}$ The intrinsic activity of the former 
was also enhanced, suggesting that reduction of the catalyst under ultrasound additionally modified the nature of the active sites.

Since the intrinsic activity of $\mathrm{Co}-\mathrm{P}$ is more than three times of that of $\mathrm{Co}-\mathrm{B}$, its active surface area is about one third of that of the latter, to take full advantages of the promotion effects of both $\mathrm{P}$ and $\mathrm{B}$, ternary $\mathrm{Co}-\mathrm{P}-\mathrm{B}$ was prepared for maltose hydrogenation. ${ }^{209}$ On $\mathrm{Co}_{72.2} \mathrm{P}_{5.9} \mathrm{~B}_{21.9}$, the weight specific activity is 2.6 times of that of $\mathrm{Co}-\mathrm{P}$, and more than three times of that of $\mathrm{Co}-\mathrm{B}$. Although the weight specific activity of $\mathrm{Co}_{72.2} \mathrm{P}_{5.9} \mathrm{~B}_{21.9}$ is about one half of that of $\mathrm{Ru}-\mathrm{B},{ }^{206}$ considering that $\mathrm{Ru}$ is about two orders of magnitude more expensive than $\mathrm{Co}$, the ternary $\mathrm{Co}-\mathrm{P}-\mathrm{B}$ is a cost-effective candidate for the hydrogenation of maltose to maltitol.

5.3.4 Chemoselective hydrogenation of unsaturated aldehydes and ketones. Chemoselective hydrogenation of unsaturated aldehydes or ketones results in unsaturated alcohols that are valuable and versatile intermediates in the synthesis of fine chemicals, pharmaceuticals, flavors, fragrances, and herbicides. $^{210}$ This reaction is also of great scientific importance, because the saturated aldehydes or ketones are thermodynamically more favorable. Selectivity manipulation is generally achieved by activating the carbonyl group and/or suppressing the adsorption of the conjugated olefinic bond or the phenyl ring. ${ }^{211}$

$\mathrm{Ni}-{ }^{81,82,86,128} \mathrm{Co}-{ }^{41,80,90,96,124,212-214}$ and Ru-based amorphous alloy catalysts ${ }^{95,215,216}$ have been investigated in chemoselective hydrogenation of unsaturated aldehydes or ketones. In the hydrogenation of furfural (FFR) to furfuryl alcohol (FFA), $\mathrm{Mo}, \mathrm{Ce}$, and $\mathrm{Fe}$ are effective promoters for $\mathrm{Ni}-\mathrm{B}$ or $\mathrm{Co}-\mathrm{B}$. As compared to $\mathrm{Ni}-\mathrm{B} / \gamma-\mathrm{Al}_{2} \mathrm{O}_{3}, \mathrm{Ni}-\mathrm{Mo}-\mathrm{B} / \gamma-\mathrm{Al}_{2} \mathrm{O}_{3}$ drastically improved the FFR conversion from $19 \%$ to $91 \%$ and the FFA selectivity from $87 \%$ to $95 \%{ }^{82}$ The weight specific activity of $\mathrm{Ni}-\mathrm{Ce}-\mathrm{B}$ is $c a .2 .8$ times of that of $\mathrm{Ni}-\mathrm{B}$, and FFA was formed almost exclusively. ${ }^{81} \mathrm{Fe}$ is more effective than $\mathrm{Ce}$ in enhancing the activity and selectivity of $\mathrm{Ni}-\mathrm{B} .{ }^{86} \mathrm{On}$ the other hand, although the weight specific activity of $\mathrm{Co}-\mathrm{B}$ is much lower than that of $\mathrm{Ni}-\mathrm{B}$, promotion by Mo drastically enhanced the activity of $\mathrm{Co}-\mathrm{B}$ by 4.7 times, and $\mathrm{Co}-\mathrm{Mo}-\mathrm{B}$ exhibited up to $100 \%$ FFA selectivity. ${ }^{80}$ In the hydrogenation of crotonaldehyde (CRAL) to crotyl alcohol (CROL) (Scheme 8), Pei et al. investigated the promotion effects of $\mathrm{Sn},{ }^{212} \mathrm{Zn},{ }^{213}$ and $\mathrm{Fe}$ on $\mathrm{Co}-\mathrm{B} .{ }^{41,214}$ Among these promoters, $\mathrm{Fe}$ showed the best promotion effect, giving rise to the CROL yield of $63 \%$, higher than those obtained on Pt-based catalysts. $^{41,214}$ The $\mathrm{Sn}$-promoted $\mathrm{Ru}-\mathrm{B} / \mathrm{SiO}_{2}$ catalyst is highly active and selective in the hydrogenation of carbonyl compounds to the corresponding alcohols at low temperature. ${ }^{215}$

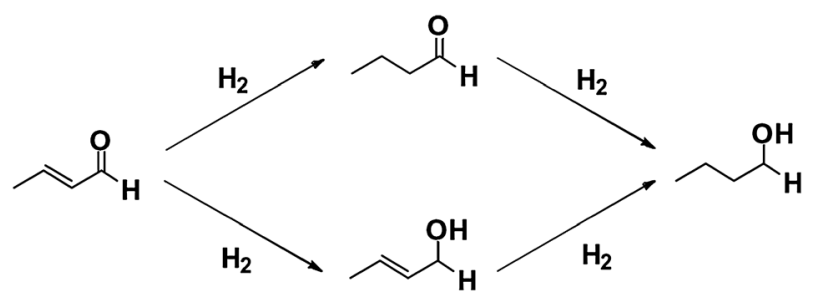

Scheme 8 Reaction pathways of CRAL hydrogenation.
At $333 \mathrm{~K}$, the benzaldehyde conversion over $\mathrm{Ru}-\mathrm{Sn}-\mathrm{B} / \mathrm{SiO}_{2}$ is nearly five times of that over $\mathrm{Ru}-\mathrm{B} / \mathrm{SiO}_{2}$. The hydrogenation of cinnamaldehyde (CMA), phenylacetaldehyde, aliphatic carbonyl compounds (capryl aldehyde and methyl hexyl ketone), diphenylketone, pyridine-2-carboxaldehyde, and 4-methoxybenzaldehyde was also evaluated at $333 \mathrm{~K}$ on $\mathrm{Ru}-\mathrm{Sn}-\mathrm{B} / \mathrm{SiO}_{2}$, giving appreciable conversion and exclusive selectivity to alcohols, although the last two compounds are less reactive than others.

Morphology control is another effective means to improve the catalytic performance of the amorphous alloy catalysts. A hexagonal $\mathrm{Ni}-\mathrm{B}$ nanoarray is more active and selective than conventional $\mathrm{Ni}-\mathrm{B}$ in the hydrogenation of acetophenone to 1-phenylethanol. ${ }^{128}$ Uniform spherical Co-B nanoparticles gave rise to the cinnamyl alcohol (CMO) selectivity of $99 \%$ at a CMA conversion of $92 \%$, which is far more selective than RANEY ${ }^{\circledR}$ Co. ${ }^{96}$ The catalytic performance was further enhanced on $\mathrm{Co}-\mathrm{B}$ nanoparticles synthesized in the $\mathrm{O} / \mathrm{W}$ microemulsion. ${ }^{90}$ On mesoporous $\mathrm{Co}-\mathrm{B}$, the $\mathrm{CMO}$ selectivity is $94 \%$ at a CMA conversion of $97 \%$, which is $c a$. $10 \%$ higher than that over conventional $\mathrm{Co}-\mathrm{B}^{124}$

5.3.5 Chemoselective hydrogenation of 2-ethylanthraquinone (eAQ). The hydrogenation of eAQ to 2-ethylanthrahydroquinone $\left(\mathrm{H}_{2} \mathrm{eAQ}\right)$ is a key step in industrial manufacture of $\mathrm{H}_{2} \mathrm{O}_{2}$, a green oxidizing agent (Scheme 9). ${ }^{217}$ However, even on the most selective $\mathrm{Pd}$ catalyst, during the hydrogenation eAQ will be deeply hydrogenated to some degradation products that cannot be oxidized to produce $\mathrm{H}_{2} \mathrm{O}_{2}$, leading to the loss of the expensive eAQ and fed $\mathrm{H}_{2}$. Besides, the oxidation rate of $\mathrm{H}_{4} \mathrm{eAQH}$ is remarkably lower than that of $\mathrm{eAQH}_{2}$, thus leading to lower production efficiency. ${ }^{83}$

Promoted and supported $\mathrm{Ni}-\mathrm{B}$ catalysts are highly effective in chemoselective hydrogenation of eAQ. Nanosized $\mathrm{Ni}-\mathrm{Cr}-\mathrm{B}$ is more active than RANEY ${ }^{\circledR} \mathrm{Ni}$, and displayed $100 \%$ selectivity to $\mathrm{AQH}_{2}$ at complete conversion of eAQ. ${ }^{83,218}$ Nanosized $\mathrm{Ni}-\mathrm{La}-\mathrm{B}^{219}$ and $\mathrm{Ni}-\mathrm{Mo}-\mathrm{B}^{220}$ showed $\mathrm{a}_{2} \mathrm{O}_{2}$ productivity of $\sim 7.5$ and $6.9 \mathrm{mg}_{\mathrm{H}_{2} \mathrm{O}_{2}} \mathrm{~g}_{\mathrm{cat}}{ }^{-1} \mathrm{~min}^{-1}$, respectively, which are much higher than the productivity of $3.7 \mathrm{mg}_{\mathrm{H}_{2} \mathrm{O}_{2}} \mathrm{~g}_{\mathrm{cat}}{ }^{-1} \mathrm{~min}^{-1}$ on RANEY ${ }^{\circledR}$ Ni.

Chen et al. studied the effect of supports on the catalytic properties of $\mathrm{Ni}-\mathrm{B} .{ }^{221}$ The catalytic activity is in the order of $\mathrm{Ni}-\mathrm{B} / \mathrm{SiO}_{2}>\mathrm{Ni}-\mathrm{B} / \mathrm{Al}_{2} \mathrm{O}_{3}>\mathrm{Ni}-\mathrm{B} / \mathrm{AC}$, and the selectivity to carbonyl group hydrogenation is in the order of

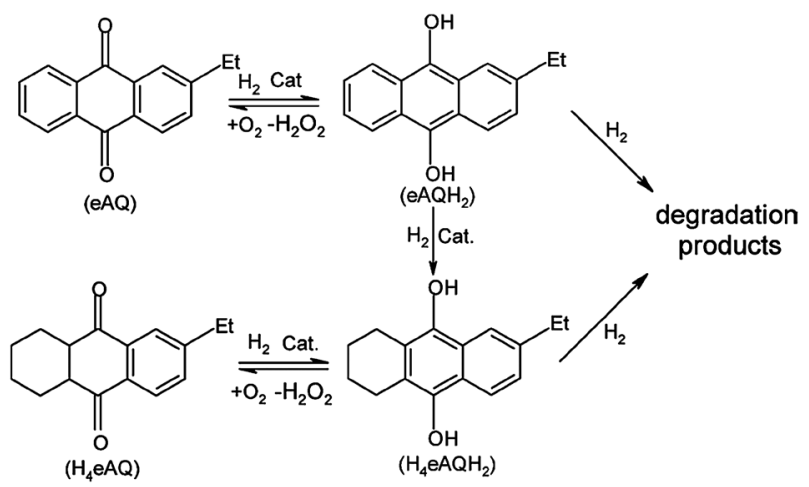

Scheme 9 The hydrogenation and oxidation cycles of eAQ and $\mathrm{H}_{4}$ eAQ. Reproduced from ref. 217 with kind permission from Elsevier. 
$\mathrm{Ni}-\mathrm{B} / \mathrm{AC}>\mathrm{Ni}-\mathrm{B} / \mathrm{SiO}_{2}>\mathrm{Ni}-\mathrm{B} / \mathrm{Al}_{2} \mathrm{O}_{3}>\mathrm{RANEY}{ }^{\circledR} \mathrm{Ni}$. HMS-, MCM-41-, and SBA-15-supported Ni-B exhibited higher selectivity than the commercial $\mathrm{SiO}_{2}$-supported one. ${ }^{153,154}$ Although on all these supported $\mathrm{Ni}-\mathrm{B}$ catalysts the maximum $\mathrm{H}_{2} \mathrm{O}_{2}$ yield of $\sim 100 \%$ was obtained, the yield of $\mathrm{H}_{4} \mathrm{eAQH}$, the phenyl ring hydrogenation product, follows the sequence of $\mathrm{Ni}-\mathrm{B} / \mathrm{SiO}_{2}>\mathrm{Ni}-\mathrm{B} / \mathrm{MCM}-41>\mathrm{Ni}-\mathrm{B} / \mathrm{HMS}>\mathrm{Ni}-\mathrm{B} /$ $\mathrm{SBA}-15$. It is notable that on $\mathrm{Ni}-\mathrm{B} / \mathrm{SBA}-15, \mathrm{eAQH}_{2}$ is the only product at the maximum yield of $\mathrm{H}_{2} \mathrm{O}_{2}$.

\subsection{Amine production}

5.4.1 Hydrogenation of nitro compounds. Amines have wide industrial applications in manufacturing engineering plastics, water treatment chemicals, surfactants, agrochemicals, and pharmaceuticals. Catalytic hydrogenation of nitro compounds is an important route for the production of amines. In the hydrogenation of $4,4^{\prime}$-dinitro-diphenylether to $4,4^{\prime}$-amino-diphenylether, the TOF over the $\mathrm{Ni}-\mathrm{B} / \mathrm{AC}$ catalyst prepared by the reductant impregnation method is $0.332 \mathrm{~s}^{-1}$, about three times of that over the catalyst prepared in the conventional impregnation sequence. ${ }^{139}$ In the hydrogenation of $p$-nitrophenol to $p$-aminophenol (PAP), $\mathrm{Pd}-\mathrm{B} / \mathrm{TiO}_{2}$ exhibited higher activity, selectivity, and stability than other Pd-based and Ni-based catalysts. ${ }^{222}$ The catalytic activity sequence is $\mathrm{Pd}-\mathrm{B} / \mathrm{TiO}_{2}(2 \%) \approx \mathrm{Pd}-\mathrm{B} / \mathrm{TiO}_{2}(0.5 \%) \approx \mathrm{Pd} /$ $\mathrm{C}(2 \%)>\mathrm{Pd} / \mathrm{TiO}_{2} \approx$ nano-sized $\mathrm{Ni}>\mathrm{Pd}-\mathrm{B}>\mathrm{RANEY}^{\circledR}$ Ni. PAP is the only product on all catalysts, with the exception of RANEY ${ }^{\circledR} \mathrm{Ni}$.

Catalytic transfer hydrogenation represents an important form of catalytic hydrogenation using hydrogen donor reagents such as hydrazine hydrate, formic acid or isopropyl alcohol as a substitution for $\mathrm{H}_{2}$. The catalysts involved in catalytic transfer hydrogenation include $\mathrm{Pt}, \mathrm{Pd}, \mathrm{Ru}$, and $\mathrm{Ni}$ in the form of complexes. ${ }^{223,224}$ Wen et al. employed polymersupported Ni-B in catalytic transfer hydrogenation of aromatic nitro compounds with hydrazine hydrate. ${ }^{225}$ Single nitro group compounds were reduced smoothly and gave excellent yields up to $100 \%$. For dinitro compounds, only one nitro group was reduced, and gave moderate yields ( $\geq 70 \%)$. The catalyst is stable and reusable. The attractive catalytic performance of the $\mathrm{Ni}-\mathrm{B} /$ polymer catalyst is explained by the unique electronic character of $\mathrm{Ni}-\mathrm{B}$ and its high activity in decomposing hydrazine hydrate.

5.4.2 Hydrogenation of nitriles. Hydrogenation of nitriles is another important route for amine production, in particular primary amines. ${ }^{226}$ Ethylamine (EA) is an intermediate widely used in medicine and surfactant production, as well as in organic synthesis. Hydrogenation of acetonitrile (AN) is a promising route for ethylamine production, however, the selectivity is a critical issue. Except for primary amine, the secondary and even the tertiary amines may form. ${ }^{227}$ Moreover, condensed byproducts may occur by transamination reactions between amines and imines (Scheme 10). ${ }^{228}$ RANEY $^{\circledR} \mathrm{Ni}, \mathrm{Co}$, and noble metals are common catalysts for the hydrogenation of nitriles. The selectivity to ethylamine is low on RANEY ${ }^{\circledR} \mathrm{Ni}$ and Co-based catalysts, ${ }^{229}$ while high cost and poor $\mathrm{S}$ and $\mathrm{N}$ resistance are involved for noble metal catalysts. $^{230}$

A comprehensive investigation of the hydrogenation of AN to EA on Co- and Ni-based amorphous alloy catalysts has been undertaken by $\mathrm{Li}$ and coworkers. ${ }^{50,230-232} \mathrm{Ni}-\mathrm{B}$ exhibited higher activity and selectivity to EA than ultrafine Ni powder, RANEY ${ }^{\mathbb{R}} \mathrm{Ni}$, and crystallized Ni-B. The EA yield over Ni-B reached $68 \%$, much higher than that over RANEY ${ }^{\circledR} \mathrm{Ni}$ $(<40 \%){ }^{230}$ Similarly, Co-B exhibited much higher activity and selectivity to EA than RANEY ${ }^{\mathbb{B}} \mathrm{Co}$, pure Co powder, and crystallized $\mathrm{Co}-\mathrm{B}{ }^{50} \mathrm{Co}-\mathrm{B}$ is also superior to $\mathrm{Ni}-\mathrm{B}$ in terms of selectivity and yield of EA, and lifetime. Remarkably, the intrinsic activity of $\mathrm{Ni}-\mathrm{Co}-\mathrm{B}$ is nearly twice of that of $\mathrm{Ni}-\mathrm{B}$ or $\mathrm{Co}-\mathrm{B}$ at the $\mathrm{Co} / \mathrm{Ni}$ molar ratio of $1 .^{232}$ The EA selectivity leveled off at this $\mathrm{Co} / \mathrm{Ni}$ ratio, leading to a maximum EA yield of $93 \%$.

Selective hydrogenation of unsaturated nitriles to unsaturated amines is of considerable challenge, since the hydrogenation of the olefinic bond is thermodynamically more favorable than the nitrile group. Molecules with olefinic and nitrile groups in conjugation or in close proximity are even more difficult to reduce selectively. ${ }^{233,234}$ Kukula et al. reported that $\mathrm{Ni}-\mathrm{B}$ and $\mathrm{Cr}$-promoted $\mathrm{Ni}-\mathrm{B}$ favor the hydrogenation of the olefinic bond, whereas $\mathrm{Co}-\mathrm{B}$ and $\mathrm{Cr}$-promoted

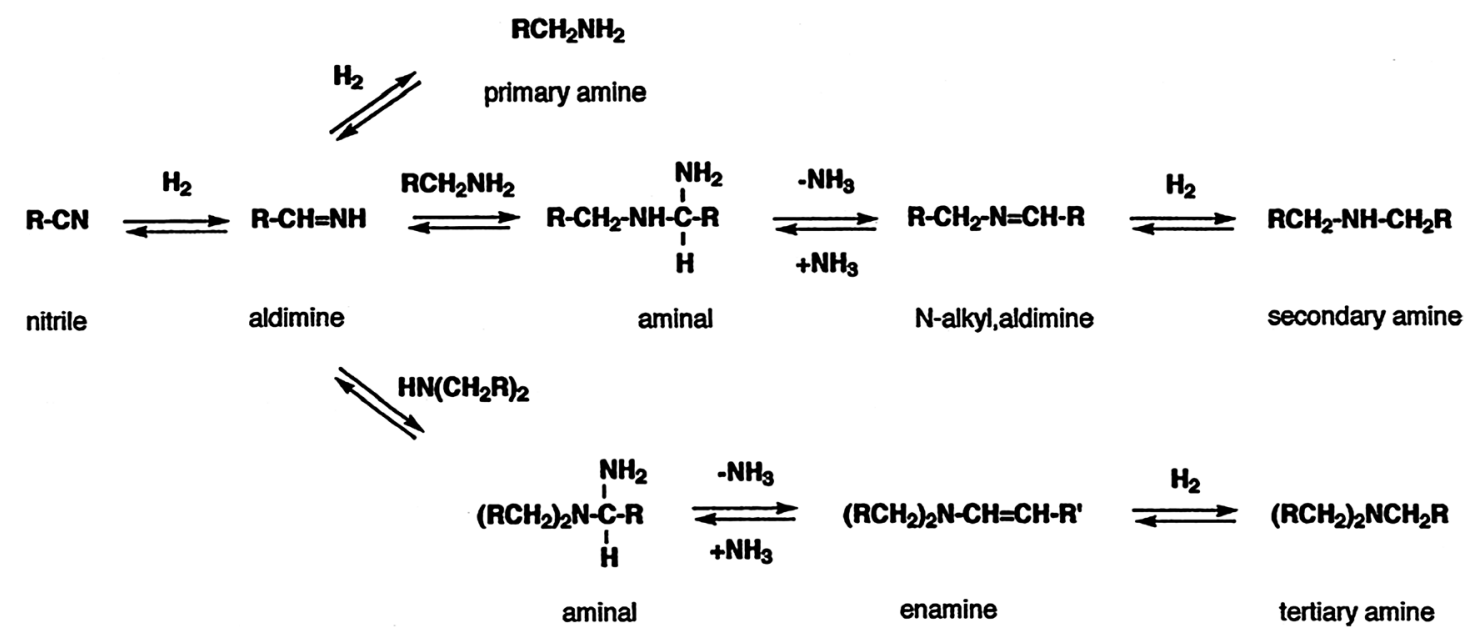

Scheme 10 Formal reaction scheme for nitrile hydrogenation. Reproduced from ref. 228 with kind permission from Elsevier. 
Co-B favor the formation of the unsaturated amine. ${ }^{235}$ The Cr-promoted $\mathrm{Co}-\mathrm{B}$ treated with $\mathrm{NaOH}$ hydrogenated cinnamonitrile, 1-cyclohexenyl-acetonitrile, and trans-3-pentenenitrile to the corresponding primary unsaturated amines with mediumto-high selectivities without the aid of ammonia at high conversion levels.

\subsection{Hydrodeheteroatom}

5.5.1 Hydrodesulfurization (HDS). Catalytic HDS is a key process in oil refinery to upgrade the oil and to remove environmental pollutants. Typically, metal sulfide catalysts are used, but the activity and lifetime are limited. ${ }^{236}$ Tao and coworkers investigated the kinetics of $\mathrm{Ni}-\mathrm{B} / \mathrm{TiO}_{2}$ and $\mathrm{Ni}-\mathrm{B} /$ $\mathrm{Al}_{2} \mathrm{O}_{3}$ in $\mathrm{HDS}$ of thiophene. ${ }^{237} \mathrm{Ni}-\mathrm{B} / \mathrm{TiO}_{2}$ is more active than $\mathrm{Ni}-\mathrm{B} / \mathrm{Al}_{2} \mathrm{O}_{3}$, since the apparent activation energy on the former is only $43.5 \mathrm{~kJ} \mathrm{~mol}^{-1}$. Bussell and coworkers identified that catalysts prepared by sulfiding $\mathrm{Ni}-\mathrm{B} / \mathrm{SiO}_{2}$ and $\mathrm{Ni}-\mathrm{Mo}-\mathrm{O}-$ $\mathrm{B} / \mathrm{SiO}_{2}$ showed significantly higher thiophene HDS activities than conventional sulfided $\mathrm{Ni} / \mathrm{SiO}_{2}$ and $\mathrm{Ni}-\mathrm{Mo} / \mathrm{SiO}{ }_{2}$ catalysts. ${ }^{238}$ The activity of sulfided $\mathrm{Ni}-\mathrm{Mo} / \mathrm{SiO}_{2}$ decreased more rapidly such that its activity is $70 \%$ of that of the sulfided Ni-Mo$\mathrm{O}-\mathrm{B} / \mathrm{SiO}_{2}$ after $24 \mathrm{~h}$ on stream, which is traced to the higher density of active sites on the amorphous alloy catalysts. It is notable that crystalline $\mathrm{Co}_{2} \mathrm{~B}$ and $\mathrm{Ni}_{3} \mathrm{~B}$ have relatively low activities and are unstable under HDS conditions. ${ }^{239}$ Addition of Mo to Ni-B/boehmite drastically increased the conversion of thiophene from $43 \%$ to $74 \%$ at a low HDS temperature of $493 \mathrm{~K}^{240}$

5.5.2 Hydrodechlorination (HDC). The HDC of the carcinogenic and mutagenic aromatic chlorides can convert chlorinated waste into products of commercial value. ${ }^{241}$ Partially crystallized $\mathrm{Ni}-\mathrm{P} / \mathrm{SiO}_{2}$ exhibited initial weight specific activity $c a .67 \%$ higher than $\mathrm{Ni} / \mathrm{SiO}_{2}$ in the $\mathrm{HDC}$ of chlorobenzene $(\mathrm{CB}){ }^{242} \mathrm{Pd} / \mathrm{Ni}-\mathrm{B} / \mathrm{TiO}_{2}$ prepared by replacement of $\mathrm{Ni}-\mathrm{B}$ nanoparticles with $\mathrm{Pd}^{2+}$ ions and treated in $\mathrm{N}_{2}$ at $473 \mathrm{~K}$ exhibited better activity and stability than Pd/PVP, a mixture of $\mathrm{Pd}$ and $\mathrm{Ni}-\mathrm{B}$ nanoparticles, and $\mathrm{Pd} / \mathrm{Ni}$ obtained by the replacement of nanocrystalline $\mathrm{Ni}$ with $\mathrm{Pd}^{2+}$ ions. ${ }^{243}$ After the 4th recycle, the $\mathrm{CB}$ conversion on $\mathrm{Pd} / \mathrm{Ni}-\mathrm{B} / \mathrm{TiO}_{2}$ is still comparable to that on the $\mathrm{Pd} / \mathrm{Ni}$ catalyst of the first run.

5.5.3 Hydrodeoxygenation (HDO). The conversion of lignin or wood biomass to bio-oil is a promising alternative for solving the problem of rapid decline of crude oil resources. However, oxygen-containing compounds like phenol and cyclopentanone in bio-oil lead to deleterious properties such as corrosion, high viscosity, poor heat value, thermal instability, immiscibility with hydrocarbon fuels, and tendency of polymerization during storage and transportation. ${ }^{244}$ It is necessary to remove these oxygen-containing compounds to expand the utilization of bio-oil. Among technologies for bio-oil upgrading like HDO and catalytic cracking, the former has attracted much attention owing to the high yield of hydrocarbons and low yields of tar and coke. ${ }^{245}$ Yang and coworkers investigated the catalytic properties of $\mathrm{Ni}-\mathrm{Mo}-\mathrm{B}$, $\mathrm{Ni}-\mathrm{W}-\mathrm{B}$, and $\mathrm{Co}-\mathrm{Mo}-\mathrm{B}$ catalysts for the HDO of phenol. ${ }^{246}$ The $\mathrm{Ni}-\mathrm{Mo}-\mathrm{B}$ prepared by ultrasound-assisted reduction exhibited higher activity than the conventional amorphous alloy catalyst.
On Ni-Mo-B, the selectivity to oxygen-free products is $93 \%$ (including $12 \%$ of benzene) at a phenol conversion of $81 \%$. The addition of $\mathrm{Co}$ or $\mathrm{La}$ to conventional $\mathrm{Ni}-\mathrm{Mo}-\mathrm{B}$ drastically increased the selectivity to deoxygenation products from $27 \%$ to $93 \%$ with a low benzene selectivity of $3.2 \%$ on $\mathrm{Co}-\mathrm{Ni}-\mathrm{Mo}-\mathrm{B} .^{247,248}$ The total $\mathrm{H} / \mathrm{C}$ atomic ratio in the products was increased from 1.95 on $\mathrm{Ni}-\mathrm{Mo}-\mathrm{B}$ to 1.99 on $\mathrm{La}-\mathrm{Ni}-\mathrm{Mo}-\mathrm{B}$. The addition of $\mathrm{Co}$ and $\mathrm{La}$ to $\mathrm{Ni}-\mathrm{W}-\mathrm{B}$ improved the selectivity of deoxygenation products to $86 \%{ }^{249}$ and $68 \%,{ }^{250}$ respectively, while benzene was not formed, which is desirable for clean fuel production. Co-Mo-B exhibited high catalytic activity in the HDO of phenol, benzaldehyde, and acetophenone; both the conversion and the deoxygenation selectivity approached $100 \%$, with low selectivity to benzene. ${ }^{251,252}$ For the HDO of cyclopentanone, Co-W-B exhibited a low cyclopentanol selectivity of $0.4 \%$ and a high deoxygenation selectivity of $95 \%$ at a cyclopentanone conversion of $97 \%,{ }^{253}$ showing that the amorphous alloy catalyst is a potential candidate for the HDO process.

\subsection{Fischer-Tropsch synthesis (FTS)}

FTS is essential for the transformation of coal and biomass to clean transportation fuels and value-added chemicals. The active metals for FTS are $\mathrm{Ru}, \mathrm{Fe}, \mathrm{Co}$, and $\mathrm{Ni}$. Ni is usually not used in FTS due to its high $\mathrm{CH}_{4}$ selectivity. ${ }^{254}$ Amorphous alloy nanoparticles may exhibit excellent FTS performance under mild reaction conditions due to their high surface area, small particle size, and high population of CUSs, which are advantageous to adsorption and surface reactions. These merits offer the opportunity to the development of energyefficient and cost-effective Fe- and Co-based amorphous alloy catalysts active in low-temperature FTS reaction. Conventional $\mathrm{Fe}$ - and Co-based FTS catalysts are active only above $473 \mathrm{~K}^{255}$

5.6.1 FTS on Ni-based catalysts. Nanosized $\mathrm{Ni}-\mathrm{B}, \mathrm{Ni}-\mathrm{P}$, and $\mathrm{Ni}-\mathrm{P}-\mathrm{B}$ were used for gas phase FTS at $573 \mathrm{~K}, 0.1 \mathrm{MPa}$, $\mathrm{H}_{2} / \mathrm{CO}=2$, and $F / W=5400 \mathrm{ml} \mathrm{h}^{-1} \cdot{ }^{256}$ Attractively, the selectivities to $\mathrm{C}_{2}-\mathrm{C}_{4}$ hydrocarbons are as high as $89 \%$ on $\mathrm{Ni}_{83} \mathrm{P}_{17}$ and $68 \%$ on $\mathrm{Ni}_{67} \mathrm{~B}_{33}$, which are higher than the value expected by the Anderson-Schulz-Flory (ASF) distribution law $\left(\mathrm{C}_{2}-\mathrm{C}_{5}<55 \%\right){ }^{21}$ In sharp contrast, crystallized $\mathrm{Ni}_{67} \mathrm{~B}_{33}$ was only selective to $\mathrm{CH}_{4}$, signifying the importance of the amorphous structure in the FTS selectivity.

5.6.2 FTS on Ru-B. Kou and coworkers used the PVPstabilized $\mathrm{Ru}-\mathrm{B}$ nanocatalyst to catalyze the FTS reaction in aqueous phase. ${ }^{257}$ This catalyst showed a superior weight specific activity of $1.6 \mathrm{~mol}_{\mathrm{CO}} \mathrm{mol}_{\mathrm{Ru}}{ }^{-1} \mathrm{~h}^{-1}$ to $\mathrm{Ru} / \mathrm{SiO}_{2}$ and $\mathrm{Ru} / \mathrm{C}$ catalysts at $423 \mathrm{~K}, 2.0 \mathrm{MPa}$ of $\mathrm{H}_{2}$, and $1.0 \mathrm{MPa}$ of $\mathrm{CO}$. It is noteworthy that since the hydrocarbon products are immiscible with water, they can be easily separated from the solvent and the catalyst, which simplifies the working up process and improves the production efficiency. ${ }^{258}$

5.6.3 FTS on Co-B. The FTS performance of the Co-B nanocatalyst has been studied in aqueous phase (stabilized by PVP) or PEG200 under mild reaction conditions (403-443 K, 2.0 $\mathrm{MPa}$ of $\mathrm{H}_{2}$, and 1.0 $\mathrm{MPa}$ of $\left.\mathrm{CO}\right) .{ }^{259} \mathrm{Co}-\mathrm{B}$ nanoclusters with a size of $\sim 5 \mathrm{~nm}$ are active at low temperature with weight 
specific activities of $0.03-0.12 \mathrm{~mol}_{\mathrm{CO}} \mathrm{mol}_{\mathrm{Co}}{ }^{-1} \mathrm{~h}^{-1}$. When the reaction was carried out in ethylene glycol (EG), syngas was converted not only to hydrocarbons, but also to 2-alkyldioxolanes with the participance of EG. ${ }^{260}$ In this case, the Co-B nanocatalyst exhibited an activity of $0.07 \mathrm{~mol}_{\mathrm{CO}}$ $\mathrm{mol}_{\mathrm{Co}}{ }^{-1} \mathrm{~h}^{-1}$, and selectivities to dioxolanes of $31 \mathrm{wt} \%$ and hydrocarbons of $69 \mathrm{wt} \%$. Wang et al. prepared two Co-B/ faujasite catalysts, with one with Co-B particles of $c a .1-2 \mathrm{~nm}$ probably located in the supercages of faujasite, and the other with particle size $>10 \mathrm{~nm}$ mainly outside of the cages. ${ }^{261} \mathrm{In}$ gas phase FTS reaction, $\mathrm{Co}-\mathrm{B} /$ faujasite with smaller particle size showed remarkably higher $\mathrm{CO}$ conversion, higher selectivity to $\mathrm{C}_{5}-\mathrm{C}_{21}$ hydrocarbons, and lower selectivity to $\mathrm{C}_{21+}$ hydrocarbons than that with larger nanoparticles.

5.6.4 FTS on Fe-B. Nanosized $\mathrm{Fe}-\mathrm{B}$ with various $\mathrm{Fe} / \mathrm{B}$ ratios were prepared by Zong et al. for gas phase FTS reaction. ${ }^{256}$ Although these catalysts are far less active than Ni-based amorphous alloy catalysts mentioned above, the main products on $\mathrm{Fe}-\mathrm{B}$ are highly desirable $\mathrm{C}_{2}-\mathrm{C}_{3}$ olefins, and the selectivity increased with the $\mathrm{B}$ content. The selectivity to $\mathrm{C}_{2}-\mathrm{C}_{3}$ olefins amounted to $74 \%$ on $\mathrm{Fe}_{60} \mathrm{~B}_{40}$, which is substantially higher than the value predicted by the ASF distribution.

There are a number of works focusing on using $\mathrm{Fe}-\mathrm{B}$ nanoparticles in liquid phase FTS reaction at low temperatures $(\leq 473 \mathrm{~K})$. $\mathrm{Wu}$ and coworkers prepared the $\mathrm{Fe}-\mathrm{B}$ nanocatalyst with the size of $30-65 \mathrm{~nm}$ and evaluated its FTS performance in PEG400 at $473 \mathrm{~K} .{ }^{262}$ This catalyst exhibited excellent activity and stability, as PEG400 can inhibit $\mathrm{Fe}-\mathrm{B}$ nanoparticles from agglomeration. They found that during the FTS reaction, $\mathrm{Fe}-\mathrm{B}$ converted to $\alpha-\mathrm{Fe}$ first, followed by carbonization and oxidation to iron carbides and $\mathrm{Fe}_{3} \mathrm{O}_{4}$, respectively. Among the catalysts reduced in solvents with different $\mathrm{EG} /$ water ratios, the $\mathrm{Fe}-\mathrm{B}$ reduced in water exhibited the highest activity of $0.83 \mathrm{~mol}_{\mathrm{CO}} \mathrm{mol}_{\mathrm{Fe}}{ }^{-1} \mathrm{~h}^{-1} \cdot 263$ Spherical and rod-like $\mathrm{Fe}-\mathrm{B}$ nanoparticles prepared in $\mathrm{W} / \mathrm{O}$ microemulsions displayed a high CO conversion of $c a .80 \%$ at $473 \mathrm{~K}$ after $12 \mathrm{~h}$ reaction in PEG400, while the selectivity to heavier hydrocarbons on the rod-like catalyst is slightly higher. ${ }^{91} \mathrm{Fe}-\mathrm{B}$ nanoclusters of $\sim 8 \mathrm{~nm}$ showed higher activity of $1.5 \mathrm{~mol}_{\mathrm{CO}} \mathrm{mol}_{\mathrm{Fe}}{ }^{-1} \mathrm{~h}^{-1}$ than $\mathrm{Co}-\mathrm{B}$ at $423 \mathrm{~K}$ in PEG200. ${ }^{259}$ When the FTS reaction was carried out in $\mathrm{EG},{ }^{260} \mathrm{Fe}-\mathrm{B}$ gave a much higher activity of $0.68 \mathrm{~mol}_{\mathrm{CO}} \mathrm{mol}_{\mathrm{Fe}}{ }^{-1} \mathrm{~h}^{-1}$ than $\mathrm{Co}-\mathrm{B}$, and selectivities to dioxolanes of $68 \mathrm{wt} \%$ and hydrocarbons of $26 \mathrm{wt} \%$, showing that $\mathrm{Fe}-\mathrm{B}$ is more favorable for the synthesis of dioxolanes. Interestingly, these results demonstrate that $\mathrm{Fe}-\mathrm{B}$ nanoparticles can be more active than $\mathrm{Co}-\mathrm{B}$ nanoparticles in low-temperature FTS reaction, in sharp contrast to the performances of those metals in crystalline form above $473 \mathrm{~K}^{255}$

\subsection{Application in other reactions}

5.7.1 Hydrogenolysis of ethyl lactate. 1,2-Propanediol (1,2-PDO) is useful for the production of polyester resins, polymers, pharmaceuticals, and functional fluids (antifreeze, deicing). Ethyl lactate, as one of the biomass-derived organic molecules, can be produced by fermentation of a number of renewable resources. ${ }^{264}$ Hydrogenation of ethyl lactate provides

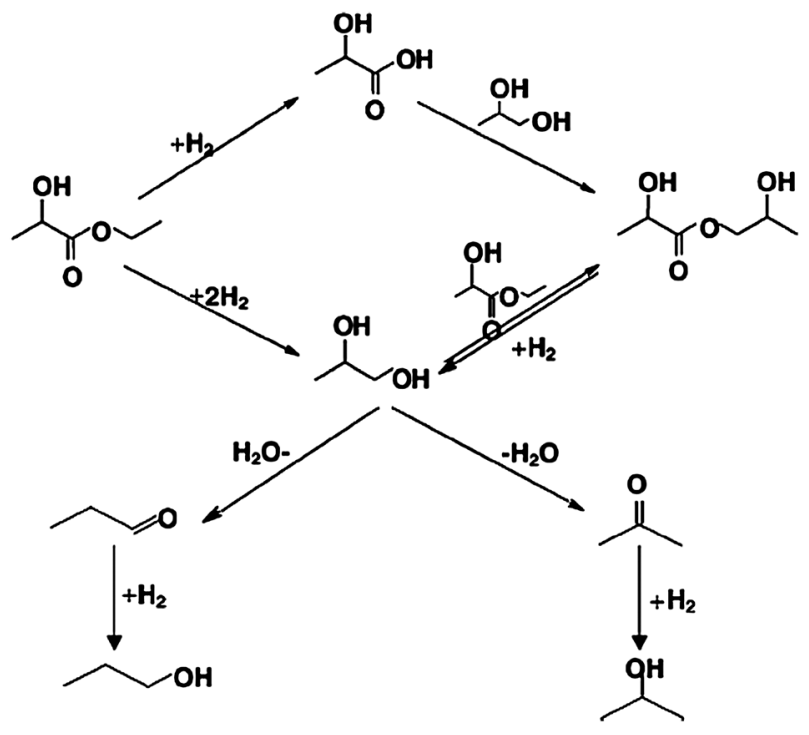

Scheme 11 Possible reaction pathway in the hydrogenation of ethyl lactate. Reproduced from ref. 84 with kind permission from Elsevier.

a green process to 1,2-PDO and thus attracts much attention. ${ }^{265}$ However, high reaction temperature should be avoided, since the reactive hydroxyl group in ethyl lactate tends to undergo side reactions, leading to a drop in 1,2-PDO selectivity (Scheme 11) ${ }^{84}$ Accordingly, developing catalysts active under mild reaction conditions is crucial for the transformation of ethyl lactate to 1,2-PDO.

A leading work on the hydrogenation of ethyl lactate to 1,2-PDO over amorphous alloy catalysts $\left(\mathrm{Ru}-\mathrm{Sn}-\mathrm{B} / \gamma-\mathrm{Al}_{2} \mathrm{O}_{3}\right)$ was conducted by Yan and coworkers. ${ }^{84}$ Addition of a suitable amount of $\mathrm{Sn}$ to $\mathrm{Ru}-\mathrm{B}$ significantly increased the ethyl lactate conversion and 1,2-PDO selectivity. The 1,2-PDO selectivity reached $92 \%$ at an ethyl lactate conversion of $91 \%$ under mild reaction conditions. On $\mathrm{Ru}-\mathrm{B} / \mathrm{Sn}-\mathrm{SBA}-15$ ( $\mathrm{Si} / \mathrm{Sn}$ molar ratio 30), the 1,2-PDO selectivity of $99 \%$ was obtained at an ethyl lactate conversion of $68 \% .{ }^{266} \mathrm{On} \mathrm{Ru}-\mathrm{B} / \mathrm{TiO}_{2}$, the 1,2-PDO selectivity of above $95 \%$ at ethyl lactate conversion of $98 \%$ was reported under even milder reaction conditions. ${ }^{267}$

5.7.2 Dehydrogenation. Dehydrogenation of alcohols can produce the corresponding aldehydes and ketones, as well as $\mathrm{H}_{2}$ and esters. ${ }^{268-270}$ The catalysts for this reaction involve $\mathrm{Cu},{ }^{271} \mathrm{Fe},{ }^{272}$ and noble metals like $\mathrm{Au},{ }^{273} \mathrm{Pd},{ }^{274} \mathrm{Ir},{ }^{270} \mathrm{Ag},{ }^{275}$ Os, and $\mathrm{Ru}^{276}$ Chen and coworkers investigated the dehydrogenation of ethanol to acetaldehyde on Fe-based amorphous alloy catalysts. ${ }^{272,277,278} \mathrm{Fe}_{72.8} \mathrm{~B}_{27.2}$ and $\mathrm{Fe}_{89.1} \mathrm{P}_{10.9}$ showed high activity and nearly $100 \%$ selectivity. ${ }^{272,277}$ Moreover, $\mathrm{Fe}-\mathrm{P}-\mathrm{B}$ exhibited higher weight specific activity than $\mathrm{Fe}-\mathrm{P}$ and $\mathrm{Fe}-\mathrm{B} .{ }^{278}$

5.7.3 Oxidation. Oxidation of $\mathrm{CO}$ has attracted much attention because of its relevance to many industrial applications. ${ }^{279}$ Over the $\mathrm{Pt} / \mathrm{Co}-\mathrm{B} / \mathrm{TiO}_{2}$ catalyst, the $\mathrm{CO}$ conversion is $86 \%$, which is much higher than the conversion of $39 \%$ on $\mathrm{Pt} / \mathrm{Co} /$ $\mathrm{TiO}_{2}$ under the same reaction conditions. ${ }^{280} \mathrm{~A}$ large number of works have been focused on the partial oxidation of $\mathrm{CH}_{4}$ (POM) to syngas, ${ }^{281-284}$ since the product is useful for FTS and methanol production. ${ }^{285}$ In POM, the Ca-decorated 
$\gamma-\mathrm{Al}_{2} \mathrm{O}_{3}(\mathrm{Ca}-\mathrm{AlO})$-supported low-Ni loading $(<1 \mathrm{wt} \%) \mathrm{Ni}-\mathrm{B}$ catalysts exhibited high activity and selectivity comparable to those on $10 \mathrm{wt} \% \mathrm{Ni} / \gamma-\mathrm{Al}_{2} \mathrm{O}_{3}$ and $1 \mathrm{wt} \% \mathrm{Rh} / \gamma-\mathrm{Al}_{2} \mathrm{O}_{3}{ }^{286}$ Moreover, the coke deposition on $\mathrm{Ni}-\mathrm{B} / \mathrm{Ca}-\mathrm{AlO}$ is much lower than that on $10 \mathrm{wt} \% \mathrm{Ni} / \gamma-\mathrm{Al}_{2} \mathrm{O}_{3}$ due to the structural effect of B.

Due to the low cost, improved safety, and low reaction pressure, the synthesis of $\mathrm{H}_{2} \mathrm{O}_{2}$ from $\mathrm{CO}, \mathrm{H}_{2} \mathrm{O}$ and $\mathrm{O}_{2}$ is more promising than the eAQ route and direct synthesis of $\mathrm{H}_{2} \mathrm{O}_{2}$ from $\mathrm{H}_{2}$ and $\mathrm{O}_{2}{ }^{52} \mathrm{Ni}-\mathrm{La}-\mathrm{B} / \gamma-\mathrm{Al}_{2} \mathrm{O}_{3}$ showed a $\mathrm{H}_{2} \mathrm{O}_{2}$ production rate of $0.07 \mathrm{mmol} \mathrm{g}_{\text {cat. }}{ }^{-1} \mathrm{~h}^{-1}$ from $\mathrm{CO}, \mathrm{H}_{2} \mathrm{O}$ and $\mathrm{O}_{2}$, which is comparable to the rate on $5 \% \mathrm{Pd} / \mathrm{CaCO}_{3}$ and $1 \%$ $\mathrm{Ru} /$ graphite $\left(0.1 \mathrm{mmol} \mathrm{g}_{\text {cat. }}{ }^{-1} \mathrm{~h}^{-1}\right) .{ }^{287-289} \mathrm{Ni}-\mathrm{P}-\mathrm{B} / \mathrm{Al}_{2} \mathrm{O}_{3}$ exhibited higher activity and stability than those noble metal catalysts, giving a $\mathrm{H}_{2} \mathrm{O}_{2}$ production rate of as high as $0.228 \mathrm{mmol} \mathrm{g}_{\text {cat. }}{ }^{-1} \mathrm{~h}^{-1} .52$

5.7.4 One-step hydrogenation of phenol to cyclohexanone. Cyclohexanone is a highly important industrial feedstock for manufacturing caprolactam and adipic acid, which are intermediates for nylon 6 and nylon 66, respectively. In comparison with the traditional routes for cyclohexanone production from the oxidation of cyclohexane, ${ }^{290}$ and the hydrogenation of phenol to cyclohexanol followed by dehydrogenation, ${ }^{291}$ one-step hydrogenation of phenol to cyclohexanone is more concise, environmentally more friendly, and more energyefficient. ${ }^{292}$ The reaction route is illustrated in Scheme 12. Li and coworkers investigated the hydrogenation of phenol to cyclohexanone on Pd-B amorphous alloy catalysts. ${ }^{293-295}$ The La- or Ce-doped Pd-B catalyst exhibited higher activity and selectivity to cyclohexanone than the undoped $\mathrm{Pd}-\mathrm{B}$, and the maximum cyclohexanone yields over $\mathrm{Pd}-\mathrm{La}-\mathrm{B}(\mathrm{La} / \mathrm{Pd}+\mathrm{La}+\mathrm{B})$ molar ratio $=1 \%)$ and $\mathrm{Pd}-\mathrm{Ce}-\mathrm{B}(\mathrm{Ce} / \mathrm{Pd}$ molar ratio $=$ $0.44 \%$ ) are $79 \%$ and $83 \%$, respectively. ${ }^{293,295}$ The properties of the supports influence the catalytic performance of the $\mathrm{Pd}-\mathrm{B}$ catalyst. ${ }^{295}$ The phenol conversion and cyclohexanone selectivity at the maximum cyclohexanone yield over the $5.8 \%$ $\mathrm{Pd}-\mathrm{Ce}-\mathrm{B} / \mathrm{MgAl}$ hydrotalcite $(\mathrm{HT})$ are $82 \%$ and $80 \%$, respectively, superior to the values on the $\mathrm{Al}_{2} \mathrm{O}_{3^{-}}, \mathrm{MgO}$-, and $\mathrm{SiO}_{2^{-}}$ supported catalysts.

5.7.5 Reduction of $N$-nitrosodimethylamine (NDMA). NDMA, a probable human carcinogen, has been recently detected as a contaminant in drinking and ground water. ${ }^{296}$ Traditional physicochemical treatment technologies are inefficient to eliminate NDMA, and ultraviolet treatment is efficient but uneconomical. ${ }^{297}$ Powdered metal catalysts like $\mathrm{Pd}$ and $\mathrm{Ni}$ in the presence of $\mathrm{H}_{2}$ present notable potential for rapid destruction

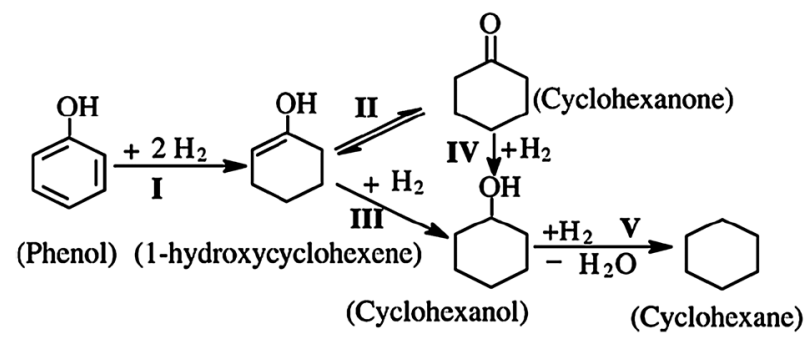

Scheme 12 A plausible reaction mechanism for phenol hydrogenation. Reproduced from ref. 295 with kind permission from Elsevier.

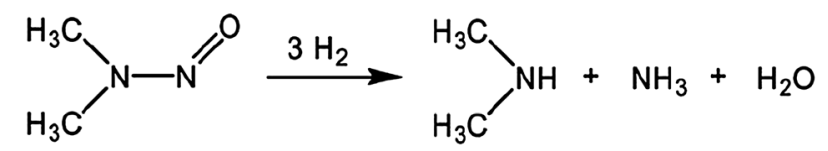

Scheme 13 Reduction of NDMA on the Ni-B catalyst. Reproduced from ref. 55 with kind permission from Elsevier.

of NDMA in water ${ }^{296}$ Strathmann and coworkers reported that $\mathrm{Ni-B}$ exhibited higher intrinsic activity than RANEY ${ }^{\circledR}$ $\mathrm{Ni}$ in the reduction of NDMA (Scheme 13). ${ }^{55}$ The activity of $\mathrm{Ni}-\mathrm{B}$ was not affected by solution $\mathrm{pH}$ and extended exposure of the dry catalyst to air, while RANEY ${ }^{\mathbb{R}}$ Ni immediately deactivated by exposure to air. Ni-B is also more tolerant to dissolved oxygen and low concentration of dissolved sulfide than RANEY ${ }^{\mathbb{R}} \mathrm{Ni}$, showing its great potential in eliminating NDMA in water.

5.7.6 Hydroamination of phenylpyruvic acid (PPA). Phenylalanine (Phe) is widely used in pabulum and pharmaceutical industries, for instance, as an amino acid infusion ${ }^{298}$ and as a precursor for manufacturing aspartame. ${ }^{299}$ Chemical synthesis of Phe from PPA hydroamination has attracted much attention, since PPA can be easily obtained via double carbonylation of benzyl chloride. ${ }^{300} \mathrm{Ni}-\mathrm{B} / \mathrm{SiO}_{2}$ is effective for the synthesis of Phe from PPA by amination and hydrogenation (Scheme 14). ${ }^{54}$ On this catalyst, the selectivity and yield of Phe are $99 \%$ and $98 \%$, respectively, both of which are higher than those on Urushibara $\mathrm{Ni}(\mathrm{U}-\mathrm{Ni})$ and RANEY ${ }^{\mathbb{B}} \mathrm{Ni}$.

5.7.7 Barbier-type carbonyl allylation. Synthesis of homoallylic alcohols via Barbier-type carbonyl allylation is of great importance, since the homoallylic alcohols are versatile subunits for manufacturing many useful biologically active molecules including polyether, macrolides, and antibiotics. ${ }^{301}$ The Barbier-type carbonyl allylation has been realized mainly by homogeneous organometallic catalysis. ${ }^{302,303}$ The Barbiertype carbonyl allylation in aqueous media was realized on metallic In powder in $1991 .^{304}$ The In powder exhibited high selectivity, but with lower efficiency compared to the homogeneous catalysts. $\mathrm{Li}$ and coworkers reported that the In-B amorphous alloy showed higher activity than the In powder in allylation of benzaldehyde in water, and maintained a high selectivity of $98 \%$ (Scheme 15). ${ }^{305}$ They further demonstrated that In-B is active for the Barbier-type allylation of substituted benzaldehydes and a number of allylic halides with selectivities $\geq 97 \%$ at conversions $\geq 94 \%$. In Barbier-type allylation of acetophenone on In-B, allyl bromide showed similar allylation result to the expensive allylboronate, giving the 2-phenyl-4-penten-2-ol selectivity of $94 \%$ at the conversion of $90 \%$.

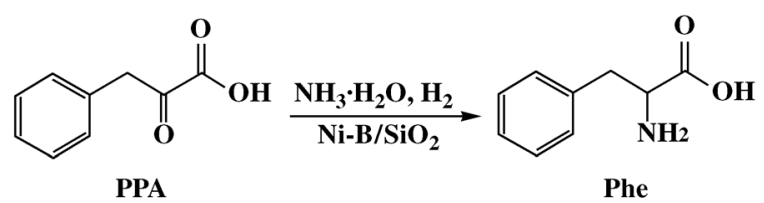

Scheme 14 The route for the synthesis of Phe. Reproduced from ref. 54 with kind permission from Elsevier. 


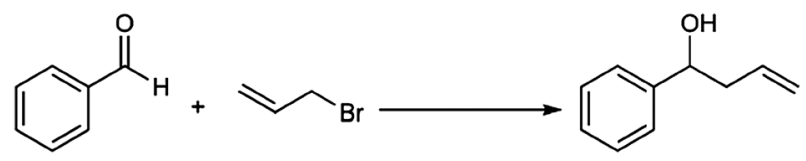

Scheme 15 Barbier-type allylation of benzaldehyde with allyl bromide.

\section{Conclusions}

The importance of amorphous alloys in catalysis has attracted the rapid expansion of research on the synthesis and catalysis of chemically reduced metal-metalloid amorphous alloy catalysts. Various synthetic strategies, transplanted from newly emerged methods ${ }^{115-117,121-125,129-132}$ or characteristic of the chemical reduction method, ${ }^{53,90,91,128}$ have been developed to prepare size-, morphology-, or texture-specific metal-metalloid amorphous alloy catalysts. New supports, such as regular mesoporous molecular sieves and CNTs, have been used to improve the dispersion and thermal stability of the amorphous alloy nanoparticles. Incorporation of a promoter, in the oxidized or metallic state, structurally or electronically modifies the physical characters of the amorphous alloy catalysts in terms of dimension, thermal stability, and electron density, which further tune the catalytic performance. In a number of catalytic reactions in petrochemistry, energy conversion, and environmental remediation, metal-metalloid amorphous alloys exhibit impressive catalytic performance. High or exclusive selectivities to targeting products were reported on some amorphous alloy catalysts. Amorphous alloy catalysts are usually more active than their crystalline counterparts and catalysts reduced by $\mathrm{H}_{2}$. In certain cases, non-noble metalbased amorphous alloy catalysts even exhibited higher activity than noble metal catalysts. In addition, a few investigations suggested that amorphous alloys can function as precursors of high-performance catalysts upon proper pretreatment. These striking results, in conjugation with the easiness of the chemical reduction method to synthesize metal-metalloid amorphous alloys with desired combinations and contents of metal and metalloid, show promise for amorphous alloy catalysts as efficient and economical alternatives to traditional RANEY $^{\circledR} \mathrm{Ni}$ and $\mathrm{Pd} / \mathrm{C}$ catalysts widely used in the chemical industry. In particular, industrial applications of metalmetalloid amorphous alloy catalysts will be most probably realized in the saturation of olefinic bonds, carbonyl groups, and nitro groups that can readily occur on these high-performance catalysts. Partial hydrogenation of benzene and chemoselective hydrogenation of conjugated unsaturated aldehydes or ketones are another two kinds of reactions that are promising for amorphous alloy catalysts to act as industrial catalysts owing to their outstanding selectivities. For further investigations, much attention may be paid to the exploration of the catalytic performance of metal-metalloid amorphous alloy catalysts in more complicated and value-added reactions such as enantioselective hydrogenation and the synthesis of pharmaceutical intermediates.

On the other hand, in most cases the catalytic performance of the metal-metalloid amorphous alloy catalysts is simply explained by the electronic effect due to the bond formation between metal and metalloid. There are very limited studies aiming to establish an in-depth understanding of the structureperformance relationship on amorphous alloy catalysts. This surprising falling-behind as compared to the rapid progress in their synthesis and catalytic applications can be mainly explained by the amorphous structure inaccessible to conventional XRD, TEM and SAED techniques, which are only suitable for extracting structural information of crystalline materials. In this respect, more attention should be paid to synchrotron- or neutron-based techniques powerful in revealing the structural mysteries of amorphous alloys of various compositions toward understanding of catalytic mechanisms on amorphous alloys. However, it should be noted that these techniques only provide structure-averaged information, while the possibility exists that the amorphous alloy is constructed by one or more types of atomic clusters. Thus, a close cooperation with theoretical modeling will be instructive to the establishment of an accurate structure-performance relationship over amorphous alloy catalysts.

As compared to the vast abundance of the reactions investigated on metal-metalloid amorphous alloy catalysts, information about the surface chemistry of this type of catalysts is lacking at the molecular level. Investigation of the adsorption strength, adsorption mode, and the reaction intermediate of the reactants on the amorphous alloy catalysts is important to elucidate the difference in the catalytic performance between amorphous and crystalline catalysts.

A vacuum approach of surface science is widely used for fundamental studies of surface adsorption, dissociation, and desorption. Due to the limit of inelastic mean free paths of electrons at ambient pressure, so far most electron-based surface analysis techniques can only be used to study surface chemistry and structure under high vacuum or ultrahigh vacuum. Thus, most studies using such techniques are performed with an approach called ex situ studies. This approach uses well-defined single crystals as model catalysts. It provides insights toward understanding the catalytic mechanism at the molecular level though a pressure gap and a materials gap were raisen in recent decade. In the case of amorphous alloy catalysts, the vacuum approach faces an additional challenge. Conventional ex situ studies demand a sputtering-annealing treatment of model catalysts to prepare a clean surface before ex situ studies. Since amorphous alloys are thermodynamically metastable, when subjected to such a harsh treatment, they are inclined to undergo structure transformation or crystallization, thus losing their pristine structural character. In this connection, in situ or Operando characterization techniques ${ }^{306,307}$ are essential for providing meaningful information on the adsorption and reaction of the reactants on amorphous alloy catalysts, which will facilitate a rational design of amorphous catalysts with desired performance.

To improve the operation longevity of the metastable metal-metalloid amorphous alloy catalysts, endeavors have been focused predominantly on catalyst preparation. Dispersing amorphous alloy nanoparticles on a high-surface area or high-porosity support, and modifying the amorphous alloy with selected element are effective ways to sustain the amorphous structure to as high as $600 \mathrm{~K}$ or above. Combined with the excellent low-temperature catalytic activity of the amorphous alloys, apparently the improved $T_{\mathrm{c}}$ can meet the temperature 
requirement of many reactions. However, to ensure a longterm operation, reaction temperature as low as possible is preferred, since the amorphous alloy may undergo slow but irreversible structure relaxation even below $T_{\mathrm{c}}$. Reaction engineering technology can be intriguing, but has long been ignored, to prolong the lifetime of the amorphous alloy catalysts. One promising reactor type for metal-metalloid amorphous alloy catalysts is the magnetically stabilized-bed (MSB) reactor. ${ }^{308}$ This reactor is conductive to good mass and heat transportations, and fine and friable catalyst particles can be used free from high pressure drop. ${ }^{309}$ For example, for a skeletal Ni catalysts, the optimal temperature for CO methanation on the MSB reactor was markedly lowered by $c a .100 \mathrm{~K}$ as compared to the same catalyst on the conventional fixed-bed reactor. ${ }^{310}$ Thus, integrating the advantages of the metalmetalloid amorphous alloy catalysts and the MSB reactor or other adequate type of reactor will surely advance the industrial application of the amorphous alloy catalysts in various chemical processes.

\section{Acknowledgements}

This work was supported by the National Basic Research Program of China (2012CB224804), the NSF of China (21073043), the Science \& Technology Commission of Shanghai Municipality (10JC1401800, 08DZ2270500), the Program of New Century Excellent Talents (NCET-08-0126), the Key Laboratory of Resource Chemistry of Ministry of Education, Shanghai Normal University, the Chemical Sciences, Geosciences and Biosciences Division, Office of Basic Energy Sciences, Office of Science, U.S. Department of Energy under the grant DE-FG02-12ER1635, and ACS PRF, and the startup funds from University of Notre Dame and seed funds from Center for Sustainable Energy at Notre Dame.

\section{Notes and references}

1 M. H. Bhat, V. Molinero, E. Soignard, V. C. Solomon, S. Sastry, J. L. Yarger and C. A. Angell, Nature, 2007, 448, 787.

2 D. B. Miracle, Nat. Mater., 2004, 3, 697.

3 F. E. Luborsky, Amorphous Metallic Alloys, Butterworths, London, 1983.

4 Z. Hu, Y. Fan and Y. Chen, Appl. Phys. A: Mater. Sci. Process., 1999, 68, 225.

5 W. H. Wang, Nat. Mater., 2012, 11, 275.

6 H. Zahn and J. Kramer, Z. Phys., 1933, 86, 413.

7 G. V. Smith, W. E. Brower, Jr and M. S. Matyjaszczyk, 7th Proc. Int. Congr. Catal., 1980, 355.

8 J. van Wonterghem, S. Mørup, C. J. W. Koch, S. W. Charles and S. Wells, Nature, 1986, 322, 622.

9 H. I. Schlesinger, H. C. Brown, A. E. Finholt, J. R. Gilbreath, H. Hoekstra and E. K. Hyde, J. Am. Chem. Soc., 1953, 75, 215.

10 Á. Molnár, M. Bartók and G. V. Smith, Adv. Catal., 1989, 36, 329.

11 A. Baiker, Faraday Discuss. Chem. Soc., 1989, 87, 239.

12 A. M. Argo, J. F. Odzak, F. S. Lai and B. C. Gates, Nature, 2002, $415,623$.

13 J. M. Thomas, J. Chem. Phys., 2008, 128, 182502.

14 J. M. Thomas, B. F. G. Johnson, R. Raja, G. Sankar and P. A. Midgley, Acc. Chem. Res., 2003, 36, 20.

15 J. M. Thomas, Top. Catal., 2008, 50, 98.

16 J. M. Thomas and R. Raja, Top. Catal., 2010, 53, 848.

17 J. M. Thomas, Z. Saghi and P. L. Gai, Top. Catal., 2011, 54, 588.

18 J. M. Thomas, Proc. R. Soc. London, Ser. A, 2012, 468, 1884.

19 W. E. Brower Jr, M. S. Matyjaszczyk, T. L. Pettit and G. V. Smith, Nature, 1983, 301, 497.
20 S. Yoshida, H. Yamashita, T. Funabiki and T. Yonezawa, J. Chem. Soc., Faraday Trans. 1, 1984, 80, 1435.

21 Y. Chen, Catal. Today, 1998, 44, 3.

22 J. F. Deng, H. X. Li and W. J. Wang, Catal. Today, 1999, 51, 113.

23 J. F. Deng and H. Y. Chen, J. Mater. Sci. Lett., 1993, 12, 1508.

24 S. Linderoth and S. Mørup, J. Appl. Phys., 1990, 67, 4472.

25 S. Linderoth and S. Mørup, J. Appl. Phys., 1991, 69, 5256.

26 J. Y. Shen, Z. Y. Li, Y. N. Fan, Z. Hu and Y. Chen, J. Solid State Chem., 1993, 106, 493.

27 J. Y. Shen, Z. Y. Li, Q. J. Yan and Y. Chen, J. Phys. Chem., 1993, 97, 8504.

28 Z. Liu, W. L. Dai, B. Liu and J. F. Deng, J. Catal., 1999, 187, 253.

29 Y. G. He, M. H. Qiao, H. R. Hu, Y. Pei, H. X. Li, J. F. Deng and K. N. Fan, Mater. Lett., 2002, 56, 952.

30 H. X. Li, H. Li, W. L. Dai and M. H. Qiao, Appl. Catal., A, 2003, 238, 119

31 S. H. Xie, M. H. Qiao, W. Z. Zhou, G. Luo, H. Y. He, K. N. Fan, T. J. Zhao and W. K. Yuan, J. Phys. Chem. B, 2005, 109, 24361.

32 S. Wells, S. W. Charles, S. Mørup, S. Linderoth, J. van Wonterghem, J. Larsen and M. B. Madsen, J. Phys.: Condens. Matter, 1989, 1, 8199.

33 W. L. Dai, M. H. Qiao and J. F. Deng, Appl. Surf. Sci., 1997, 120, 119.

34 Z. B. Yu, M. H. Qiao, H. X. Li and J. F. Deng, Appl. Catal., A, 1997, 163, 1.

35 J. Y. Shen, Z. Hu, Y. F. Hsia and Y. Chen, Appl. Phys. Lett., 1991, 59, 2510 .

36 J. Y. Shen, Z. Hu, Q. Zhang, L. F. Zhang and Y. Chen, J. Appl. Phys., 1992, 71, 5217.

37 J. F. Deng, X. P. Zhang and E. Z. Min, Appl. Catal., 1988, 37, 339.

38 K. Hashimoto, Mater. Sci. Eng., A, 1997, 226-228, 891.

39 S. Q. Wei, H. Oyanagi, Z. R. Li, X. Y. Zhang, W. H. Liu, S. L. Yin and X. G. Wang, Phys. Rev. B: Condens. Matter Mater. Phys., 2001, 63, 224201.

40 Z. Jiang, H. W. Yang, Z. Wei, Z. Xie, W. J. Zhong and S. Q. Wei, Appl. Catal., A, 2005, 279, 165.

41 Y. Pei, P. J. Guo, M. H. Qiao, H. X. Li, S. Q. Wei, H. Y. He and K. N. Fan, J. Catal., 2007, 248, 303.

42 Z. Wei, Z. R. Li, Z. Jiang, J. Ye, W. J. Zhong, J. X. Song and S. Q. Wei, J. Alloys Compd., 2008, 460, 553.

43 M. S. Nashner, A. I. Frenkel, D. Somerville, C. W. Hills, J. R. Shapley and R. G. Nuzzo, J. Am. Chem. Soc., 1998, 120, 8093 .

44 J. H. Kang, L. D. Menard, R. G. Nuzzo and A. I. Frenkel, J. Am. Chem. Soc., 2006, 128, 12068.

45 J. F. Geng, D. A. Jefferson and B. F. G. Johnson, Chem. Commun., 2007, 969.

46 B. J. Liaw and Y. Z. Chen, Appl. Catal., A, 2001, 206, 245.

47 Y. Z. Chen, B. J. Liaw and B. J. Chen, Appl. Catal., A, 2002, 236, 121.

48 P. J. Guo, L. F. Chen, S. R. Yan, W. L. Dai, M. H. Qiao, H. L. Xu and K. N. Fan, J. Mol. Catal. A: Chem., 2006, 256, 164.

49 Y. Z. Chen and Y. C. Chen, Appl. Catal., A, 1994, 115, 45.

50 H. X. Li, Y. D. Wu, H. S. Luo, M. H. Wang and Y. P. Xu, J. Catal., 2003, 214, 15.

51 Y. C. Liu and Y. W. Chen, Ind. Eng. Chem. Res., 2006, 45, 2973.

52 Z. L. Ma, S. K. Jiang, L. Zhang and C. Q. Liu, Appl. Catal., A, 2006, 311, 34

53 S. J. Chiang, B. J. Liaw and Y. Z. Chen, Appl. Catal., A, 2007, 319, 144.

54 Q. F. Liang, A. Q. Zhang and L. Li, J. Nat. Gas Chem., 2008, 17, 303.

55 A. J. Frierdich, C. E. Joseph and T. J. Strathmann, Appl. Catal., B, 2009, 90, 175.

56 Y. Okamoto, Y. Nitta, T. Imanaka and S. Teranishi, J. Chem. Soc., Faraday Trans. 1, 1979, 15, 2027.

57 Y. Okamoto, Y. Nitta, T. Imanaka and S. Teranishi, J. Catal., 1980, 64, 397.

58 T. Imanaka, J. Tamaki and S. Teranishi, Chem. Lett., 1984, 449.

59 J. Tamaki and T. Imanaka, Chem. Lett., 1986, 679.

60 W. S. Xia, Y. Fan, Y. S. Jiang and Y. Chen, Appl. Surf. Sci., 1996, 103,1 .

61 J. F. Deng, H. Y. Chen, X. H. Bao and M. Muhler, Appl. Surf. Sci., 1994, 81, 341.

62 H. Li, H. X. Li, W. L. Dai, W. J. Wang, Z. G. Fang and J. F. Deng, Appl. Surf. Sci., 1999, 152, 25.

63 L. Finney, Nature, 1977, 266, 309.

64 J. Li, M. H. Qiao and J. F. Deng, J. Mol. Catal. A: Chem., 2001, 169, 295. 
65 H. B. Guo, H. X. Li, J. Zhu, W. H. Ye, M. H. Qiao and W. L. Dai, J. Mol. Catal. A: Chem., 2003, 200, 213.

66 S. Diplas, J. Lehrmann, S. Jørgensen, T. Våland and J. Taftø, Philos. Mag., 2005, 85, 981.

67 S. Diplas, S. Jørgensen, J. Taftø, T. Tønnessen, T. Knutsen, J. Lehrmann, T. Våland, M. L. Abel and J. F. Watts, Surf. Interface Anal., 2006, 38, 238.

68 S. Diplas and O. M. Løvvik, J. Phys.: Condens. Matter, 2009, 21, 245503.

69 S. N. Ishmaev, S. L. Isakov, I. P. Sadikov and E. Svab, J. NonCryst. Solids, 1987, 94, 11.

70 T. A. Weber and F. H. Stillinger, Phys. Rev. B: Condens. Matter Mater. Phys., 1985, 31, 1954.

71 Z. G. Fang, B. R. Shen, J. Lu, K. N. Fan and J. F. Deng, Acta Chim. Sin. (Engl. Ed.), 1999, 57, 894.

72 Z. G. Fang, B. R. Shen, K. N. Fan and J. F. Deng, Acta Chim. Sin. (Engl. Ed.), 1999, 57, 1246.

73 Z. G. Fang, B. R. Shen and K. N. Fan, Chin. J. Chem. Phys., $2002,15,17$.

74 Z. G. Fang, K. N. Fan and H. L. Jiang, Chin. J. Chem. Phys., 2004, 17, 684 .

75 Q. S. Zeng, W. K. Chen, Y. F. Zhang, W. X. Dai and X. Guo, J. Nat. Gas Chem., 2010, 19, 300.

76 Q. S. Zeng, W. K. Chen, W. X. Dai, Y. F. Zhang, Y. Li and X. Guo, Chin. J. Catal., 2010, 31, 423.

77 M. H. Qiao, S. H. Xie, W. L. Dai and J. F. Deng, Catal. Lett., 2001, 71, 187.

78 B. R. Shen, S. Q. Wei, K. N. Fan and J. F. Deng, Appl. Phys. A. Mater. Sci. Process., 1997, 65, 295.

79 L. F. Chen and Y. W. Chen, Ind. Eng. Chem. Res., 2006, 45, 8866.

80 X. F. Chen, H. X. Li, H. S. Luo and M. H. Qiao, Appl. Catal., A, 2002, 233, 13.

81 H. X. Li, S. Y. Zhang and H. S. Luo, Mater. Lett., 2004, 58, 2741.

82 S. Q. Wei, H. Y. Cui, J. H. Wang, S. P. Zhuo, W. M. Yi, L. H. Wang and Z. H. Li, Particuology, 2011, 9, 69.

83 J. Fang, X. Y. Chen, B. Liu, S. R. Yan, M. H. Qiao, H. X. Li, H. Y. He and K. N. Fan, J. Catal., 2005, 229, 97.

84 G. Luo, S. R. Yan, M. H. Qiao, J. H. Zhuang and K. N. Fan, Appl. Catal., A, 2004, 275, 95.

85 B. J. Liaw, C. H. Chen and Y. Z. Chen, Chem. Eng. J., 2010, 157, 140.

86 H. X. Li, H. S. Luo, L. Zhuang, W. L. Dai and M. H. Qiao, J. Mol. Catal. A: Chem., 2003, 203, 267.

87 X. H. Yan, J. Q. Sun, Y. W. Wang and J. F. Yang, J. Mol. Catal. A. Chem., 2006, 252, 17.

88 C. Luo, W. N. Wang, M. H. Qiao and K. N. Fan, J. Mol. Catal. A. Chem., 2002, 184, 379.

89 D. Acosta, N. Ramírez, E. Erdmann, H. Destéfanis and E. Gonzo, Catal. Today, 2008, 133-135, 49.

90 H. Li, J. Liu, S. H. Xie, M. H. Qiao, W. L. Dai and H. X. Li, J. Catal., 2008, 259, 104.

91 X. F. Cheng, B. S. Wu, Y. Yang and Y. W. Li, Catal. Commun., 2011, 12, 431.

92 B. J. Liaw, S. J. Chiang, C. H. Tsai and Y. Z. Chen, Appl. Catal., A, 2005, 284, 239.

93 J. Bu, J. Q. Wang, M. H. Qiao, S. R. Yan, H. X. Li and K. N. Fan, Acta Chim. Sin. (Engl. Ed.), 2007, 65, 1338.

94 B. J. Liaw, S. J. Chiang, S. W. Chen and Y. Z. Chen, Appl. Catal., A, 2008, 346, 179.

95 H. Li, C. J. Ma and H. X. Li, Chin. J. Chem., 2006, 24, 613.

96 H. X. Li, H. Li, J. Zhang, W. L. Dai and M. H. Qiao, J. Catal., 2007, 246, 301.

97 H. Li, J. Zhang and H. X. Li, Catal. Commun., 2007, 8, 2212.

$98 \mathrm{H}$. Li, Y. Wang, Q. F. Zhao and H. X. Li, Res. Chem. Intermed., 2009, 35, 779.

99 G. Y. Bai, L. B. Niu, M. D. Qiu, F. He, X. X. Fan, H. Y. Dou and X. F. Zhang, Catal. Commun., 2010, 12, 212.

100 A. Roucoux, J. Schulz and H. Patin, Chem. Rev., 2002, 102, 3757.

101 H. Goesmann and C. Feldmann, Angew. Chem., Int. Ed., 2010, 49, 1362.

102 K. S. Suslick, Science, 1990, 247, 1439.

103 K. S. Suslick, S. B. Choe, A. A. Cichowlas and M. W. Grinstaff, Nature, 1991, 353, 414.

104 N. A. Dhas and A. Gedanken, Chem. Mater., 1997, 9, 3144

105 L. H. Thompson and L. K. Doraiswamy, Ind. Eng. Chem. Res., 1999, 38, 1215.
106 S. Devarakonda, J. M. B. Evans and A. S. Myerson, Cryst. Growth Des., 2003, 3, 741.

107 T. Prozorov, R. Prozorov and K. S. Suslick, J. Am. Chem. Soc., 2004, 126, 13890.

108 Y. F. Lu, H. Y. Fan, A. Stump, T. L. Ward, T. Rieker and C. J. Brinker, Nature, 1999, 398, 223.

109 J. N. Cha, G. D. Stucky, D. E. Morse and T. J. Deming, Nature, 2000, 403, 289

110 S. W. Kim, M. Kim, W. Y. Lee and T. Hyeon, J. Am. Chem. Soc., 2002, 124, 7642.

111 X. Y. Chen, W. L. Yang, S. Wang, M. H. Qiao, S. R. Yan, K. N. Fan and H. Y. He, New J. Chem., 2005, 29, 266.

112 G. W. Xie, Z. G. Lu, Z. B. Wang and Z. L. Cui, Catal. Commun., 2008, 9, 1766.

113 S. Wang, W. L. Yang, G. B. Yu, S. H. Xie, M. H. Qiao and K. N. Fan, Chin. J. Chem., 2008, 26, 1191.

114 X. L. Zhang, J. H. Liu and S. M. Li, Mater. Lett., 2009, 63, 1907.

115 H. Li, Y. Xu, J. Liu, Q. F. Zhao and H. X. Li, J. Colloid Interface Sci., 2009, 334, 176.

116 Y. Zhu, F. P. Liu, W. P. Ding, X. F. Guo and Y. Chen, Angew. Chem., Int. Ed., 2006, 45, 7211.

117 W. P. Ding, X. F. Guo, M. Mo, Y. Zhu and Y. Chen, Chin. J. Catal., 2010, 31, 887.

118 C. T. Kresge, M. E. Leonowicz, W. J. Roth, J. C. Vartuli and J. S. Beck, Nature, 1992, 359, 710.

119 D. Y. Zhao, J. Feng, Q. S. Huo, N. Melosh, G. H. Fredrickson, B. F. Chmelka and G. D. Stucky, Science, 1998, 279, 548.

120 H. Li, H. X. Yang and H. X. Li, J. Catal., 2007, 251, 233.

121 Q. Meng, H. Li and H. X. Li, J. Phys. Chem. C, 2008, 112, 11448.

122 H. X. Li, Q. F. Zhao, Y. Wan, W. L. Dai and M. H. Qiao, J. Catal., 2006, 244, 251.

123 D. G. Tong, X. Han, W. Chu, H. Chen and X. Y. Ji, Mater. Lett., 2007, 61, 4679

124 D. G. Tong, W. Chu, Y. Y. Luo, H. Chen and X. Y. Ji, J. Mol. Catal. A: Chem., 2007, 269, 149.

125 H. Li, D. Q. Zhang, G. S. Li, Y. Xu, Y. F. Lu and H. X. Li, Chem. Commun., 2010, 46, 791.

126 F. Gao, Q. Y. Lu and D. Y. Zhao, Adv. Mater., 2003, 15, 739.

127 A. H. Lu and F. Schüth, Adv. Mater., 2006, 18, 1793.

128 X. Y. Chen, Z. Y. Lou, S. H. Xie, M. H. Qiao, S. R. Yan, Y. L. Zhu, K. N. Fan and H. Y. He, Chem. Lett., 2006, 390.

129 Q. H. Wang, L. F. Jiao, H. M. Du, D. W. Song, W. X. Peng, Y. C. Si, Y. J. Wang and H. T. Yuan, Electrochim. Acta, 2010, $\mathbf{5 5}, 7199$.

130 Z. J. Yan and D. S. Xue, J. Mater. Sci., 2008, 43, 771.

131 N. Patel, R. Fernandes, G. Guella, A. Kale, A. Miotello, B. Patton and C. Zanchetta, J. Phys. Chem. C, 2008, 112, 6968.

132 N. Patel, R. Fernandes, G. Guella and A. Miotello, Appl. Catal., $B, 2010,95,137$.

133 H. Li, C. Z. Wang, Q. F. Zhao and H. X. Li, Appl. Surf. Sci., 2008, 254, 7516.

134 B. Liu, M. H. Qiao, J. Q. Wang, S. H. Xie, H. X. Li and K. N. Fan, J. Chem. Technol. Biotechnol., 2003, 78, 512.

135 Z. J. Wu, S. H. Ge, M. H. Zhang, W. Li and K. Y. Tao, Catal. Commun., 2008, 9, 1432.

136 R. Dagani, Chem. Eng. News, 1997, 75, 26.

137 W. J. Wang, M. H. Qiao, J. Yang, S. H. Xie and J. F. Deng, Appl. Catal., A, 1997, 163, 101.

138 W. J. Wang, M. H. Qiao, H. X. Li, W. L. Dai and J. F. Deng, Appl. Catal., A, 1998, 168, 151.

139 Y. G. He, M. H. Qiao, H. R. Hu, J. F. Deng and K. N. Fan, Appl. Catal., A, 2002, 228, 29.

140 H. Yan, W. Li, M. H. Zhang and K. Y. Tao, Chin. J. Catal., 2009, 30, 89.

141 L. Wang, W. Li, M. H. Zhang and K. Y. Tao, Appl. Catal., A, 2004, 259, 185.

142 G. O. Mallory and J. B. Hajdu, Electroless Plating: Fundamentals and Applications, American Electroplaters and Surface Finishers Society, Orlando, 1990.

143 Z. J. Wu, S. H. Ge, M. H. Zhang, W. Li, S. C. Mu and K. Y. Tao, J. Phys. Chem. C, 2007, 111, 8587.

144 S. H. Ge, Z. J. Wu, M. H. Zhang, W. Li and K. Y. Tao, Ind. Eng. Chem. Res., 2006, 45, 2229.

145 H. L. Wen, K. S. Yao, J. Wei, Z. M. Zhou and A. Kirschning, J. Nanopart. Res., 2009, 11, 499. 
146 C. Q. Xu, D. J. Zhu and G. X. Li, J. Funct. Mater., 2004, 35, 1974.

147 R. F. Nystrom, J. Am. Chem. Soc., 1955, 77, 2544.

148 S. Caddick, A. K. de K. Haynes, D. B. Judd and M. R. V. Williams, Tetrahedron Lett., 2000, 41, 3513.

149 A. Rahman and S. B. Jonnalagadda, Catal. Lett., 2008, 123, 264.

150 A. Rahman and S. B. Jonnalagadda, J. Mol. Catal. A: Chem., 2009, 299, 98.

151 A. Corma, Chem. Rev., 1997, 97, 2373.

152 S. T. Wong, J. F. Lee, J. M. Chen and C. Y. Mou, J. Mol. Catal. A: Chem., 2001, 165, 159.

153 X. Y. Chen, H. R. Hu, B. Liu, M. H. Qiao, K. N. Fan and H. Y. He, J. Catal., 2003, $220,254$.

154 X. Y. Chen, S. Wang, J. H. Zhuang, M. H. Qiao, K. N. Fan and H. Y. He, J. Catal., 2004, 227, 419.

155 H. Li, J. Liu, H. X. Yang and H. X. Li, Chin. J. Chem., 2009, 27, 2316.

156 H. Li, Y. Xu, H. X. Yang, F. Zhang and H. X. Li, J. Mol. Catal. A: Chem., 2009, 307, 105.

157 A. Fukuoka, Y. Sakamoto, S. Guan, S. Inagaki, N. Sugimoto, Y. Fukushima, K. Hirahara, S. Iijima and M. Ichikawa, J. Am. Chem. Soc., 2001, 123, 3373.

158 M. W. Wang, F. Y. Li and R. B. Zhang, Catal. Today, 2004, 93-95, 603.

159 H. Li, H. X. Li and J. F. Deng, Appl. Catal., A, 2000, 193, 9.

160 H. Li, H. X. Li, W. L. Dai and J. F. Deng, Appl. Catal., A, 2001, 207, 151.

161 Z. Q. Xiong, Z. T. Mi and X. W. Zhang, Catal. Commun., 2007, 8, 571 .

162 H. S. Chung, C. S. H. Chen, R. A. Kremer and J. R. Boulton, Energy Fuels, 1999, 13, 641.

163 J. J. Zou, Z. Q. Xiong, X. W. Zhang, G. Z. Liu, L. Wang and Z. T. Mi, Ind. Eng. Chem. Res., 2007, 46, 4415.

164 J. J. Zou, Z. Q. Xiong, L. Wang, X. W. Zhang and Z. T. Mi, J. Mol. Catal. A: Chem., 2007, 271, 209.

165 Y. J. Choi, K. W. Cho, B. W. Cho and Y. K. Yeo, Ind. Eng. Chem. Res., 2002, 41, 5504.

166 Y. F. Ma, W. Li, M. H. Zhang, Y. Zhou and K. Y. Tao, Appl. Catal., A, 2003, 243, 215.

167 Y. F. Ma, M. H. Zhang, W. Li, B. G. Zhang and K. Y. Tao, Chin. J. Catal., 2004, 25, 973.

168 L. J. Wang, W. Li, M. H. Zhang and K. Y. Tao, Appl. Catal., A, 2004, 259, 185.

169 W. Li, C. Han, W. Liu, M. H. Zhang and K. Y. Tao, Catal. Today, 2007, 125, 278.

170 M. X. Wu, W. Li, M. H. Zhang and K. Y. Tao, Chin. J. Catal., 2007, 28, 351.

171 P. Sabatier, Ind. Eng. Chem., 1926, 18, 1005.

172 A. Stanislaus and B. H. Cooper, Catal. Rev.: Sci. Eng., 1994, 36, 75.

173 K. M. Bratlie, M. O. Montano, L. D. Flores, M. Paajanen and G. A. Somorjai, J. Am. Chem. Soc., 2006, 128, 12810.

174 M. Zahmakıran, Y. Tobul and S. Özkar, J. Am. Chem. Soc., 2010, 132, 6541 .

175 J. Li, M. H. Qiao and J. F. Deng, Chem. J. Chin. Univ., 2001, 22, 1022.

176 R. B. Zhang, F. Y. Li, N. Zhang and Q. J. Shi, Appl. Catal., A, 2003, 239, 17.

177 M. H. Yang, R. B. Zhang and F. Y. Li, Chin. Chem. Lett., 2004, 15,1230 .

178 S. X. Xu, F. Y. Li and R. Z. Wei, Carbon, 2005, 43, 861.

179 H. X. Li and Y. P. Xu, Mater. Lett., 2001, 51, 101.

180 Q. Y. Cheng, W. Li, M. H. Zhang, N. J. Guan and K. Y. Tao, Chin. J. Catal., 2001, 22, 326.

181 Y. Ju and F. Y. Li, J. Nat. Gas Chem., 2006, 15, 313.

182 R. Zhang, F. Li, Q. Shi and L. Luo, Appl. Catal., A, 2001, 205, 279.

183 H. Song, X. C. Wu, H. Y. Wang and F. Li, Chin. J. Chem. Eng., 2011, 19, 698.

184 S. H. Xie, M. H. Qiao, H. X. Li, W. J. Wang and J. F. Deng, Appl. Catal., A, 1999, 176, 129.

185 J. Struijk and J. J. F. Scholten, Appl. Catal., 1990, 62, 151.

186 J. Struijk and J. J. F. Scholten, Appl. Catal., A, 1992, 82, 277.

187 J. Struijk, M. Angremond, W. J. M. Regt and J. J. F. Scholten, Appl. Catal., A, 1992, 83, 263.

188 J. Q. Wang, P. J. Guo, S. R. Yan, M. H. Qiao, H. X. Li and K. N. Fan, J. Mol. Catal. A: Chem., 2004, 222, 229.

189 J. B. Ning, J. Xu, J. Liu and F. Lu, Catal. Lett., 2006, 109, 175.
190 Z. Liu, S. H. Xie, B. Liu and J. F. Deng, New J. Chem., 1999, 23, 1057 .

191 H. Z. Liu, T. Jiang, B. X. Han, S. G. Liang, W. T. Wang, T. B. Wu and G. Y. Yang, Green Chem., 2011, 13, 1106.

192 S. C. Liu, Z. Y. Liu, Z. Wang, S. H. Zhao and Y. M. Wu, Appl. Catal., A, 2006, 313, 49.

193 G. Y. Fan, W. D. Jiang, J. B. Wang, R. X. Li, H. Chen and X. J. Li, Catal. Commun., 2008, 10, 98.

194 S. C. Liu, G. Luo, H. R. Wang, Y. L. Xie, B. J. Yang and M. L. Han, Chin. J. Catal., 2002, 23, 317.

195 Z. Y. Liu, H. J. Sun, D. B. Wang, S. C. Liu and Z. J. Li, Chin. J. Chem., 2010, 28, 1927.

196 P. Gallezot, P. J. Cerino, B. Blance, G. Fleche and P. Fuertes, J. Catal., 1994, 146, 93.

197 M. H. Qiao, S. H. Xie, W. L. Dai and J. F. Deng, Acta Chim. Sin. (Engl. Ed.), 2000, 58, 904.

198 J. Guo, Y. J. Hou, C. H. Yang, Y. Q. Wang and L. N. Wang, Mater. Lett., 2012, 67, 151.

199 J. Guo, Y. J. Hou, C. H. Yang, Y. Q. Wang, H. Q. He and W. Li, Catal. Commun., 2011, 16, 86.

200 H. B. Guo, H. X. Li, Y. P. Xu and M. H. Wang, Mater. Lett., 2002, 57, 392.

201 Y. D. Wu, H. B. Guo, Y. Wan, M. H. Wang and H. X. Li, Chin. J. Catal., 2004, 25, 533.

202 A. W. Heinen, J. A. Peters and H. van Bekkum, Carbohydr. Res., $2000,328,449$.

203 L. W. Wright, CHEMTECH, 1974, 42.

204 I. Toufeili and S. Dziedzic, Food Chem., 1993, 47, 17.

205 F. Capet, S. Comini, G. Odou, P. Looten and M. Descamps, Carbohydr. Res., 2004, 339, 1225.

206 H. Li, D. S. Chu, J. Liu, M. H. Qiao, W. L. Dai and H. X. Li, Adv. Synth. Catal., 2008, 350, 829.

207 H. Li, P. F. Yang, D. S. Chu and H. X. Li, Appl. Catal., A, 2007, $325,34$.

208 E. van Steen and M. Claeys, Chem. Eng. Technol., 2008, 31, 655.

209 H. Li, P. F. Yang, D. S. Chu and H. X. Li, Appl. Catal., A, 2007, $325,34$.

210 P. Gallezot and D. Richard, Catal. Rev.: Sci. Eng., 1998, 40, 81.

211 Y. Zhu, L. Tian, Z. Jiang, Y. Pei, S. H. Xie, M. H. Qiao and K. N. Fan, J. Catal., 2011, 281, 106.

212 Y. Pei, H. R. Hu, J. Fang, M. H. Qiao, W. L. Dai, K. N. Fan and H. X. Li, J. Mol. Catal. A: Chem., 2004, 211, 243.

213 Y. Pei, J. Fang, H. R. Hu, J. H. Zhuang, K. N. Fan, H. X. Li and M. H. Qiao, Acta Chim. Sin. (Engl. Ed.), 2005, 63, 289.

214 Y. Pei, J. Q. Wang, Q. Fu, P. J. Guo, M. H. Qiao, S. R. Yan and K. N. Fan, New J. Chem., 2005, 29, 992.

215 M. Casagrande, L. Storaro, A. Talon, M. Lenarda, R. Frattini, E. Rodríguez-Castellón and P. Maireles-Torres, J. Mol. Catal. A: Chem., 2002, 188, 133.

216 H. B. Ji, Y. Y. Huang, L. X. Pei and X. D. Yao, Catal. Commun., $2008,9,27$.

217 B. Liu, M. H. Qiao, J. F. Deng, K. N. Fan, X. X. Zhang and B. N. Zong, J. Catal., 2001, 204, 512.

218 B. Liu, M. H. Qiao, J. Q. Wang and K. N. Fan, Chem. Commun., 2002, 1236.

219 Y. J. Hou, Y. Q. Wang, S. Han, Z. T. Mi, W. Wu and E. Z. Min, Chin. J. Catal., 2004, 25, 149.

220 Y. J. Hou, Y. Q. Wang and Z. T. Mi, J. Mater. Sci., 2005, 40, 6585.

221 X. Y. Chen, M. H. Qiao and H. Y. He, Chin. J. Catal., 2011, 32, 325.

222 Z. Y. Ma, L. X. Zhang, R. Z. Chen, W. H. Xing and N. P. Xu, Chem. Eng. J., 2008, 138, 517.

223 A. Furst, R. C. Berlo and S. Hooton, Chem. Rev., 1965, 65, 51.

224 A. Robertson, T. Matsumoto and S. Ogo, Dalton Trans., 2011, 40, 10304.

225 H. L. Wen, K. S. Yao, Y. D. Zhang, Z. M. Zhou and A. Kirschning, Catal. Commun., 2009, 10, 1207.

226 B. Chen, U. Dingerdissen, J. G. E. Krauter, H. G. J. L. Rotgerink, K. Möbus, D. J. Ostgard, P. Panster, T. H. Riermeier, S. Seebald, T. Tacke and H. Trauthwein, Appl. Catal., A, 2005, 280, 17.

227 D. Gavroy, C. Joly-Vuillemin, G. Cordier, P. Fouilloux and H. Delmas, Catal. Today, 1995, 24, 103.

228 B. Coq, D. Tichit and S. Ribet, J. Catal., 2000, 189, 117.

229 P. F. Yang, Z. X. Jiang, P. L. Ying and C. Li, Chin. J. Catal., $2007,28,670$. 
230 M. H. Wang, H. X. Li, Y. D. Wu and J. Zhang, Mater. Lett., 2003, 57, 2954.

231 H. X. Li, Y. D. Wu, Y. Wan, J. Zhang, W. L. Dai and M. H. Qiao, Catal. Today, 2004, 93-95, 493.

232 H. X. Li, Y. D. Wu, J. Zhang, W. L. Dai and M. H. Qiao, Appl. Catal., A, 2004, 275, 199.

233 J. L. Dallons, G. Jannes and B. Delmon, Catal. Today, 1989, 5, 257.

234 G. D. Yadav and M. R. Kharkara, Appl. Catal., A, 1995, 123, 115.

235 P. Kukula, V. Gabova, K. Koprivova and P. Trtik, Catal. Today, 2007, 121, 27.

236 I. Mochida and K. Sakanishi, Fuel, 2000, 79, 221.

237 Q. Y. Cheng, W. Li, J. Wu, N. J. Guan and K. Y. Tao, J. Fuel Chem. Technol., 2000, 28, 249.

238 G. L. Parks, M. L. Pease, A. W. Burns, K. A. Layman, M. E. Bussell, X. Wang, J. Hanson and J. A. Rodriguez, J. Catal., 2007, 246, 277.

239 S. Skrabalak and K. Suslick, Chem. Mater., 2006, 18, 3103.

240 X. Qi, Q. Shi, W. Chen and R. Zhang, Chin. J. Catal., 2012, 33, 543.

241 M. L. Hitchman, R. A. Spackman, N. C. Ross and C. Agra, Chem. Soc. Rev., 1995, 95, 423.

242 J. X. Chen, D. H. Ci, R. J. Wang and J. Y. Zhang, Appl. Surf. Sci., 2008, 255, 3300.

243 Z. J. Wu, M. H. Zhang, Z. F. Zhao, W. Li and K. Y. Tao, J. Catal., 2008, 256, 323.

244 E. Furimsky, Appl. Catal., A, 2000, 199, 147; G. W. Huber, S. Iborra and A. Corma, Chem. Rev., 2006, 106, 4044.

245 J. Zakzeski, P. C. A. Bruijnincx, A. L. Jongerius and B. M. Weckhuysen, Chem. Rev., 2010, 110, 3552.

246 W. Y. Wang, Y. Q. Yang, J. G. Bao and H. A. Luo, Catal. Commun., 2009, 11, 100.

247 W. Y. Wang, Y. Q. Yang, H. A. Luo and W. Y. Liu, Catal. Commun., 2010, 11, 803.

248 W. Y. Wang, Y. Q. Yang, H. A. Luo and W. Y. Liu, React. Kinet., Mech. Catal., 2010, 101, 105.

249 W. Y. Wang, Y. Q. Yang, H. A. Luo, H. Z. Peng, X. Z. Zhang and T. Hu, Chin. J. Catal., 2011, 32, 1645.

250 W. Y. Wang, Y. Q. Yang, H. A. Luo, H. Z. Peng and F. Wang, Ind. Eng. Chem. Res., 2011, 50, 10936.

251 W. Wang, Y. Yang, H. Luo, T. Hu and W. Liu, Catal. Commun., 2011, 12, 436.

252 W. Wang, Y. Yang, H. A. Luo, T. Hu and W. Liu, React. Kinet., Mech. Catal., 2011, 102, 207.

253 W. Wang, Y. Yang, H. Luo, H. Peng, B. He and W. Liu, Catal. Commun., 2011, 12, 1275.

254 B. Sun, M. H. Qiao, K. N. Fan, J. Ulrich and F. Tao, ChemCatChem, 2011, 3, 542.

255 A. Y. Khodakov, W. Chu and P. Fongarland, Chem. Rev., 2007, 107, 1692.

256 B. N. Zong, E. Z. Min, S. Z. Dong and J. F. Deng, Acta Chim. Sin. (Engl. Ed.), 1989, 47, 1052.

257 C. X. Xiao, Z. P. Cai, T. Wang, Y. Kou and N. Yan, Angew. Chem., Int. Ed., 2008, 47, 746.

258 N. Yan, C. X. Xiao and Y. Kou, Coord. Chem. Rev., 2010, 254, 1179.

259 X. B. Fan, Z. Y. Tao, C. X. Xiao, F. Liu and Y. Kou, Green Chem., 2010, 12, 795.

260 X. B. Fan, N. Yan, Z. Y. Tao, D. Evans, C. X. Xiao and Y. Kou, ChemSusChem, 2009, 2, 941.

261 Y. Wang, H. L. Wu, Q. H. Zhang and Q. H. Tang, Microporous Mesoporous Mater., 2005, 86, 38.

262 X. F. Cheng, B. S. Wu, H. W. Xiang and Y. W. Li, Chin. J. Catal., 2010, 31, 579.

263 X. F. Cheng, B. S. Wu, Y. Yang, H. W. Xiang and Y. W. Li, J. Mol. Catal. A: Chem., 2010, 329, 103.

264 R. Datta and M. Henry, J. Chem. Technol. Biotechnol., 2006, 81, 1119.

265 R. D. Cortright, M. Sanchez-Castillo and J. A. Dumesic, Appl. Catal., B, 2002, 39, 353.

266 G. Luo, S. R. Yan, M. H. Qiao and K. N. Fan, Appl. Catal., A, 2007, 332, 79.

267 G. Y. Fan, Y. Zhang, Y. F. Zhou, R. X. Li, H. Chen and X. J. Li, Chem. Lett., 2008, 852.

268 F. H. A. Bolder, Ind. Eng. Chem. Res., 2008, 47, 7496.

269 R. J. Shi, F. Wang, Tana, Y. Li, X. M. Huang and W. J. Shen, Green Chem., 2010, 12, 108.
270 K. Oded, S. Musa, D. Gelman and J. Blum, Catal. Commun., 2012, 20, 68.

271 S. Sato, R. Takahashi, T. Sodesawa and F. Nozaki, J. Catal., 1997, 169, 447

272 B. Rajesh, N. Sasirekha and Y. W. Chen, Ind. Eng. Chem. Res., 2007, 46, 2034

273 W. Fang, Q. Zhang, J. Chen, W. Deng and Y. Wang, Chem. Commun., 2010, 46, 1547

274 M. Hayashi, K. Yamada, S. Nakayama, H. Hayashi and S. Yamazaki, Green Chem., 2000, 2, 257.

275 T. Mitsudome, Y. Mikami, H. Funai, T. Mizugaki, K. Jitsukawa and K. Kaneda, Angew. Chem., Int. Ed., 2008, 47, 138.

276 M. Bertoli, A. Choualeb, A. J. Lough, B. Moore, D. Spasyuk and D. G. Gusev, Organometallics, 2011, 30, 3479.

277 B. Rajesh, N. Sasirekha and Y. W. Chen, J. Mol. Catal. A. Chem., 2007, 275, 174.

278 B. Rajesh, N. Sasirekha, S. P. Lee, H. Y. Kuo and Y. W. Chen, J. Mol. Catal. A: Chem., 2008, 289, 69.

279 A. Biabani-Ravandi and M. Rezaei, Chem. Eng. J., 2012, 184, 141.

280 Z. X. Ding, H. Y. Yang, J. F. Liu, W. X. Dai, X. Chen, X. X. Wang and X. Z. Fu, Appl. Catal., B, 2011, 101, 326.

281 Q. Miao, G. Xiong, S. Sheng, W. Cui, L. Xu and X. Guo, Appl. Catal., A, 1997, 154, 17.

282 J. H. Ryu, K. Y. Lee, H. J. Kim, J. I. Yang and H. Jung, Appl. Catal., B, 2008, 80, 306.

283 F. Mudu, B. Arstad, E. Bakken, H. Fjellvåg and U. Olsbye, J. Catal., 2010, 275, 25.

284 K. Li, H. Wang, Y. Wei and D. Yan, Chem. Eng. J., 2011, 173, 574.

285 M. A. Peña, J. P. Gómez and J. L. G. Fierro, Appl. Catal., A, 1996, 144, 7.

286 L. Chen, Y. Lu, Q. Hong, J. Lin and F. M. Dautzenberg, Appl. Catal., A, 2005, 292, 295.

287 Z. L. Ma, R. L. Jia, C. J. Liu and Z. T. Mi, Chem. Lett., 2002, 884.

288 Z. L. Ma, R. L. Jia and C. J. Liu, J. Mol. Catal. A: Chem., 2004, 210, 157.

289 R. L. Jia, Z. L. Ma, C. Y. Wang and S. M. Wang, React. Kinet. Catal. Lett., 2005, 85, 73

290 Y. Wang, J. S. Zhang, X. C. Wang, M. Antonietti and H. R. Li, Angew. Chem., Int. Ed., 2010, 49, 3356.

291 V. Z. Fridman and A. A. Davydov, J. Catal., 2000, 195, 20.

292 H. Z. Liu, T. Jiang, B. X. Han, S. G. Liang and Y. X. Zhou, Science, 2009, 326, 1250.

293 L. Zhuang, H. X. Li, W. L. Dai and M. H. Qiao, Chem. Lett., 2003, 1072

294 J. L. Liu, H. Li and H. X. Li, Chin. J. Catal., 2007, 28, 312.

295 H. Li, J. L. Liu and H. X. Li, Mater. Lett., 2008, 62, 297.

296 M. G. Davie, M. Reinhard and J. R. Shapley, Environ. Sci. Technol., 2006, 40, 7329.

297 M. G. Davie, K. Shih, F. A. Pacheco, J. O. Leckie and M. Reinhard, Environ. Sci. Technol., 2008, 42, 3040.

298 S. Takaç, B. Akay and T. H. Özdamar, Enzyme Microb. Technol., 1995, 17, 445.

299 Y. P. Chao, Z. J. Lai, P. Chen and J. T. Chern, Biotechnol. Prog., 1999, 15, 453.

300 G. X. Li, L. Li, H. M. Huang and H. Q. Cai, J. Mol. Catal. A. Chem., 2003, 193, 97.

301 C. M. Hayward, D. Yohannes and S. J. Danishefsky, J. Am. Chem. Soc., 1993, 115, 9345.

302 R. E. Estévez, J. Justicia, B. Bazdi, N. Fuentes, M. Paradas, D. Choquesillo-Lazarte, J. M. García-Ruiz, R. Robles, A. Gansäuer, J. M. Cuerva and J. E. Oltra, Chem.-Eur. J., 2009, 15, 2774.

303 T. D. Haddad, L. C. Hirayama and B. Singaram, J. Org. Chem., $2010,75,642$.

304 C. J. Li and T. H. Chan, Tetrahedron Lett., 1991, 32, 7017.

305 H. Li, F. X. Dong, M. W. Xiong, H. X. Li, P. Li and X. G. Zhou, Adv. Synth. Catal., 2011, 353, 2131.

306 F. Tao and M. Salmeron, Science, 2011, 331, 171.

307 M. A. Bañares, Adv. Mater., 2011, 23, 5293.

308 B. N. Zong, Catal. Surv. Asia, 2007, 11, 87.

309 R. E. Rosensweig, Science, 1979, 204, 57.

310 Z. Y. Pan, M. H. Dong, X. K. Meng, X. X. Zhang, X. H. Mu and B. N. Zong, Chem. Eng. Sci., 2007, 62, 2712. 